University of Louisville

ThinkIR: The University of Louisville's Institutional Repository

Electronic Theses and Dissertations

$5-2017$

\title{
The dangers and self protective behaviors of ride share drivers.
}

\author{
M. Angela Schwendau \\ University of Louisville
}

Follow this and additional works at: https://ir.library.louisville.edu/etd

Part of the Criminology Commons, and the Work, Economy and Organizations Commons

\section{Recommended Citation}

Schwendau, M. Angela, "The dangers and self protective behaviors of ride share drivers." (2017). Electronic Theses and Dissertations. Paper 2635.

https://doi.org/10.18297/etd/2635

This Doctoral Dissertation is brought to you for free and open access by ThinkIR: The University of Louisville's Institutional Repository. It has been accepted for inclusion in Electronic Theses and Dissertations by an authorized administrator of ThinkIR: The University of Louisville's Institutional Repository. This title appears here courtesy of the author, who has retained all other copyrights. For more information, please contact thinkir@louisville.edu. 


\title{
THE DANGERS AND SELF PROTECTIVE BEHAVIORS \\ OF RIDE SHARE DRIVERS
}

\author{
By \\ M. Angela Schwendau \\ B.S., University of Louisville, 1996 \\ M.S., University of Louisville, 2005
}

\begin{abstract}
A Dissertation
Submitted to the Faculty of the

College of Arts and Sciences of the University of Louisville In Partial Fulfillment of the Requirements
\end{abstract}

For the Degree of

Doctor of Philosophy in Criminal Justice

Department of Criminal Justice

University of Louisville

Louisville, KY

May 2017 
Copyright 2017 by M. Angela Schwendau 

THE DANGERS AND

SELF PROTECTIVE BEHAVIORS

OF RIDE SHARE DRIVERS

By

M. Angela Schwendau

B.S., University of Louisville, 1996

M.S., University of Louisville, 2005

A Dissertation Approved on

April, 2017

By the following Dissertation Committee:

Dissertation Chair

Dr. Richard Tewksbury

Dr. Price Foster

Dr. Kristin Swartz

Dr. Ryan Schroeder 


\section{ACKNOWLEDGEMENTS}

I would like to thank by Dissertation Chair and mentor, Dr. Richard Tewksbury, for his guidance and support throughout my experience in the doctoral program. He has been gracious to work with me through many challenges and never held back his criticisms or praise. All of this has made me a better writer and scholar. I would also like to thank Dr. Price Foster for being my mentor throughout my academic career. He has watched me grow both academically and personally and I appreciate everything he has done for me. Gratitude is also extended to Dr. Kristin Swartz and Dr. Ryan Schroeder for their willingness to participate as members of my dissertation committee. Additionally, I must thank the ride share drivers who gave their consent and allowed me to interview them for this project. Without them this project would not have been possible, so thank you. I must also thank my daughters, Alexandra and Rebecca, for their patience and support during this entire process. I hope they are as proud of me and I am of them. And lastly, I must thank my parents - Bill and Mary - and the other members of my family for their everlasting love and support. I love you all. 


\section{ABSTRACT \\ THE DANGERS AND \\ SELF PROTECTIVE BEHAVIORS \\ OF RIDE SHARE DRIVERS}

M. Angela Schwendau

April 14, 2017

Ride-sharing companies have sprung up in various countries around the world, starting in the United States, in the past five years (Uber, 2015). These entrepreneurial upstarts have invaded the transportation industry with contract drivers and no regulations. As independent contractors, these drivers are not afforded the rights and protections as employees. Therefore, they question whether the companies, Uber and Lyft, are concerned about their safety and security. The closest profession to ride share drivers are taxicab drivers, who are considered to have one of the most violent jobs in the United States (Richardson \& Windau, 2003). Specifically, they have a higher rate of homicide than police officers (Bureau of Labor Statistics, U.S. Department of Labor, 2012). Therefore, it would make sense that ride share drivers are concerned about their safety. The present qualitative study utilizes interviews with 50 drivers throughout the United States to understand their fears about the lack of safety and security provided by the companies. Analysis of the interviews provide in depth knowledge into the world of ride share from the drivers' point of view, including their suggestions for making the job safer. Lastly, a discussion that includes a summary of the findings, contributions and policy implications, and limitations will be followed with a conclusion. 
TABLE OF CONTENTS

PAGE

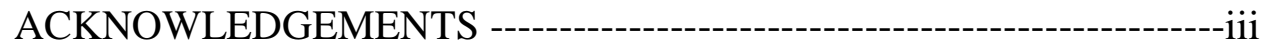

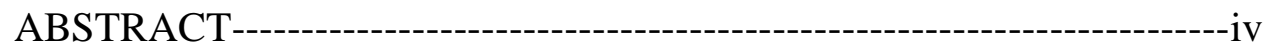

\&+ \$ 37 ( 5, IINTRODUCTION-----------------------------------------------1

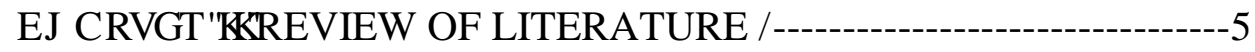

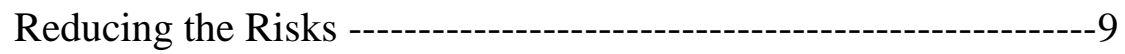

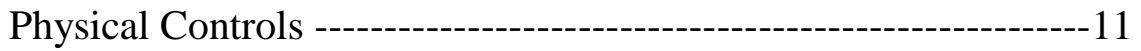

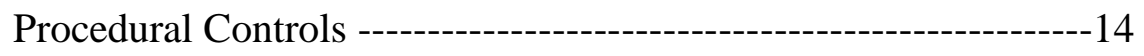

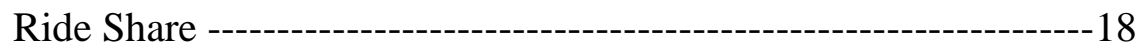

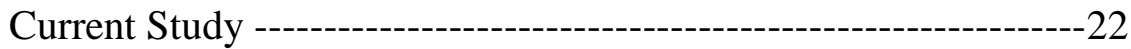

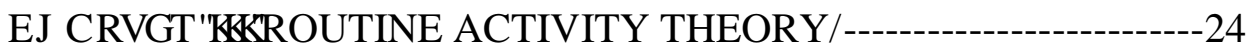

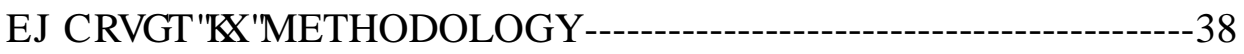

Sample---------------------------------------------------------------------38

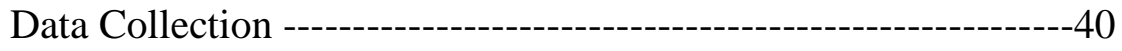

Analysis ---------------------------------------------------------------------41 
Sources of Income--------------------------------------------------------44

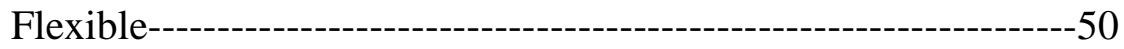

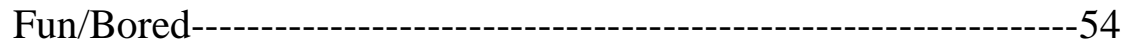

\&+ \$ 37 ( 5 [9 , ¿UBER OR LYFT----------------------------------------------59

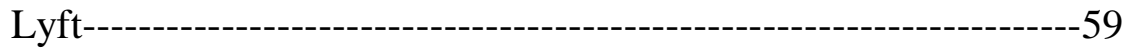

Uber--------------------------------------------------------------------------63

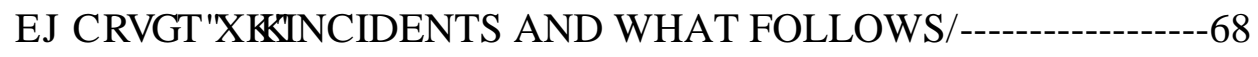

Incidents in the first week----------------------------------------------69

Impaired passengers------------------------------------------------------72

Police assistance-----------------------------------------------------------84

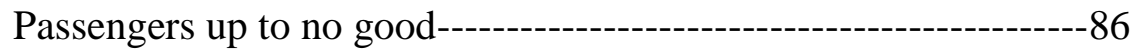

Responses from Uber and Lyft-----------------------------------------90

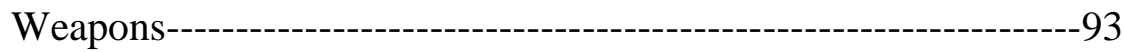

Dashcams--------------------------------------------------------------------96 


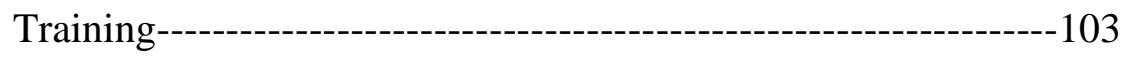

Passenger identification-----------------------------------------------110

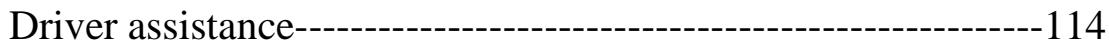

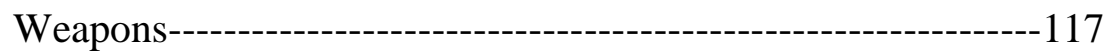

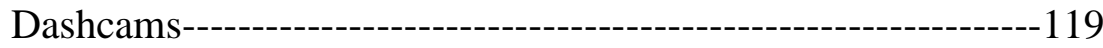

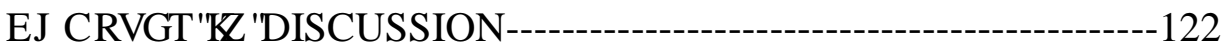

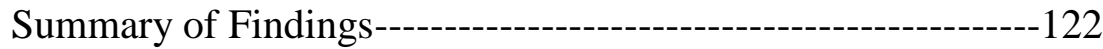

Contributions and Policy Implications----------------------------129

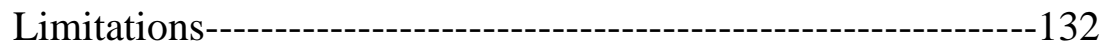

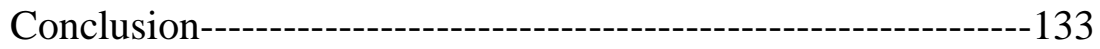

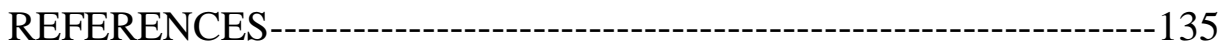

TABLE--------------------------------------------------------------------------149

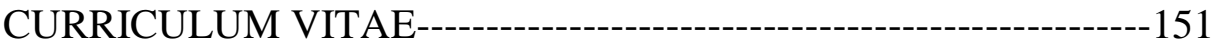




\section{CHAPTER I}

\section{INTRODUCTION}

Crime prevention efforts have been around for as long as there has been crime. The simple act of using punishment to deter individuals from committing crime does not work. Therefore, criminologists must find ways to stop the offender from committing the crime before it happens. In an effort to discover how to prevent crime, criminologists have developed theories on why crime happens.

Environmental criminologists believe that opportunity is the basis of crime rather than looking only at the individual that commits the crime. Government and society cannot change how a person is born or raised, that is in the past. Without being able to eliminate these roots of crime, government and society turn their focus to the current situation of how to prevent crime through a change in opportunity. Within the scope of opportunity theory lies routine activity theory and its approach to understanding crime through the offender's point of view, not society's or the victim's. Historically, routine activity theory suggests that in the everyday actions of the offender, within his awareness space, he will come into contact with opportunity to commit crime.

Routine activity theory (Cohen \& Felson, Social Rate and Crime Rate Trends: A Routine Activity Approach, 1979) is a lifestyles theory that can be viewed at the micro level or macro level. On the micro level, routine activity theory proposes that criminal opportunity exists when three elements--a motivated offender coming in contact with a suitable target that is missing a capable guardian-converge in time and space (p. 593). 
On the macro level, routine activity theory suggests that it is the elements of the society or community at large that makes such encounters possible (p. 592) From a control perspective, it is no longer about internal control but the lack of control from others who may be guardians that may allow for crime to occur.

Normally when we think of crime and routine activities theory, thoughts of people getting robbed, property being burgled, and personal assaults occurring in seedy areas come to the forefront of our minds. These crime-generating places or hot spots are where motivated offenders and suitable victims converge in time and space without guardians to protect. The attributes of these spaces are what makes them vulnerable to crime. Robbers, for instance, will lurk around ATMs because they are easily accessible and highly profitable places to rob a person (Braga, Hureau, \& Papachristos, 2011). A mall or sporting event is another place in which potential victims do not fear crime, but because they reduce their guard, they become easy targets for crime (Wortley \& Mazerolle, 2011). According to a study by Mustaine and Tewksbury, your risk of victimization is based on where you are, what you are doing, and how you are protecting yourself in a given situation (Mustaine \& Tewksbury, Predicitng Risks of Larceny Theft Victimization: A Routine Activity Analysis Using Refined Lifestyle Measures, 1998). This awareness of individual guardianship is not something that many people possess; therefore, it is up to the community to provide social and environmental-level guardianship. Through target hardening such as street lighting, neighborhood watch, more locks on doors, and environmental design that includes defensible space, communities promote surveillance and hopefully residents will continue this collective effort to rid their area of crime 
(Wilcox, Madensen, \& Tillyer, Guardianship in Context: Implications for Burglary Victimization Risk and Prevention, 2007).

This viewpoint is fine for the general public, but what about preventing crime opportunities for people while they are working? According to the National Institute of Occupational Safety and Health (NIOSH), occupational violence can be defined as "violent acts, including physical assaults and threats of assault, directed toward persons at work or on duty" (National Institute of Occupational Safety and Health (NIOSH), 2006, p. 5). Police officers, for instance, already have the skills and training to protect themselves and others, yet they are still murdered. Even with the protection of a gun and taser, these officers may come into contact with a potential offender, and should the officer let his guard down or not have any backup, he or she can become a victim. Occupations dealing with the public allow for more opportunity to come into contact with a would-be offender. Just like police officers, transportation drivers deal with the public every day. Whether a bus driver or cab driver, each individual that enters that vehicle becomes a potential threat. The driver does not know if the passenger is having a good or bad day, is high on drugs, intoxicated, or has an agenda to rob and/or assault the driver. Most, if not all, of these drivers are provided some training for their position (Barton, 1996; Durham, 2012; Stone \& Bienvenu, 1995; Toronto Police Services). Additionally, safety mechanisms are put into place to ward off would-be offenders such as protective barriers to prevent access to the driver as well as child-like locks on the back doors. Yet, taxicab drivers have a higher rate of homicide victimization than police officers. According to the Bureau of Labor Statistics (BLS), in 2010, taxicab drivers had a higher 
rate of homicide victimization than police officers at 7.4 versus 6.7 per 100,00 workers (Bureau of Labor Statistics, U.S. Department of Labor, 2012).

According to the Bureau of Labor Statistics 381, taxicab drivers were killed while driving on the job between 1998 and 2007, an average of 34 per year (OSHA, 2010). Taxicab drivers are considered to have one of the most violent jobs in the United States (Richardson \& Windau, 2003).

A Chicago newspaper reported on results from a 2008 survey conducted by the University of Illinois at Chicago that stated that over $58 \%$ of cab drivers admitted to having been "threatened, attacked and subjected to hostile racial comments" (Vivanco, 2014, p. 1). Those altercations that became physical usually involved a gun as the weapon of choice, followed by knives. But what about drivers that do not have training or safety mechanisms in their vehicle? How are they to prevent becoming that unprotected victim when opportunity presents itself?

Drivers that are independent contractors utilizing their own vehicle are these potential victims. These drivers now number in the hundreds of thousands with the advent of ride share. These ride sharing services utilize computer software applications, found on most smartphones, to match a driver with a passenger. These drivers, however, are independent contractors utilizing their own vehicle to transport passengers from point $\mathrm{A}$ to point $\mathrm{B}$. They are provided no training and work in a dangerous industry with nothing or no one protecting them. How can these drivers prevent crime from occurring if they are left on their own? This study focuses on answering this question through in-depth interviews with current ride share drivers. 


\section{CHAPTER II}

\section{LITERATURE REVIEW}

Transportation has been around since the development of the wheel so many years ago. Millions of people use some sort of transportation in their daily lives in order to get from one place to another. From the bicycles to mass transit, individuals can find the best form of transport for their needs. Transportation is not without its problems though, whether it is the "fender benders" that car owners all seem to have experienced, the buses that never seem to run on time, or the airplane flights that get cancelled. Utilizing modes

of transportation other than walking will continue without a second thought. But how safe is it?

According to the Centers for Disease Control, in 2014 accidents (unintentional injuries) were the $4^{\text {th }}$ leading cause of death in the United States. Of these accidents $(136,053)$, transportation accidents accounted for 27.3 percent $(37,195)$ with 24.8 percent $(33,736)$ being motor vehicle accidents. Breaking down the motor vehicle deaths further, 8,098 occupants, 4,036 motorcyclists, 623 pedal cyclists, 5,226 pedestrians, and 15,783 other/unspecified died as a result of a motor vehicle accident. Additionally, there were 1,032 pedestrians killed not as a result of a motor vehicle accident (Kochanek, Murphy, $\mathrm{Xu}, \&$ Tejada-Vera, 2016). Therefore, it appears that whether you walk or ride, any type of transportation can lead to an accidental death. However, the report fails to contain information about intentional deaths while driving or riding in a motor vehicle. It really is 
not something that is thought about when stepping onto a bus, train, or into someone's car.

Reports on intentional motor vehicle deaths are increasing with drunk-driving incidents (National Center for Injury Prevention and Control (U.S.), 2011; National Center for Injury Prevention and Control (U.S.), \& Centers for Disease Control and Prevention (U.S.), 2011; Scott, Emerson, Antonacci, \& Plant, 2006; United States, 2006; United States, 2009), other impaired driving tragedies including under the influence of drugs, distracted driving, or drowsy driving (National Center for Victims of Crime (U.S.), \& United States, 2009; United States, 2006; United States, 2011), and speeding and aggressive driving (Blankenship, Nesbit, \& Murray, 2013; Laing, 2010; United States, 2006). Drivers rarely think that stepping into their car could result in an injury or death. Furthermore, drivers do not think that they would succumb to becoming a victim to various crimes while in their vehicle. These may include carjacking, theft, threats, assaults, and even homicide, which may result in simply being in the wrong place at the wrong time. (Copes \& Cherbonneau, 2006; Gilbert, 2011; Jacobs, Topalli, \& Wright, 2003; Jacobs B. , 2012; Jacobs B. , 2013; Kloberdanz, 2016).

Previous research has focused on motor vehicle accidents, injuries, and general crimes such as theft and carjacking. There is limited research on personal crimes in motor vehicle transport. The research that exists centers primarily on crimes against taxicab drivers (Burgel, Gillen, \& White, 2014; Dalziel \& Job, 1997; Gilbert, 2011; Kloberdanz, 2016; McGhee, 2015; Ministry of Transport, New South Wales, 2007; Smith, 2005). Unlike the United States, only Australia, Canada, and the United Kingdom have focused their efforts to prevent this violence and ensure safety of taxicab drivers (Appleby, 2000; 
Barton, 1996; Dalziel \& Job, 1997; Mayhew, 2000; Ministry of Transport, New South Wales, 2007; Toronto Police Services; Victorian Taxi Directorate, Department of Infrastructure, 2007).

As mentioned above, currently only taxicab drivers are the subject of research on personal violent crime in motor vehicle transportation. This type of personal crime can range from harassment to threats to homicide. As employees, they are protected under OSHA guidelines that require the employers to provide safe working conditions. However, for self-employed or independent contractors, there are no regulations to ensure their safety and security. This extends beyond taxi drivers into a new realm of drivers, ride share drivers. These drivers are independent contractors with no training, protection, or prevention strategies in place to ensure their safety and security. Unlike self-employed taxi drivers, these drivers are not working with a company or in an industry with guidelines or resources available to assist them in knowing what to do as far as training or procedures. They are simply instructed how to use the computer application to pick up passengers and left to fend for themselves. Currently, there is no research available on how the lack of regulations has affected the drivers with respect to safety and security. This study serves as the first of its kind to interview drivers to hear their stories, concerns, and suggestions on how to make their life as a ride share driver safer.

Transporting a person from place to place, regardless of the type of motor vehicle, should be an uneventful ride. The driver or passenger may strike up a conversation as a way to fill the void found in the transport, but besides that, it should be unexciting. Most drivers would like to get their passenger to the correct location without any problems. 
Additionally, most passengers would also agree that getting to where they need to go without any complications is ideal for them. However, taxicab drivers die from violence at work at a greater rate than law enforcement officers and security guards (Gilbert, 2011).

There is scarce research on the subject of taxicab driver safety even though these drivers have been estimated to die while at work at a rate of 9 to 36 times higher than that of the average worker (Bureau of Labor Statistics (BLS), 2007; Toscano, 1997). The most recent OSHA Fact Sheet states that taxicab drivers "are over 20 times more likely to be murdered on the job than other workers" (Occupational Safety and Health Administration, 2010). The primary reason for these staggering statistics is that taxicab drivers are put in dangerous situations and face more risks than the average worker. Risks found with taxicab drivers include working late at night, handling cash, working in high crime neighborhoods, working alone and in isolated areas, and coming into contact people that may be under the influence of alcohol or drugs (OSHA, 2010; Smith, 2005). Few, if any other professionals, must deal with all of these concurrently.

According to the Bureau of Justice Statistics, in 2011 there were 4,693 fatal occupational incidents with 10\% (468) being homicides (Bureau of Labor Statistics, U.S. Department of Labor, 2012). Of those fatal incidents, 64 were taxicab or limo drivers with 32 being homicides (Bureau of Labor Statistics (BLS), 2012). The breakdown of all occupational homicides shows that $83 \%$ of the victims were males, $54 \%$ were white, $20 \%$ black and 16\% Hispanic. Almost half (48\%) were between the ages of 35 and 54 with no one over 65 years of age. Additionally, $30 \%$ of all victims were self-employed (Burgel, Gillen, \& White, 2014). The average taxicab driver is male and approximately $80 \%$ are 
foreign born with the majority considered a member of a "visible minority" or not white (Gilbert, 2011). Therefore, the occupational violence that these drivers face is not substantially higher than other occupations due to their minority status.

In an effort to measure the violence that taxicab drivers experience, Burgel, Gillen, \& White (2014) surveyed 130 taxicab drivers in 2010. This study population was $94 \%$ male, $55 \%$ foreign born with a mean age of 45 years (Burgel et al, 2014). These statistics are similar to the general population of occupational homicides reported above. Results showed that $48 \%$ of all drivers reported that they had been robbed, confronted with a weapon, and/or physically assaulted during their career as a taxicab driver. In the past year, $6 \%$ were robbed, $6 \%$ were confronted with a weapon, and $14 \%$ were physically assaulted (Burgel et al, 2014). These statistics reveal that there needs to be some effective crime prevention efforts to reduce the violence that these drivers face day to day.

\section{Reducing The Risks}

Outside of the standard statistics provided by government departments, scant academic research is available to assist employers and taxicab drivers in reducing the alarming rate of violence. It is likely that the reason is that the majority of taxicab drivers are foreign born and this population has not garnered the attention to be academically studied with such fervor as those of other more prominent populations. However, as employees, drivers are protected under the Occupational Safety and Health Act. Under the "General Duty Clause" this act "requires employers to provide their employees with a workplace free from recognized hazards likely to cause death or serious physical harm" (Occupational Safety and Health Administration, 2010). 
In addition to the requirements of the Occupational Safety and Health Act

(OSHA), the act also provides some safety recommendations for employers to enact to provide a safe working environment for their employees. The taxicab industry is no different in being provided these recommendations, which come in the form of physical and procedural controls.

According to OSHA these physical controls include:

1. Barriers - such as bullet-resistant glass - between drivers and passengers prevent robberies, injuries and death.

2. Security cameras record activities within the vehicle, discouraging violent behavior, and aiding in identifying passengers, if an assault does occur.

3. Silent alarms (such as an external light) and/or radio communication allow drivers to safely request help.

4. Vehicle tracking devices, such as global positioning satellite (GPS) systems, allow drivers in distress to be located.

5. Improved lighting inside the taxi allows the driver to be aware of passenger behavior.

The procedural controls include:

1. Establishing police protocols - including authorizing police stops.

2. Promoting the use of credit card payments to limit the amount of cash in the taxi and thereby discourage robberies.

3. Providing safety training to teach drivers, dispatchers and company owners about protective measures. (Occupational Safety and Health Administration, 2010)

The following provides some descriptions and examples of the above recommended physical and procedural controls. 


\section{Physical Controls}

Partitions or barriers made of plexiglass or some other bullet-resistant glass installed between the front and back seats can offer protection for drivers from robberies, injuries, and or death. Stone and Stevens conducted a case study on the city of Baltimore, Maryland when the city mandated that all licensed cabs must have partitions by the end of 1996. Comparing the years before shielded taxicabs to the years after, in 1991 only 5\% were shielded with 1997 when all were shielded, they found an 88\% decrease in assaults (Stone \& Stevens, 1999). Other cities reported similar results. Boston saw a 70\% drop in assaults and New York had a 70\% drop in robberies after the installation of safety screens or shields (Appleby, 2000; Stone \& Bienvenu, 1995).

This reduction in assaults and robberies is only effective if the driver installs and uses the safety shield properly. According to the Workplace Safety Advice website in the UK, those drivers with shields in their cab and needing to have access to the passenger for money exchange should install lockable sliding screens, making sure they are not behind the driver's head (Durham, 2012). However, if used properly, "bullet-resistant safety shields are the most effective deterrent to an attack," according to James Szekely Sr., a former taxicab driver and who currently heads the International Taxi Drivers Safety Council (Kloberdanz, 2016, p. 2).

Cameras and dash-cams that have the ability to record what is happening inside and outside the vehicle may deter motivated offenders from doing anything illegal. And if something should happen, then the company and/or police can utilize the information on the camera to apprehend the criminal. As a result of a multi-year, multi-city study of the effectiveness of taxicab security equipment, it was discovered that compared to control 
cities, cities with cameras installed in the taxicabs saw a three-fold reduction in taxicab driver homicides (Menendez, Amandus, Damadi, Wu, Kanda, \& Hendricks, 2013). These cameras also have been used as a defense for drivers when passengers have falsely accused them of personal violations like sexual harassment. Female drivers have also been able to rely on this camera footage to show evidence of sexual harassment or assault by male passengers (Radbone, 1998).

Many drivers inform their passengers of the cameras and in some states, it is required to have posting indicating that the passenger(s) is being video and/or audio recorded. A taxi-driver in Sydney stated that this has been an effective deterrent (Dalziel \& Job, 1997).

Silent Alarms that the driver has easy and quick access to can initiate a call to dispatch, a call to police, or initiate a flashing light atop the car to alert the police or passersby that he is in danger. Emergency lights are rather inexpensive and can be a quick way for drivers to alert others outside the vehicle that there is a problem (Mayhew, 2000). However, most drivers do not support audio or visual alarms because the response times are very slow, if any (Haines, 1998).

Another example of physical controls put into place to assist drivers are radios and other emergency communication systems. Even with the advent of cell phones, taxicab drivers still utilize their radio as their "lifeline" to others outside of the vehicle (Barton, 1996). Unfortunately, radios can be disabled, which is why a new emergency communication system has been developed. Many taxicabs are now equipped with global positioning satellite (GPS) systems. These systems allow for the car to be tracked at all times. Should a driver trigger the silent alarm, the dispatcher or police can immediately 
locate the vehicle (Mayhew, 2000). To date, only one taxi service has incorporated this technology as a safety precaution and they have not reported any instances where it has been used to stop violence (Tracking System Direct, 2016).

Improved lighting inside and outside of the vehicle will allow the driver to be more cognizant of the actions of the passenger. In addition, it will allow those outside the vehicle the ability to see if there is a problem inside (Smith, 2005). Adequate lighting and no obstruction (like tinting) has been found to reduce the amount of robberies in convenience stores (Casteel \& Peek-Asa, 2000); deter prospective vandals, thieves, drug dealers, and rapists from school campuses (Sowell, 2001); and keep hotel guests safe in the parking lot and in all areas of the hotel (Mest, 2012).

To determine whether some of these physical controls are effective at reducing taxicab driver homicide, a group of researchers from the National Institute for Occupational Safety and Health (NIOSH) conducted a national study of 26 cities in the United States that used either security cameras or bullet-proof partitions or both in their taxicabs. Looking at a fifteen-year span from 1996 to 2010, it was determined that there was no difference in the homicide rates in cities that had the bullet-proof partitions versus those that did not. However, there was a substantial reduction, almost four times lower rate, in homicides in cities that has cameras installed in their taxicabs (Menendez et al., 2013). This does not indicate that taxicabs should not have the bullet-proof shields; it merely means that research has not indicated that they are effective in reducing homicides or attempted homicides. Cameras may prove to be more effective at reducing homicides, but that should not discount the need or effectiveness of bullet-proof shields to reduce the number of assaults on taxicab drivers. 


\section{Procedural Controls}

Taxicab drivers can employ some procedural controls to ensure their health and safety. Police stops are an example of a procedure that is set up to promote safety for the drivers. New York City set up a TRIP initiative (Taxi Robbery Inspection Program) where taxicabs, that are registered, were without cause to check on the safety of the driver and passenger. This program, which also runs in Boston, allows for random stops or stationary stops similar to drunk driving stations (Smith, 2005). This is just one of many of the recommendations made to the Ministry of Transport in the Taxi Industry Safety and Security Taskforce Report (Ministry of Transport, New South Wales, 2007).

This Taskforce was formed to assess the current risks of taxi drivers in New South Wales and review existing safety measures in the hopes of developing a new strategy to increase the safety for taxi drivers. Recommendations like the police stops mentioned above were made to the Ministry of Transport in a final report in 2007. This report is meant to offer recommendations to the taxi industry as a whole and not merely those drivers within the country of Australia.

Even though many taxicab drivers and companies may not like it because of the additional costs, having passengers use credit cards would cut down on the amount of cash in the vehicle. If this is not acceptable, then perhaps have the driver make frequent deposits throughout the night at ATMs instead of holding on to large amounts of cash. Drivers can also not allow large denominations to be accepted. Should the driver be faced with this dilemma, the driver can take the customer to a nearby store to get change (Barton, 1996). 
A rare but effective way to increase a cashless system for taxicabs is the authorization of company accounts. Passengers would need a code or simply provide their signature on a waybill, then the driver would submit the bill to the proper company for payment. This payment method has been used by companies, restaurants, hospitals, bars, and even regular ride share customers (Smith, 2005). Most regular ride share customers do not have these special accounts; it is focused more on companies and businesses to provide a service to their guests.

Probably the most important way to reduce risks of violence is to provide safety training. Not just for the drivers but also the dispatchers so that each person knows how to protect themselves as well as what to do in the event of an emergency. This training should also include how to properly use the equipment - car, radio, alarms, cameras, etc. - as well as the operating procedures of the company (Mayhew, 2000).

According to Facey (2010) an additional "health-protective strategy" includes teaching taxicab drivers how to talk to their passengers. These three types of talk strategies include entertaining, placative, and evaluative (pp. 1263-4). Based upon the situation that each driver found themselves in would require choosing a style of talking. Entertaining talk can include stories, jokes, or compliments. Anything to make the ride an enjoyable experience. Placative talk builds trust between the driver and the passenger. If the driver senses a bit of hostility in the passenger when they get in the car, he may offer compliments or agree with everything the passenger says. Drivers also use this type of talk when passengers are distrustful and believe they are going to be ripped off. In this instance, a driver may offer two routes to the passenger and allow them to choose. 
The third type of talk is evaluative. This type starts even before the passenger gets into the taxicab. The driver can assess the passenger or the route to be taken to allow them to know how to begin the conversation or what steps should be taken to ensure their safety. By asking questions, the driver assesses if the passenger has money, if he knows where he is going, if he is angry or tired. Depending on the answers to those questions, the driver can determine if he wants to take the fare, or if he has already started the ride, whether he should continue (Facey, 2010). These types of talking to passengers are examples of non-physical behavioral protective measures that drivers have at their disposal.

Taxi-library.org offers the taxicab drivers a plethora of information on types of vehicles entering the market, types of insurance available, new technology for purchase, new safety equipment and services available, as well as advertising services to purchase. In addition, this site includes the most up to date regulations and/or links to find them, a memoriam page, and a homicide prevention page to assist drivers that receive little to no training a source for keeping them safe. On this page is Gord Barton's “28 Taxi Driver Safety Tips" with the goal, "to maximize personal safety for taxicab drivers" (Barton, 1996).

Some additional danger reducing actions of taxicab drivers include positioning mirrors for better sight of passengers and keeping an eye on passengers so they know they are being watched and less likely to initiate deviant behavior. Additionally, having drivers only drive to the address given, would not allow would-be criminals to change the route to a more desolate or unlit area so they can rob or assault the driver. Drivers should be told to not chase non-paying customers, as driving or even running after such 
customers is not worth losing a life. Educating the drivers on watching what they say to customers may also ward off the potential for robbery. For example, when a customer asks how your night is going, drivers should simply say that they just started; this gives them the impression that you do not have a lot of money and they are less likely to rob you (Burgel, Gillen, \& White, 2012).

Those taxicab companies that use only self-employed or independent contractors (1 in 5) for their taxicab drivers are not bound by the OSHA requirements (Bureau of Labor Statistics, United States Department of Labor, 2015).Therefore, if they offer any kind of safety training, it is strictly voluntary (Facey, 2010). For this reason, some city police departments have come up with their own recommendations for cab company owners, drivers, and dispatchers to prevent crime. For instance, the police department in St. Petersburg, Florida has made some suggestions to increase driver safety and reduce the amount of robberies and homicides taking place in their city. One of these suggestions includes having the dispatchers screen the calls from clients. Having dispatchers require the name, address, and phone number of the person requesting a taxicab puts the passenger on notice that someone knows who they are, and by having them repeat the information, helps to confirm that the person is telling the truth. After the call ends, the dispatcher should call the person back to make sure it was not a crank call while informing the passenger that they needed to verify the address (Taxi Library, 2015).

Toronto Police also provide taxi driver safety on its website to promote crime prevention and community safety. Safety items discussed on this site include reducing the amount of cash, looking safe and in control, staying in well-lit areas, and monitor danger 
by trusting your instincts (Toronto Police Services). Every driver has a right to be protected and feel safe regardless of their employment status.

One would think with all the research on safety and available violence-reducing practices and equipment that any driver-based company would be do everything in their power to ensure driver safety. Unfortunately, one type of non-regulated company exists, and they are referred to as ride sharing companies.

\section{Ride Share}

Ride-sharing companies have sprung up in various countries around the world, starting in the United States, in the past five years (Uber, 2015). These entrepreneurial upstarts have invaded the transportation industry with contract drivers and no regulations. Lawmakers have even given them a new term, Transportation Network Companies (TNC). The basic premise being that the company does not own the vehicles, nor do they employ the drivers, and they rely on software to coordinate passengers with rides. This software consists of computer applications found on most smartphones.

Currently there is one academic piece of research available on this ride share phenomena. Published in the American Journal of Epidemiology, this study conducted by the Spatial Sciences Institute at the University of Southern California sought to determine if the arrival of ride sharing services (Uber more specifically) reduced the number of drunk driving incidents that result in traffic fatalities. It was concluded that there was no such association (Brazil \& Kirk, 2016). It should be noted that Uber did not begin its ride sharing service to reduce the number of drunk driving incidents or traffic fatalities but rather as a "technology service for independent drivers" (Chafkin, 2015). All other 
information about ride sharing is made available through newspapers, magazines, and online sources, and while relevant, it is not guaranteed to be accurate.

Uber's way of keeping drivers safe is by the use of a rating system for passengers in which the driver can give the passenger a low rating and they will never have that passenger again. A low rating after an incident does not promote safety for or protect the other drivers, only the most recent driver. The other drivers only see an average of the scores of each passenger, no specifics are given as to why they have a rating lower than ideal, 5 is the best. Even though passengers are strangers just as in cabs, Uber believes that because the passengers have to create a profile, the drivers should feel safer (Vivanco, 2014). However, anyone can purchase a prepaid phone and credit card and sign up for Uber using a bogus name and picture for their profile. This does not promote safety.

Uber also touts the fact that because their app system is cashless that will keep drivers safe from robbery. According to an Uber spokesperson, "every transaction is cashless, so drivers never have to worry about the risk or hassle of carrying cash or making change" (Vivanco, 2014). Unfortunately, Uber is not a cashless system. Uber does not have a feature on the app to allow passengers to tip the drivers; so many drivers feel the need to carry cash so they can make change. Additionally, drivers must have a smart phone to access the app system, which has led to drivers being robbed of their cell phones in addition to any cash on hand. For example, in two separate incidents in Jamaica Plain, Massachusetts, two Uber drivers were robbed at gunpoint of their wallets and cellphones (Ellement, 2016). 
The additional security measures of having a live dispatcher and radio communication has escaped Uber's business plan. Drivers and passengers must send an email for any problems, questions or concerns. Uber does have a 1-800 number but calling that number will result in a recorded message asking the caller to send an email. This lack of instant responsiveness is a safety concern for drivers which may be a reason; many are unaware of what to do in many circumstances.

Another safety mechanism in place for taxicab drivers that is lacking for Uber drivers is the use of a barrier or shield between the driver and passenger. Uber promotes itself with the tagline, "Everyone's Private Driver" (Uber, 2015) and as a friendly, social transportation provider. Unlike taxicabs, Uber promotes passengers sitting in the front seat so that the passenger and driver can have conversations. This informality, while it may make the ride more pleasurable, can also be a safety concern for drivers.

News reports about Uber drivers being attacked by passengers are on the rise. In March of 2015, a 51-year-old driver was attacked in Los Angeles by two male passengers. She called 911 and made a report to the police since there was no way to contact Uber by phone. She sent emails requesting the passenger's information so that she could press charges but Uber denied the request. She told the local news channel, "It's hard to be out there working as hard as I do, and to not feel supported by them" (CBS Los Angeles, 2015). Once the news channel was involved, Uber finally responded and said that they have "removed the rider's access to the Uber platform" (CBS Los Angeles, 2015). The driver is not satisfied with that response and said that she thinks Uber should have an emergency hotline and be willing to release the contact information on the attackers. 
Another driver was attacked in Long Beach, California after he picked up two intoxicated passengers that got in his vehicle pretending to be the requested riders. When they arrived at their destination, the riders attacked the driver because he asked them to pay for the ride since they did not request it through Uber. After being beaten and choked, the driver was eventually able to fight back and the riders ran away (Moreno, Cheng, \& Mester, 2015).This event may not have happened if Uber allowed drivers to see who they are picking up. Uber only allows the riders to have pictures of the drivers, but only gives the names of the passengers to the drivers. Therefore, drivers do not know what the passenger looks like and anyone can say they requested the Uber ride.

Another rider in Miami, Florida decided she was taking someone else's ride too. This time, the original requester decided to document the event on his camera. The rider, a $4^{\text {th }}$-year neurology resident was belligerent and physically abusive when the Uber driver exited his vehicle because she was not the correct rider. According to the report, she was "erratic, screaming, cursing" (ABC News, 2016). She eventually left the scene but her actions resulted in her being placed on administrative leave pending an investigation.

Even when the passenger is the correct rider, it does not mean that the ride will go smoothly. In February of 2016 in Arlington, Virginia, an Uber driver was attacked by three passengers when he told them they could not drink their beer in his car and ask them to throw it out. The passengers preceded to attack the driver, hitting him in the head with a glass bottle and shattering the passenger window before fleeing in a taxi. All three men were caught by the police and charged with their crimes (NBC Universal Media, 2016). 
Probably the most well-known attack on an Uber driver came in November 2015 in Costa Mesa, California. A drunk Taco Bell executive (Golden) assaulted the driver when the trip ended because Golden was too drunk and could not give directions to his destination. When asked to get out of the car, Golden did and started hitting the driver and pulling his hair. It was not until the driver sprayed him with pepper spray did the assault end. The driver had a dashcam and videotaped the entire episode. The video was posted online and on many news stations. Uber told officials that Golden would be banned from the service. The driver has gone on to sue Golden and Golden has lost his job at Taco Bell.

Given that taxicab drivers have safety regulations in place and they still have an average of 34 homicides each year (Occupational Safety and Health Administration, 2010), imagine the potential number for ride-sharing drivers. Without any procedural or physical controls in place, ride-sharing drivers are likely to be victims. Presently, ridesharing drivers have no voice in company regulations to reduce their risks because they are considered independent contractors. The objective of this study should enlighten drivers' concerns, what they are doing to protect themselves, and what the government should do, through legislation, to keep them safe while driving.

\section{The Current Study}

The purpose of this dissertation is to conduct a qualitative-based study that will examine the concerns of the ride share drivers about their safety and security. In addition, this study explores what measures they take individually to protect themselves and what they think that the owners of these companies should do to train and protect the drivers. 
Ride share drivers are a new population that has yet to be researched--given the newness of the ride share industry. The number of drivers increases monthly; 50,000 drivers are recruited monthly according to Uber president Travis Kalanick (MacMillan, Uber Touts Its Employment Opportunities, 2015). Additionally, new drivers are needed in previously recruited areas as the news of an option to taxicabs becomes more mainstream. Although this rapid growth may bring riches to the owners of the companies, it has failed to answer to the increasing concerns of safety. These companies are unwilling to change policies and remain staunch in their stance that the drivers are independent contractors and are not afforded the rights and protections as employees. Should drivers expect these Transportation Network Companies (TNCs) to be responsible for their safety? Do current drivers feel safe? Are drivers taking any precautions to ensure their safety? If, so how? Should these companies provide training? Should there be federal regulations in place to protect drivers so that the incidents of homicide seen in taxicab drivers, are not higher for ride-sharing drivers? This study will explore these questions and provide the answers from the drivers' point of view. 


\section{CHAPTER III}

\section{ROUTINE ACTIVITIES THEORY}

Criminologists have long used theory to explain why crime happens, why criminals are the way they are, and what makes a person a victim. Cohen and Felson (1979) are recognized as establishing routine activity theory as one of the opportunity theories under the umbrella of environmental criminology. Building upon Hindelang, Gottfredson and Garofalo's (1978) lifestyle theory, this theory posits that crime occurs based on situational factors. These factors include a "spatial-temporal interaction" (Groff, 2007 , p. 75) of a motivated offender, a suitable target, and the absence of a guardian for a crime to occur. Cohen and Felson claim that "the lack of any one of these elements is sufficient to prevent the successful completion of a direct-contact predatory crime" (Cohen \& Felson, 1979, p. 589).

As interest in this micro-level theory grew, criminologists began to consider routine activity theory as a victimization theory because it focuses on the daily routines and lifestyles of victims (Birkbeck \& LaFree, 1993; Brown, Esbensen, \& Geis, 2015; Cohen, Kluegel, \& Land, 1981; Hindelang, Gottfredson, \& Garofalo, 1978; Madriz, 1996; Meier \& Miethe, 1993). It has only been recently that criminologists have included offenders and their lifestyles, which may give them increased odds of committing a crime (Brown, Esbensen, \& Geis, 2015). 
Breaking down the elements further, a motivated offender is an individual prepared to commit an illegal act (Felson \& Clarke, 1998). When criminologists think about this element, it is considered a given (Cohen \& Felson, 1979). That is, there is always an ample supply (Brown, Esbensen, \& Geis, 2015; Mustaine \& Tewksbury, 1997; Mustaine \& Tewksbury, 2000). There are always individuals wanting to commit crime, they are just waiting for the right time, place, and victim to commit this crime. Most offenders are not willing to spend a lot of time planning the commission of a crime, they are looking for a potential victim that is free of any guardianship. He is interested in the easiest target that does not require a lot of time or energy to obtain the items of worth or the mental domination he seeks. His motivation then, is to seek out targets based on "the perceived value, visibility, accessibility, and inertia of the object" (Boetig, 2006, p. 14). Therefore, routine activity theory is considered a victimization theory. It was developed to explain violent crimes against persons (Cohen \& Felson, 1979), not why an offender commits crime; there are plenty of other theories that can be used to explain that element (i.e., self-control, rational choice, bio-social, etc.).

However, Felson in 1986 considered a fusion of Hirschi's (1969) control theory and routine activity theory by adding Hirschi's idea of social bond to create the idea of a "handle" (p. 121). This "intimate handler" can be a family member, friend, or some other significant person in the offender's life that helps to keep him from initiating criminal or delinquent behavior. Through the use of bonds, the presence of an effective handler can cause the offender to refrain from committing a crime "for fear of losing respect, emotional support, or other related personal connections” (Eck \& Madensen, 2015, p. 7). 
This addition of an intimate handler to the routine activity theory triad shows that the possibility exists for expanding the theory.

As mentioned above, most criminologists consider routine activity theory to be a victimization theory. Looking more closely at the second and third element, Meier and Miethe (1993) indicated that there are four risk factors to explain victimization. They are proximity, exposure, target attractiveness, and guardianship. This section will focus on the first three factors relating strictly to the second element of suitable target. Following this section will be a section giving attention to the last risk factor, guardianship.

A suitable target can be defined as a person or place that may become a target to a motivated offender because it is attractive to the offender and it is not guarded (Felson \& Clarke, 1998). This person or place becomes victim to this motivated offender for the sheer fact of not being guarded and also being attractive (Cohen, Kluegel, \& Land, 1981; De Coster, Estes, \& Mueller, 1999; Felson \& Clarke, 1998; Landau \& Bendalak, 2008; Lynch, 1987; Wittebrood \& Nieuwbeerta, 2000). According to Brown and others (2015), "there must be something that tempts the hedonistic calculus of the would-be offender" (Brown, Esbensen, \& Geis, 2015, p. 189). According to Mustaine and Tewksbury (1999), this attractiveness can also be seen as vulnerability when the target is a woman.

Additionally, many targets make themselves open to attack. For example, the advent of smartphones has resulted in many people walking around and staring at their phone instead of paying attention to their surroundings. In doing so, they may not notice that they are being followed and they become easy prey to having their purse snatched or wallet pickpocketed. This exposure is defined as "the physical visibility and accessibility 
of persons and objects to potential offenders at any given time and place" (Cohen, Kluegel, \& Land, 1981, p. 507).

Furthermore, the proximity of the offender to the victim will also have repercussions. In other words, the closer the victim and the offender are in distance, the higher the probability that a crime may occur (De Coster, Estes, \& Mueller, 1999;

Landau \& Bendalak, 2008; Lynch, 1987; Madriz, 1996; Miethe \& Meier, 1990; Mustaine \& Tewksbury, 1998; Mustaine \& Tewksbury, 1999; Wittebrood \& Nieuwbeerta, 2000; Wooldredge, Cullen, \& Latessa, 1992). Further, the proximity of the target to high crime areas increases to opportunity for crime to occur (Meier \& Miethe, 1993).

The last risk factor associated with victimization is guardianship which coincides with the third element in the routine activity theory triad, lack of capable guardian(s). A guardian can be a person or thing that provides a protective barrier, so to speak, around individuals. Examples of guardianship include a police officer patrolling the streets, a security guard standing watch, or a friend or relative accompanying a person to an event. According to Felson and Clarke (1998), a capable guardian is defined as "anybody whose presence or proximity would discourage a crime from happening” (p. 4). In other words, these guardians make targets unattractive to offenders. Cohen et al., (1981) defines guardianship as the presence of others that cannot only prevent crime but also protect people, and they have the capability and willingness to practice formal and informal means of social control. For example, in dealing with sexual harassment in the workplace, supportive supervisors act as guardians. They protect the victims throughout the process of any case that will arise against the accuser, as well as providing courage to 
the victim to stand up for herself in any future instances of potential sexual harassment (De Coster, Estes, \& Mueller, 1999).

Early studies of routine activity theory suggested that leaving one's home to go to work was allowing the house to be an attractive target because of a lack of a capable guardian (Boetig, 2006; Hindelang, Gottfredson, \& Garofalo, 1978; Miethe \& Meier, 1990; Wittebrood \& Nieuwbeerta, 2000). Crime prevention efforts for these property crimes have consisted of installing burglar alarms, getting a dog, or having a neighbor watch your house, thereby adding a guardian to the equation in hopes of reducing crime (Buck, Hakim, \& Rengert, 1993; Clarke \& Bichler-Robertson, 1998; Cohen \& Cantor, 1981; Cromwell, Olson, \& Avary, 1990; Wright \& Decker, 1994).

Many criminologists have moved away from these property crimes and have focused more on predatory crimes to explain guardianship or lack thereof (Bryant \& Miller, 1997; Miethe, Stafford, \& Long, 1987; Mustaine \& Tewksbury, 1998; Mustaine \& Tewksbury, 2000; Wooldredge, Cullen, \& Latessa, 1992). Felson and Boba (2010) have gone a step further in the definition of guardianship to say that "Guardians' should not be mistaken for police officers or security guards who are very unlikely to be on the spot when a crime occurs" (p. 28). In other words, we should not rely on official sources to protect people and property. A guardian can be a friend, neighbor, coworker, or the individual. The operationalization of guardianship according to Reynald (2009; 2010) involves supervising or monitoring and intervention as needed. Cohen and Felson added the critical need for availability (Cohen \& Felson, 1979; Felson \& Boba, 2010).

Previous research has shown that, according to offenders and their preference of targets, individual level guardianship is more effective than institutional or official types 
of guardianship (Buck, Hakim, \& Rengert, 1993; Cromwell, Olson, \& Avary, 1990; Tewksbury \& Mustaine, 2003; Wright \& Decker, 1994). This is a distinct difference from using security alarms, the police, or a watchdog. This approach suggests that individuals are taking a proactive approach to changing their lifestyle by adding self-protective behaviors or measures, such as carrying a gun or mace, to guard against possible victimization (Tewksbury \& Mustaine, 2003). However, there is some debate that these self-protective behaviors or measures are more of a target hardening rather than a guardianship (Garofalo \& Clark, 1992; Miethe \& Meier, 1994; Tseloni, Wittebrood, \& Farrell, 2004; Wilcox, Madensen, \& Tillyer, Guardianship in Context: Implications for Burglary Victimization Risk and Prevention, 2007). Target hardening is decreasing the attractiveness of the target, while guardianship deters would-be offenders by having a person or thing watch over the target (Hollis-Peel, Reynald, van Bavel, Elffers, \& Welsh, 2011).

The methodology used to study guardianship are as numerous as the definitions. They vary from survey to macro-structural to the more recently suggested observational approaches (Hollis-Peel, Reynald, van Bavel, Elffers, \& Welsh, 2011). These tests have shown that guardianship does have significant effects on crime; however, there appears to be a lack of experimental testing of guardianship in the research (Hollis-Peel et al., 2011). What this suggests is that there needs to be additional research on guardianship and its role in the crime triad. The development of a better definition of guardianship should be addressed, as well as the best way to measure the concept.

Felson (1995) also expanded the idea of guardians to include "place managers." A landlord, hotel manager, or a bar owner would take on this role to monitor and control the 
area they oversee. This 'place' is a concept that was incorporated into routine activity theory, but it had to be small. These settings or places and the way that they are managed can affect the amount of crime that will occur. Bars, for example, are known for crime due to the intake of alcohol and/or drugs and the effects they have on the customers. Bar owners and employees must not only perform their assigned duties but they must take on a secondary role as a place manager. This role performs constant surveillance just from their presence as well as having the capability to intervene should a situation arise (Welsh, Mudge, \& Farrington, 2009). This can be seen as deterrence to would-be offenders. Unfortunately, since this is a secondary function, research has shown that "the surveillance technique of place managers appears to be of unknown effectiveness in preventing crime in public places" (Clarke \& Bichler-Robertson, 1998; Poyner, 1991; Welsh, Mudge, \& Farrington, 2009).

Mazerolle, Kadleck, \& Roehl (1998) sought to investigate the place manager role in "controlling drug and disorder problems on 100 street blocks in Oakland, California" (p. 371). Randomly assigned as the control group, half (50) of the street blocks were patrolled as usual by the police. They made arrests but did not go out of their way to create relationships with community place managers. The other half (50) street blocks were assigned to Oakland Police Department's civil remedy program called "Beat Health". These officers built and maintained relationships with community place managers, issued citations for various health and safety violations, and coerced third parties, through the use of "drug nuisance abatement laws" (p. 372) to clean up their properties. 
Data were obtained through the use of on-site observations, at day one and five months later, and surveying the 398 place managers to ascertain any changes in the drug and disorder problems that plagued the city. Results from the study indicated that place managers are most effective when "built-in resistances exist on street blocks and when place managers engage in collective community activism" (Mazerolle, Kadleck, \& Roehl, 1998, p. 396). In other words, the presence of place managers alone does not have an effect on reducing crime; it must be combined with other efforts. Place managers, in this instance, must forego their individual efforts to reduce crime and become a collective force with the police and other members of the neighborhood if they want long-term crime reduction. Perhaps this is what Eck (1994) was referring to when he extended the theory by adding place controllers to this event. Similar to place managers, their primary interest is in "the functioning of the place rather than keeping a potential offender out of trouble, or in protecting a particular target (other than the place itself, or its contents)" (Eck \& Madensen, 2015, p. 9).

In addition to the various personal, predatory crimes that occur in everyday life, the idea of crime happening in the workplace is one that has lacked sufficient research. Previous research has indicated that individuals in the workplace have higher risks of victimization than those that do not work outside the home (Cohen \& Cantor, 1981). But is there something about the daily activities at work that put them at greater risk of become a victim? In 1982, the National Crime Survey was awarded funds from the Bureau of Justice Statistics to add a supplement to their survey. This addition, the Victim Risk Supplement (VRS) focused on the crime that was occurring while people were at work (Lynch, 1987). Utilizing routine activity theory as the theoretical foundation, the 
survey included four variables to measure victimization at work. These were exposure, guardianship, perceived dangerousness, and target suitability or attractiveness. Exposure can be defined as the "physical access to victims by potential offenders" (p. 287); thereby using availability to the public to measure this variable. Guardianship is similar to the definition already provided by routine activity theory and focused on travel to measure this variable. Perceived dangerousness can be defined by potential offenders in the area and was measured by "perceptions of safety" (p. 288). Attractiveness was measured by how often the worker would handle money.

The findings of the Victim Risk Supplement (VRS) found that the activity of those employed outside the home is a major determining factor of victimization specifically, exposure, guardianship, and attractiveness. In essence, the routine activity of workers does affect their victimization. Further, an increase in dealing with the public, handling money during your shift, or travelling all contribute to an increase chance of victimization. Further, if an employee is subject to all those duties there is the greatest amount of risk to become a victim (Lynch, 1987).

Madriz (1996) used this same data to test the relationship between routine activity theory and the "perception of risk in the workplace" (p. 407). This research goes beyond the basic opportunity variables and utilizes demographics to understand if a relationship exists. The results indicated that opportunity variables such as having contact with people, living in large cities, handling money at work, working at places that do not have security practices in place or have only a minimum, working during the night time hours, using public transportation only, and being a prior victim were all relevant to how a 
person perceives the safety of their workplace. The demographic variables were found to be less predictive of a person's perception of safety at work (p. 415).

Utilizing the same data from the National Crime Survey Victim Risk Supplement, Mustaine and Tewksbury (1997) focused their analysis on the difference in victimization between men and women in the workplace coupling routine activity and lifestyle theory as their theoretical framework. The results of their analysis suggests that male and female victimization risks are different. More women are at risk for being victimized if they are required to work late hours or they are better-educated (p. 33). Men's levels of victimization are a result of quite different sources. These include the absence of security at their place of work, living in a highly populated area, working in a facility open to the public, and having a job description which requires them to be responsible for the protection or people or property (p. 33). Therefore, it can be concluded that "victimization risks vary by sex and by context" (p. 34). For this reason, further research on victimization risks should include various lifestyles, groups, and workplaces.

A step beyond perception of workplace safety or possible victimization brings us to actual workplace violence. These are specific occupations, which may cause an employee to be exposed to the possibility of becoming a crime victim. In a study of twenty-five emergency hospital wards in Israel, Landau and Bendalak (2008), using routine activity theory as a basis, developed a General Exposure to Violence Index (GEVI) to report the type and frequency of victimization that employees faced in the preceding year. The original three elements of routine activity theory were transformed into four concepts similar to those of the VRS: exposure, target suitability, guarding, and proximity to offenders. The index included 15 variables ranging from the structural 
aspects of the hospital to the personal and professional characteristics of the various employees. Normally security personnel, nurses, and those with authority endure the highest levels of victimization due to their frontline exposure to potential offenders. New employees and those unable to deal with or cope with violence were more suitable targets. However, there was a contradiction with regard to target suitability in that those with prior training on coping with violence tended to have higher levels of victimization (p. 98).

Having an emergency button available for employees reduces the possibility for victimization in these emergency wards. This type of guarding is part of the environmental and situational factors that play a part in the daily routines of employees (p. 98). The concept of proximity for this study centered on the levels of victimization that resulted from a policy implemented of not allowing more than one person to accompany the patient into the hospital. It is believed that those family members and friends become disgruntled and frustrated because they feel they are ignored by the staff by not being able to be close to their loved one. As a result, violence can ensue. The policy was not set up as a punishment but rather to keep the emergency ward free from wandering guests which may hinder the medical personnel from doing their job. However, it results in higher levels of victimization for the staff as they try to deal with unruly family and friends (p. 98). Should this occur, the use of the emergency button would be an added safeguard.

An additional example of how routine activity theory is used to explain workplace victimization is a study conducted of workplace bullying in a volunteer organization (Daewood, 2008). Even though routine activity theory was developed to explain personal, 
predatory crime, Cohen and Felson admitted that it can also be used to explain other deviant behaviors (Cohen \& Felson, 1979). Previous studies of juvenile bullying (Clarke, Situational Crime Prevention: Successful Case Studies, 1997), victimization at work (Lynch, 1987), and sexual harassment at work (De Coster, Estes, \& Mueller, 1999) all had the ability to use routine activity theory to explain "domain specific" examples of victimization (Lynch, 1987, p. 284). This study aimed to further this type of research in a more modern era of criminal behavior.

The results, however, only partially supported routine activity theory to solely explain workplace bullying in a volunteer organization. The study did further the position that if one of the elements of the triad is missing, workplace bullying would be "less likely to occur" (Daewood, 2008, p. 295). This particular crime of workplace violence is more of a combination of dispute-related and predatory crime rather than a predatory crime alone, as most often studies of routine activity theory are measured (Daewood, 2008).

In addition to previous studies that focused only on situational (routine activities) factors for domain specific violence, Kodellas, Fisher \& Wilcox (2015) added dispositional factors (negative affectivity and low self-control) when explaining workplace victimization. Utilizing a sample of Greek and Cyprus journalists, they were able to find support for the routine activities factors like the previous research before them. Additionally, negative affectivity was able to predict workplace victimization. But low self-control was not supported in their study.

Prior to this study, all research on workplace victimization, utilizing routine activities, has been mostly limited to the United States and Britain. This study broadens the scope of 
generalization for the use of routine activities theory to explain workplace violence in various cultures. According to Lynch (1987), utilizing domain-specific studies like workplaces allow for a classification of crime according to the location of people when they are victimized.

Hospital staff and journalists are not the only occupations where high levels of victimizations can be found as a result of routine activities. Taxicab drivers have higher risks for criminal victimization because their daily routines put them into locations and situations where the potential exists to come into contact with an increased number of likely offenders. Furthermore, the routine activities of taxicab drivers that put them in these dangerous locations can make them more exposed as an unguarded target. For example, taxicab drivers may start their shift at the airport but their passenger may request them to drive to a dangerous area of town. If the driver is unfamiliar with that area, he may turn down the wrong street and wind up in a neighborhood where shootings occur every day, which could subject him to becoming victim to stray bullets. Or that same passenger could be taking the driver to a place where his friends could be waiting to rob him and/or steal the taxicab.

As shown, routine activities theory centers on the idea that crime is most likely to occur when there is a convergence of a motivated offender, without an intimate handler, a suitable target, and the lack of a capable guardian. Should one of these elements be absent, the likelihood of a crime occurring declines (Cohen \& Felson, 1979).

Examinations of routine activity theory have shown that it can explain both property and predatory crime. Furthermore, routine activity theory can explain crime in the workplace 
as well as other domain specific crimes because it assists in explaining the exact location where a person can become victimized.

Previous victimization studies in the workplace have used household data (Lynch, 1987; Madriz, 1996; Mustaine \& Tewksbury, 1997), while others used self-report questionnaires (Empie, 2001; Landau \& Bendalak, 2008; Kodellas, Fisher, \& Wilcox, 2015) and surveys (Daewood, 2008). This study will be using semi-structured interviews to glean information from victims and potential victims of workplace victimization. These face-to-face interactions will not only gather recordable data but also the nonverbal cues that would be missing from a survey or questionnaire. 


\section{CHAPTER IV \\ METHODOLOGY}

The data for the present study is the result of fifty semi-structured interviews with ride share drivers from 22 metropolitan areas/cities in the United States. These interviews took place during the spring and summer of 2016. This number of interviews may seem small compared to the thousands of ride share drivers in the United States, but without any previous research on the subject, the amount of interviews was within the acceptable median size thirty-five (35) for semi-structured ethnographic research found in many top criminal justice and criminology journals (Copes, Brown, \& Tewksbury, 2011). Additionally, many themes in the interviews appeared to reach saturation (no new information could be attained) as the number of interviews grew near the 40-45 mark.

\section{Sample}

Table 1 illustrates the demographic characteristics of the sample. Ride share drivers are mostly male (70\%) and white (76\%). The drivers' ages ranged from 27 to 67 , with a mean of 43.1. It should be mentioned that all drivers must be at least 21 years of age before being accepted as a driver. Slightly less than half (40\%) of drivers only drove for Uber, while the majority (58\%) chose to drive for both Uber and Lyft. Interestingly, only one driver chose to drive for Lyft and not Uber.

It was interesting to discover that only $32(64 \%)$ of the drivers I interviewed drove part time, while $18(36 \%)$ drove full time. I assumed that with all the additional drivers in 
the cities that it would be difficult for someone to make a living driving full time. However, I did not explain what I meant by full time or part time to the drivers. As I learned, some believe that full time is making enough money for the week. This may be possible with less than 20 hours of work if there is an event in town. Additionally, some of the unemployed drivers believe that full time is any amount of time they are working.

Almost half of the drivers (48\%) have been driving for less than a year, while close to one-quarter $(24 \%)$ have been driving for one year to two years, and over onequarter $(28 \%)$ have been driving for two or more years with the most being four years. There are a few reasons for these numbers. First, ride sharing is a relatively new industry and some of the cities may have only started the service within the past year. Second, there is a high turnover in ride share drivers. Many drivers are lured into signing up with bonuses and the expectation of making good money. However, once they work past the required time to earn the bonus, they often leave because they are not making as much money as they hoped. Third, the drivers who have been driving for two years have learned what areas of town are best to pick up passengers and at what times. They often have regular passengers that they take to and from work. As indicated by Table 1, only two of the drivers I spoke to had driven for three years or more. Both of these individuals only work part-time on weekends to earn extra money.

Ride share drivers are required to have a vehicle no more than ten years old at the time they sign up. However, four of the drivers have vehicles older than 10 years and they have only been driving for less than a year. But, they only drive with Uber. Apparently, Uber is a little more forgiving in the ten-year rule. Lyft is firm in their tenyear rule, which is why these drivers do not drive for Lyft. I did discover one source 
(http://rideshareapps.com/uber-vehicle-requirements-for-2016/) that suggested that Uber has varied the year rule based on city and that they will not stop a driver from driving his/her vehicle once it hits the ten-year mark.

\section{Data Collection}

In an effort to obtain interviews with current ride share drivers, the researcher needed to find ways of finding drivers without soliciting the assistance of Uber or Lyft to obtain driver information. Since the researcher is a ride share driver with both Uber and Lyft, it was possible to gain access to group forums on social media, specifically Facebook. These forums ranged from general drivers to specialty groups (women only, cities, singles). Some of the forums were open to the public, but many of them required the researcher to submit a picture of her active driver profile before gaining access to the forum. The researcher submitted requests to the forum hosts to be allowed to solicit drivers to take part in her study. Upon approval, a pre-authorized social media announcement was posted to the groups. It should be noted that the researcher refrained from driving during the study as to not add any additional biases to the study.

Many of the drivers said they were hesitant in agreeing to the interview, believing that the researcher worked for Uber or Lyft and was trying to spy on the drivers. The researcher provided the drivers her and her chairperson's university contact information in the solicitation should they wish to verify the information. The researcher discovered that the specialty forums provided the best results, mainly those of individual cities or areas. Drivers from the same city as the researcher were the first to accept to be interviewed. However, the researcher discovered that getting drivers to show up to 
interviews was quite a task. Most people that become ride share drivers do so because it allows them the freedom to work whenever they want to. This lackadaisical approach to work seemed to carry forward into the confirming of appointments and/or showing up for interviews. Therefore, it was essential to allow for Skype and FaceTime interviews to be able to reach the 50-interview point. Both methods allowed both the researcher and interviewee to see and hear each other throughout the interview. The number of in-person interviews was 21 and through Skype and Facetime was 29.

Once the researcher met with the driver face-to-face, the interviews were conducted in a semi-structured style. After a few demographics were answered, many interviews became more conversational, which allowed the drivers to relax and have the freedom to share stories of events they have encountered as a ride share driver. Ten of the fifty drivers reported that had not encountered an incident and only two mentioned they had never thought about their safety. The duration of the interviews lasted from 15 minutes to over an hour, with most lasting around 30 minutes. Prior to data collection, all of the above procedures were reviewed by the researcher's university institutional review board, in order to ensure that ethical standards were met.

\section{Analysis}

The method used to analyze the data was based on a grounded theoretical approach through analytic-inductive techniques (Berg \& Lune, 2012). This process began with the interviews being transcribed in full. The researcher enlisted the aid of a professional transcriptionist for this task. A few of the interviews may have missing words or phrases due to the surrounding sounds during the interview; however, none of 
the interviews were compromised as a result. All identifying information, which included the name of the driver, was removed and each driver was given a respondent number to protect his or her confidentiality.

Demographic data was retrieved from the interviews and entered in an Excel spreadsheet for further consideration and analysis. Those results are provided in Table 1. Multiple readings of the interviews were then performed to correspond the respondents' answers to the multiple items on the questionnaire, which was used as a basis for the semi-structures interviews. Responses that did not appear to match up to a particular question were put in a miscellaneous category for future review. Many of those initial interview questions became the focal themes for analysis.

The following is a list of the questions asked to each of the respondents:

1. What made you decide to drive for Uber/Lyft?

2. Which one (Uber or Lyft) do you prefer and why?

3. Do you carry any weapons or sprays to ensure you safety? If so, please explain what you carry and why? Where is it kept? Have you ever used it?

4. Do you have a dashcam in your vehicle? Why or why not? Has it made a difference for you as a driver?

5. Can you tell me about any incidents in which you felt unsafe driving? Have you had any?

6. Have you ever contacted Uber/Lyft about your safety? If so, what was their response?

7. If you were attacked as a driver, would you stop driving for Uber/Lyft? Or would you start taking precautions on your own like carrying a weapon? Please explain.

8. Is there anything you would like to tell the company executives about driver safety? If so, what?

9. Do you have any suggestions for Uber/Lyft and other ride-sharing companies to ensure driver safety? If so, what?

10. What regulations do you think the federal or state government should enact to ensure driver safety?

11. Is there anything you would like to add about driving, safety, or other issues? 


\section{CHAPTER V \\ RIDE SHARE DRIVERS}

Why does anyone start a new job? Perhaps they need to supplement their income or need an entirely new income source because they are no longer working. Others may start a particular job because it is convenient and/or flexible for their lifestyle. Rarely do you hear from someone that they started a new job because they like to meet new people and that they continued this particular job because it was fun. But, is not that the dream? According to Marc Anthony "If you do what you love, you'll never work a day in your life" (Brainy Quote, 2017).

All of the reasons above and more are what Uber and Lyft are focusing their advertising toward as they gain more ride share drivers. According to Uber's website under the drive page it states "Work that puts you first", "Drive when you want, earn what you need", "Set your own schedule", and "Earn more at every turn" (Uber Technologies, 2017). The webpage goes into further detail with the following, "You can drive with Uber anytime, day or night, 365 days a year. When you drive is always up to you, so it never interferes with the important things in your life" (Uber Technologies, 2017).

Lyft is also attracting new drivers with their driver webpage. Statements such as, “Make Up to \$35/hour Driving Your Car", "Don’t have wheels? Get one for \$0/week", “See How Much You Can Make”, and "Whether you're trying to offset costs of your car, 
cover this month's bills, or fund you dreams, Lyft will get you there. So, go ahead. Be your own boss" (Lyft, Inc. , 2017). In addition to these headlines, Lyft also has a section explaining what Lyft is and why a person should drive for Lyft, to include keeping your tips (Uber does not have a tip option on their platform) and promoting that Lyft is a community of drivers and passengers.

A person that is wanting a new or different job may have seen these ads and looked at the websites to learn more about ride sharing. Once they finished reviewing them they may decide that becoming a ride share driver would be an ideal job for them. For some, becoming a ride share driver may stem from needing the income, which is why most people work. However, many found that having a flexible job, in which they could work whenever they wanted, was perfect for them. While others thought that the concept of being a ride share driver might be a fun and exciting job. After analyzing the interview data, these three themes were the primary motivations of these respondents for becoming a ride share driver.

\section{Source of Income}

People, for the most part, obtain a job because they need income. This, new source of income, is the primary reason for many ride share drivers as well. However, there are different types of income that can be suggested. Some drivers work full time and this job is their only source of income, while the majority only work part time. These part time drivers may need the income to supplement their current job, or save for something special, or allow them to have fun money to spend frivolously.

Employment to earn income can be difficult for some. Older individuals are often discriminated against when applying for jobs (Roscigno, Mong, Byron, \& Tester, 2007; Sargeant, 2001; Ursel \& Armstrong-Stassen, 2006). Employers want younger employees 
that have an expected long life ahead of them, not someone that is a few years from retirement. The only age restrictions for becoming a ride share driver is that of being at least 21 years of age. As long as an individual has a valid driver's license and a good driving record, there is no maximum age to which a driver can be excluded. This is a wonderful policy to have for many drivers that are near or above the typical retirement age of 65 .

Age discrimination is difficult to prove so many older people find it difficult to obtain a job that does not care about age. For example, a 66-year-old driver from Charlotte, North Carolina, believed that he was discriminated against when his position was eliminated during the recession and he was looking for over a year to find a job. He finally said to himself, "okay at 66 they're not hiring". He then decided to become a ride share driver and found out that "I enjoyed it enough and said I'm not looking to get back into the corporate world". Becoming a ride share driver is a great choice, as one 60 -yearold explained, "I need money and there's not a significant amount of job discrimination for people like me".

The absence of age discrimination allows people to consider going back to work after they have retired. Many retirees complain that they cannot live on social security alone so they must supplement their income. Being a ride share driver allows retirees to generate that "secondary income" according to a 67-year-old driver from Louisville. He said he is grateful to have a part time job that keeps him busy as well.

Age discrimination is not the only barrier to obtaining a "regular" job for some of these ride share drivers. Certain medical conditions can cause individuals to have restrictions that would not allow them to work in any other position. One Louisville 
driver said that he needed a job to work around medical needs, "Because I'm on dialysis I needed a job that was flexible that I could do when I felt like doing". This ability to work while attending to medical needs attracted another driver that became disabled in 2013. He said his disability check is not very big so he needed to earn more money. His disability forces him to take breaks when he needs to, "So I can do one or two rides and if I can tell when my legs need to get out of the car I can log off and get out of the car and maybe walk around for 10 or 15 minutes". For drivers with medical needs, becoming a ride share driver is a convenient way to earn money while still taking care of themselves.

Confronted with medical issues and discrimination allows ride share drivers to earn money that they would not have been able to in the mainstream economy. However, becoming a ride share driver does not require one to be in a certain class of people to choose this job. Forced unemployment as a result of losing a job can make some people become a ride share driver until they could find a new job. Originally working for Uber as a source of extra income, this 53-year-old lost her regular job and was grateful that she had Uber to fall back on "as soon as unemployment was over". Losing a job can be devastating, especially when it is the primary source of income. However, having a second job that has the ability to turn into a full-time job, respondent \#1 explained, was pivotal when he lost his regular job. Now, he continues to work full time as a ride share driver because he enjoys it more than a "regular" job.

Deciding to become a full time driver after working part time is a choice for some drivers and not a necessity because of losing a job. The ability to work as often as you want and earn as much as you want is very desirable. Respondent \#12, who drives in Louisville, started out driving to earn extra money but he liked it so much he decided to 
make it a full time job. He originally began as a Lyft passenger, using the service when he and his girlfriend would go out for the evening and not want to worry about drinking and driving. Having such an enjoyable experience during those rides, he decided to try being a driver for Lyft and loved it. After driving for a while he said he, "decided to sign up for Uber full-time" as well. There are not many jobs in which there is the ability to switch from part time to full time at any moment. Drivers have the ability to work 2 hours a week or 80 hours a week depending on their needs and desires. There is no defined limit on time or earnings for drivers.

Not having restrictions on earnings can allow drivers to pay off debt or save for a special occasion or item. Drivers can work for just a couple of months until they have achieved their goal and stop driving if they wish. The very first interview conducted in this study was with a driver who was planning on getting married in the coming year. Driver \#46, who brought his fiancé along to the interview, shared that he chose this type of job because "you make your own hours, kind of chase your own pay. You set your own goal you can work as long as you want to achieve that goal". He did not say whether he would stop driving after getting married. Sometimes having extra money available is too tempting to give up or perhaps it fills a void in a rather dull or boring life. For example, some respondents like \#26 said that even though he did not need the extra money, he started driving because, "well it's a way to make extra money while not just sitting around". Sitting around and not having anything to do besides watch television or play games is not for everyone.

Working a 9-5 job or a full time job in general, is not enough for some people to fill their day. Therefore, some may join sports leagues, volunteer, or seek out part time 
jobs as a way to keep them from just sitting around at home. Those part time jobs have requirements and restrictions like schedules and bosses that could be a turn-off to someone just wanting to fill time and earn extra cash. Becoming a ride share driver is ideal for many because they can decide when and how long they are going to work. They do not have to abide by a schedule and can decide in an instant to start driving whenever they want. But how did they learn about this new type of job? Would they really be able to work whenever and earn as much money as they wanted?

For decades, positions for employment were advertised in the paper and potential employees would submit their resumes. However, with today's technological advances, job postings can pop up on the computer screen without notice. This usually occurs on well-known and frequently visited websites such as Facebook. As mentioned earlier, both Uber and Lyft advertise for drivers with the potential to earn as much as they want. This is exactly how some drivers were able to learn about becoming ride share driver. As a self-proclaimed Facebook hoarder, driver \#10 said she saw the ad to become an Uber driver. Already driving her brother and his friends around for free, she "signed up and like 3 days later I was in". Now she earns money for something she was doing every day for free. Facebook has been a great source of advertising for both companies, but another source is that of driver referrals and bonuses.

Discovering both Lyft and Uber ads while on Facebook, driver \#32 noticed that she could get a bonus by just signing up to be a ride share driver. Needing to get a part time job and was unable to find one in mainstream work, she knew she has to "think outside the box". So when she saw ads and bonuses she got excited and said to herself, “oh I like bonuses let's take a look here". She immediately signed up for Lyft and Uber to 
obtain the bonuses. Unfortunately, sign-up bonuses are usually only given in new cities or marketplaces but there are still referral bonuses available.

Both companies provide occasional bonuses to existing drivers when they refer a new driver. The new driver must be approved and start driving within thirty days of approval for the driver to receive the bonus. This is how many drivers are introduced to Uber and Lyft, through a friend that is a current driver. Driver \#14 explained that he was having a conversation with his friend who mentioned that he was earning " $\$ 150$ a weekend" for driving. His also said that if he signed up and used a referral code that each of them could earn a referral bonus. It was because of that conversation and learning about making easy money that he chose to "sign up to drive the next day". It was unclear how much of a referral bonus each of them received, but according to many of the drivers, the average referral is $\$ 500$.

Online advertisements and driver referrals and not the only way that people learn about ride sharing. Sometimes word of mouth is the best advertisement. For example, a college student was talking to her father one day and mentioned that she would take an Uber whenever she would go out on the weekends. The father asked her what Uber was and she explained all about ride sharing to him. Even though he had a full time job, he knew that he could use some extra money to pay for her college. That was when it came to him that, "I thought that would be a perfect part-time job for me". Regardless of how drivers learn about ride sharing, many are intrigued by the opportunity to earn money and eventually they find out they enjoy their new job. 


\section{Flexible}

Both Uber and Lyft advertise that becoming a driver allows you to work whenever you want to work. For many, the flexibility and convenience that is offered by becoming a driver is why they signed up. Many drivers that have full time jobs know that it is difficult to find a part time job that works with their schedule. For example, not all full-time jobs have a set schedule, so having the ability to work as little as an hour at a time works for many drivers. In addition, starting work is as simple as getting into the car and turning on the app. This flexibility and convenience are difficult to come by in a “regular" job.

Many jobs require employees to work a schedule based upon the demands of the position. Athletic personnel, like coaches or assistants, are perfect example of employees that must be willing to work long after the game is scheduled to end. Whether there is overtime or the game is just running long, it is impossible for someone in this field to know what exact hours he will work. This is why being a ride share driver is a perfect position for these people. Getting out of an event at " 10 o'clock I can log on 11 o'clock or 10:15 depending on when I wrap up everything" according to driver \#6, it allows him to start work whenever he wants. It is this kind of flexibility that allows him to "make a decent amount of money by picking specific times". Drivers can start and stop at any time, they can work as little as a few minutes to as long as they want. It is all up to the driver to determine what is best suited for him.

A driver can work one hour a day or twelve hours a day, pick up one passenger and stop for the day if he wants. The driver can also drive on his lunch hour or before or after a regular job. This flexibility is not found in a typical part-time position. There is no discrimination based on age, gender, or race. As long as the driver passes the 
requirements set forth by the company - approved car, valid driver's license, car insurance, car registration, and passing the background check - he can start driving. A ride share driver can stop driving anytime he wants for any reason. This convenience and flexibility is not available in any other part time or full time positions, self-employed or not.

The ability to pick up a passenger in between sales calls or meetings, makes ride sharing ideal for real estate agents or salespeople. If they should have some free time before their next meeting or appointment, they can simply go online and pick up passengers. For example, a consultant in North Carolina recently started his own company and was looking for something to supplement his income until his new business took off. He chose to become a ride share driver because, "You know I'm out on the road anyway so in between appointments with customers I can do a little bit of this if I want to". Depending on how much time he has between appointments, he can drive for one ride or pick up multiple rides. He has the power to choose what is right for him.

In addition to consultants, real estate agents must be willing to show a house on demand or meet with potential buyers or sellers. Furthermore, real estate is commission based which means that agents are not guaranteed income, no matter how hard they work. This demanding, unstructured position does not allow for agents to obtain the typical part time job to supplement their income. So, when a new real estate agent learned of ride share, she knew that becoming a driver would be ideal for her. Having two children to support she needed "something that's really, really flexible" and also "be able to pay the bills". Not having to worry about money, allows her focus on building her clientele in the real estate market. 
Ride share driving is not only a position for full time workers needing something to supplement their income. It is also a convenient way for others to work when they have not found anything that is flexible enough for them. Before the advent of ride sharing, most advertisements for flexible jobs centered on working at home. Whether it was medical coding, accounting, or customer service, these jobs were ideal for parents that did not want a set schedule. Having school age children means that parents must adapt to changing schedules due to illnesses, field trips, and after-school activities. There is no typical week or even day for parents with children in school, regardless if it is preschool or high school. Unfortunately, these work-at-home positions did not offer much money and they still had stipulations like deadlines, set work hours, and bosses. In contrast, a ride share driver is an independent contractor that has no set hours or deadlines and each person can earn as much as they want.

As mentioned, the flexibility of not having set hours is what attracts many parents to the world of ride share driving. For a single mother of three boys, who are in two different schools across town, ride share driving is perfect. She said she must take and pick up the kids daily and "It's very hard to find a job that will hire you for that short of a time". So when her sister told her about ride share driving, she knew it was the job for her. It seems that becoming a ride share driver can be an ideal job for a parent, according to a 41-year-old mother in Boston, Massachusetts who started with Lyft when it first came to the city. She recalls, "I didn't even really honestly know what I was getting into. It was a new thing, it sounded cool, I needed my own hours, I was a divorced Mom. I guess that was the lure having your own hours". This ability to choose when to work and 
for how long allows parents to take a break from driving if their duties as parents needs to take priority.

The flexibility of the job is a big winner for parents trying to juggle their schedules and still earn an income. Having three kids and a part-time job, a Baltimore driver enjoys being a ride share driver, "How many jobs do you know of that you pick the hours you can work". For her, ride share driving, "couldn't fit any better". The time that kids are at school is shorter than eight hours, so having a job that works within that time frame is wonderful for parents. Additionally, when both parents are working, it is difficult to decide who has to take a day off when there is a sick kid a home. But if one of those parents is a ride share driver, the choice is simple. No longer do parents have to explain to their bosses that they have to leave early because their child got sick or hurt. As a ride share driver, the parent can go offline and attend to whatever issues may arise. This freedom to be able to control their schedule is why many drivers enjoy their new job as a ride share driver.

The flexibility and convenience that ride share driving offers allows people that would like to work, the opportunity to do so. Whether, they have existing jobs and need something to work around those hours or they just need a job and have been unable to find one. Driving whenever they want and for how long they want, is what attracts many to the world of ride share driving.

This attraction that has led drivers to begin a ride share job has also resulted in many drivers continuing in this type of work. Stepping into their vehicle and going online is all that it takes to start working as a ride share driver. This can occur at any time of day or night and the driver can stay online as long as he wants. A driver can decide to go 
online and 10 minutes later change his mind and decide not to drive. Or a driver can go online and drive for hours until he gets too tired and wants to stop. Nonetheless, it is up to the driver to make the choice, he is not restricted.

Whether a driver gets hungry, needs to use the restroom, needs to run an errand, or simply wants to stop driving to stretch, this job allows him to do so. There is no supervisor or time clock, drivers are free to work as little or as much as they want. Drivers prefer this type of position because they will not be "punished" for deciding to take time off. "If I get hungry I can stop and eat any time I want to instead of like waiting for a certain time" mentions a former security officer turned ride share driver. Additionally, he loves driving, so having a job that allows him to make money while doing something he loves is a bonus.

\section{Fun/Bored}

As discussed, many people become ride share drivers for the money or because driving is more convenient and flexible than mainstream jobs. But the idea of starting a new job because it sounds like fun, is not something a typical person would do, right? Going to work every day is something that is required to pay the bills, put food on the table, and provide the necessities of life like clothing and medicine. Whether a person works in a factory or an office, there are demands set forth by company policy and procedure governing the actions of the employees. Each position has hours in which the employee should be at work and at what time he can leave, when he can take a break and for how long. In addition, the required duties of each employee are set forth by superiors and they are strictly enforced. Failure to follow any of the company's policies and procedures can lead to reprimands or termination. All of these restrictions make the idea 
of working a begrudging task, not a fun way to meet new people. But the ride share industry has made it possible to have a job which is enjoyable for many drivers.

The idea of ride share is still a relatively new concept. Having only been introduced in 2010 in select cities, many people are just getting to know what it is all about. Passengers have discovered this new form of transportation as a way to get around town while enjoying the ride. Drivers seem to be enjoying the ride as well. By using their own vehicle, drivers are careful to keep their car clean and tidy, so it appears polished. There are no partitions or restrictions from allowing a passenger to ride in the front seat. This friendly atmosphere promotes conversation and allows the drivers and passengers to appreciate the ride. It is this enjoyment that has triggered the idea for some passengers to become drivers.

Neither ride share company advertises that becoming a ride share driver is a fun job, Lyft simply suggests a friendly ride. However, some drivers have indicated that becoming a driver is all about having fun, especially if they have nothing else better to do. "A hobby at first" was how one driver explained how he got started as a ride share driver. But he enjoyed it so much, he continued working. For him it was better than sitting on the couch.

Many drivers are retirees that do not want to waste time staying home doing nothing. However, they have worked long enough that they want to do something fun with their time. Learning about ride share from his son, a retired veteran decided to research Uber to see what it was all about. He decided to give it a shot because it looked like fun and he ended up loving it. For him, he loves "driving and meeting people and if I can get paid for the two things at the same time, so be it and I have found it to be an 
absolute blast and I really like doing it". Meeting people that you would not normally meet is definitely a plus for some.

For those drivers who already consider themselves to be social by nature, meeting and talking to new people provides an adrenaline rush. Meeting people from different parts of the country or world, listening to all the stories that people have, learning new things can provide a lot of excitement. Taking a famous line from the movie Forrest Gump, driver \#13 said, “it's a box of chocolates, you never know what you're going to get and you never know where you're going". Which is why drivers enjoy the job so much, they do not fear the unknown they embrace it. "I don't always know what I'm going to be in for tonight" said driver \#40 and that is exactly how he likes it. This is a good thing because you never know who your next passenger might be. Plus, if they work on the weekends, they may have some pretty amazing stories to tell the next day to family and friends.

Many of the part time drivers choose to work on Friday and Saturday nights because it can be more lucrative due to high demand. However, they learned that they really enjoy driving around and even feel like they are part of the scene. While there is no dress code for drivers, most dress business casual. However, for those weekend drivers, they get dressed as if they are going out on the town as well. Whether the driver is a man or a woman, having the driver dressed in similar attire makes the passengers feel more comfortable. Instead of thinking of the driver as a paid worker, he could be just one of the guys or the designated driver for the night. This type of relaxed atmosphere allows both the passengers and the driver to have a good time. 
Having fun is not limited to driving on the weekends, drivers have fun and exciting stories that took place all hours of the day and night. Being a ride share driver for almost 4 years has taught one driver about how to have fun. He said you have got to be a people person or you are going to fail. The way to make sure you do not fail is to take this advice, "Once your customers or your riders get in your car treat them like your own, treat them like you own family, your own friends". Being successful makes a person feel good about themselves and enjoy what they are doing. And sometimes that success can be as simple as enjoying adult conversation.

Occasionally grandparents may be relied on to watch their school aged grandchildren during the school year. However, once the summer break arrives these grandparents are left with nothing to do. One particular grandmother was lamenting about the upcoming summer with a teacher when the teacher suggested that she should check out Uber. So the grandmother researched it and decided to try it out. She found out she loved it, especially meeting new people and being able to talk to other adults. For her and others, being a driver is not about working but about doing something you enjoy with your time.

It seems rare to find people that actually enjoy what they are doing, especially when it is discovered they do not need the money. But for some ride share drivers, this is exactly what life is like for them. They like meeting new people, having adult conversations, and keeping themselves busy. It is not a job; it is a fun way to pass the time.

Each driver comes with their own back story as to why he decided to become a ride share driver. Many come because of financial need, either as a full time or part time 
job, or maybe just to earn some extra money. While others were lured by the promise of working whenever they wanted, this flexibility and convenience in a job was unlike any other. And lastly, some became drivers because they had nothing else going on and needed something to do to fill their time.

The job of ride share driver is not a typical job nor are the drivers conventional. They each have their reasons for becoming a driver as well as why they continue to drive. The flexibility and convenience that attracted them to the job was not a lie. They can work whenever they want, for as long as they want, and stop at any time. And for others, ride share driving turned out to be pretty fun. 


\section{CHAPTER VI}

\section{UBER OR LYFT}

As the first ride share company, Uber is more widely known and recognized throughout the world. Uber is also the company that is normally the first to enter a new marketplace and attract drivers. Uber has commercials and billboard advertisements to supplement their existing internet advertising. Therefore, it would make sense that all but one of the drivers interviewed, drive for Uber. Of those fifty drivers, twenty-nine also drive for Lyft. It should be noted that not all cities that have Uber also have Lyft. Since Lyft started two years after Uber, it is still playing catch-up in terms of covering all the markets. Additionally, Lyft does not have the advertising budget to entice new drivers to use their platform like Uber.

When the question of which company do you prefer was posed to those twentynine drivers who drive on both platforms, many of them responded with, "I prefer them both for different reasons" or "I don't really have a preference". However, for those drivers (20 out of 29 ) that did have a favorite, they were adamant about which platform they preferred to drive and those were the Lyft fans (12 out of 20).

\section{Lyft}

Perhaps the biggest reason that drivers prefer Lyft over Uber is the tipping. Lyft has an option on the app that allows passengers to add a tip, whereas Uber does not. What is worse is that false advertisements from Uber have allowed the passengers to believe 
that a tip was already included in the fare. As a result, some Uber drivers began placing signs in their vehicles schooling the passengers about the tips. This resulted in severe backlash from Uber and the company required the drivers to take down the signs or they would be deactivated and no longer allowed to drive for Uber. Uber touts itself as having a cashless transaction, yet in order to provide tips the passenger must have cash to give the driver and the driver must have cash to make change. Many drivers have begun using card readers on their smartphone that allows the passenger to provide a tip when no cash is available. According to many drivers, having a tip option would just make it easier for both the drivers and passengers.

Tipping may not seem like a big deal to most but one or two dollars a ride can really add up. Driver $\# 47$ said that he gets tipped about $70 \%$ of the time with $\$ 2$ or more on each trip. However, respondent \#17 said that he only gets tipped from $20-30 \%$ of his passengers. But for him it is still better than what he gets from Uber passengers, nothing. He goes into more detail to explain how much he can earn while driving with Lyft:

Lyft customers will give a few dollars, nothing huge but if you multiply that on average nine or ten-hour shift, I like to average out maybe two or three rides an hour. So, that's anywhere between eighteen or twenty rides in a day... you know that amounts to twenty or thirty dollars at the end of the shift that's something Uber rides never have to pay".

After all, the point of having a job is to make money, and having the ability to make more money is extremely important to ride share drivers. In a recent report, Lyft announced that their drivers have received over $\$ 200$ million in tips (Cava, 2017). The ability to earn tips is why drivers would rather work for Lyft than Uber.

Along the lines of making more money, drivers also indicated the incentives that Lyft offers as another reason they prefer the platform. These incentives allow drivers to 
make more money during certain times of the day or particular days of the week. It is during these incentives that a driver can earn up to $100 \%$ of the fares just by driving on those designated days or at those designated times. How this works is that Lyft sends out an email at the beginning of the week to drivers in an area in which they see high demand due to a local event, or because of previous high demand at that time. The email asks the drivers if they will drive during the time indicated, thereby locking them into the higher percentage if they indeed drive during that time. Drivers will then respond by letting Lyft know what days and times they plan on driving. As with any promotion there is a requirement that the driver must accept almost all the rides and they must drive during the entire shift of the promotion, most are 2-3 hour windows.

Lyft's incentives are also a way of promoting the company and getting more drivers to sign on. For example, in the Charlotte, North Carolina market they paid 100\% of the fare to the drivers during one month. This instance, as well as referral bonuses are just two more reasons why many of the drivers said that "Lyft treats the drivers better".

Lyft's motto is "Your friend with a car on demand" versus Uber's motto of “Everyone's Private Driver", brings up the next point of why drivers prefer Lyft over Uber: the friendliness. This friendliness spreads from the company, to other drivers, to the passengers. For example, respondent \#19 said he prefers Lyft "because the company people have an interest in having a relationship with their drivers and Uber has absolutely zero interest in the drivers". Not only is the company friendlier, but many drivers stated that Lyft passengers are overall more friendly. The passengers on Lyft appear to be regular clients that enjoy the Lyft experience over Uber and many said they will never use Uber as long as Lyft is around. 
Continuing on with the friendliness component from the company, unlike Uber, Lyft provides live driver assistance. Should a driver have an issue he or she can call the driver assistance line and have someone from the company talk to them. Uber, on the other hand, has a customer service/driver assistance line but it is a recording asking the driver or passenger to please email them their questions or comments. For drivers, not only does this delay the response from Uber but the response they receive is often a canned response that does not address the question asked. This frustration was heard when a female driver from Philadelphia discussed her preference for Lyft,

They have live customer service (driver assistance) which is awesome because you can call a critical response line if you have an issue with Lyft and you can talk to a live person. As with Uber it's all email, email, email, and it gets frustrating.

This issue will be addressed further in Chapter VII about when drivers have contacted the companies.

The last major reason that drivers cite as why they prefer Lyft is the fact that Lyft has a more thorough screening process of their drivers. Yes, both do the standard state background check and require copies of the drivers' license and proof of insurance, as well as pictures of the vehicle they will be driving. But Lyft goes a step further, they have each new driver meet with a mentor before they can start driving with Lyft. This meeting allows the mentor to make sure the vehicle is in proper condition and that the driver is friendly. The recruit must take the mentor on a ride to ensure that he or she is a good driver as well. The mentor explains more about Lyft to the new driver and is there to answer any questions. This is the primary reason why respondent \#41 said that he prefers Lyft, "I think it's probably their driver recruiting process and how they pick their drivers. They are a little more thorough... and that ends up providing a safer and better experience 
for their passengers". Unfortunately, it was discovered throughout the interviews with other drivers that Lyft has discontinued this mentor program in some cities.

\section{Uber}

Uber was the first ride share company and hence the first to enter most marketplaces. Even though many of the drivers said that they prefer Lyft, all but one drive for Uber as well. Driving for Uber must have some redeeming qualities that keep drivers actively working under the platform. The biggest reason why drivers prefer Uber is because it more widely recognized in the ride share industry. Due to the popularity, Uber has a larger client base and therefore drivers are busier while driving under the Uber platform. Recall that Uber started two years before Lyft and they are the ones that almost always enter a new marketplace first. Uber is so well known to drivers and passengers alike that Uber and Ubering have become vocabulary words for drivers and passengers. For example, this researcher has been asked by relatives "are you Ubering this weekend"?

The word Uber has also taken its place when people refer to ride share in general. Passengers will often say they are going to get an Uber and that could mean they are going to use Lyft. But since most people have heard of Uber, it is just easier to always say that name. Kind of like when you may go to a restaurant and order a coke. You do not necessarily want a Coke; it is just what most people say when referring to a carbonated soda. Of course that request may be followed up with "is Pepsi ok?" to which more times than not, the customer will say that is fine.

Therefore, Uber drivers enjoy the larger client base due to the recognition that the name Uber provides. "People know Uber, so it's busy all the time...Uber is better it is 
more popular", said a driver from Louisville. Because of the popularity, drivers use the Uber platform because if they only use the Lyft platform, they will not stay busy. Whenever drivers begin working they will have both platforms running and whichever gives them a trip first is the one they choose. The driver will then turn the other service off until his new ride is complete and then he will turn it back on, waiting for the next ride request. It is just a matter of which app provides the next passenger, and more often than not Uber has more requests.

In addition to the name recognition, Uber touts itself as a more sophisticated company. This sophistication is attractive to many drivers that prefer to stay away from the immaturity of young passengers that ride with Lyft. With the motto of "Everyone's Private Driver", the company wants passengers to feel that they are being taken care of in a more luxurious way than a taxicab. Uber passengers "tend to be the more professional, more older", according to one female driver, and that is who she prefers to have as passengers. Lyft's approach, while friendlier, attracts younger passengers who can be rowdier and unpredictable. Additionally, due to the variety of Uber services, drivers can choose the type of platform they wish to drive under. Often, this will dictate the type of passengers in the car.

The ability to offers different platforms allows Uber to provide passengers with services tailored to their needs. These platforms are also another reason why drivers prefer Uber over Lyft. Currently Lyft drivers can only driver under 2 platforms, which means there is only an opportunity to make two levels of pay. But with Uber, there are up to 7 platforms (based on location) that the driver may choose to drive. The ability to 
provide extra levels of service allows drivers to make substantially more than their Lyft counterparts.

The platforms/services offered by Uber include UberX, UberXL or UberSUV, Uber Black Car, UberSelect, UberLUX, UberTaxi, and UberPool. UberX is the most popular and found in every market. Requesting this service would include a driver with a 4-door sedan that seats 4 passengers. Should a driver have an SUV or minivan, he could drive under the UberXL or UberSUV which means that the vehicle can seat more than 4 people. The rates are also higher when using UberXL. Many passengers try to fit more people into an Uber-X vehicle so they can pay the lower fares but that is illegal and they are often left on the side of the road needing to order a larger vehicle. Many drivers that can drive under the UberXL also drive under the UberX platform to keep busy. Of course the same instance occurs when a passenger orders an UberX vehicle and when a minivan or SUV comes they try to fill up the car with more than 4 passengers. At this point the driver can tell them they will be charged the higher rates and let them decide to continue or not, or the driver can just contact Uber and tell them that there were more than 4 passengers and they need to be charged the higher rates.

Uber's original tag line "Everyone's Private Driver" was created as a result of Uber's original platform, the Uber Black Car. This platform provides the passenger with high-end sedan (black in color) that seats up to four people. There is a list of the cars that Uber will accept under this platform when a driver signs up and he will know whether his car qualifies. Again this platform has a higher rate and the drivers may also select to drive under the UberX platform to stay busy. The next is the UberLUX and UberSelect, which similar to the Uber Black Car except that the vehicle does not have to be black. Is still 
must be a luxury sedan that can seat up to four people. The difference between the two is that UberLUX has a professional chauffer.

Uber has started to move more into the taxi industry by providing UberTaxi, similar to regular taxis this just allows the passenger pay through the app. This platform is only provided in the San Francisco area as a test city. The most recently added platform is the UberPool and it is available in 27 cities. This service allows passengers to share the ride with others going in the same direction. This saves money to passengers but drivers do not like it because instead of 2 fares they have only one.

Lyft, on the other hand, only offers two regular platforms to choose from and one they are testing. There is the Lyft, which is any 4-door sedan seating up to 4 passengers and there is LyftPlus which are larger vehicles that can seat up to 6 passengers. The new platform that Lyft is trying out is LyftLine which is similar to UberPool but it is only available in 3 cities, New York, Los Angeles and San Francisco. Based on this comparison of platforms it is understandable that drivers that own black or luxury vehicles would prefer Uber because they would make more money. One driver in particular said that when she needed a new vehicle she was reminded of the different platforms and chose to buy a black Infinity QX56, which is a luxury SUV, so that she could drive on multiple platforms and make more money. Even though she said that she likes driving for both companies, she prefers Uber because, "I like the different levels of service, I love that I'm getting to do black car now. I love the high demand with Uber and the name recognition with Uber". She and others who drive the black car platform also enjoy the increase in revenue they receive by offering a higher level of service. 
As the first ride share company by two years, it is inevitable that the public will recognize Uber over Lyft. Additionally, Uber provides service in various countries around the world including, Canada, Mexico, Central and South America, Europe, The Middle East, Africa, East Asia, South Asia, Southeast Asia, Australia and New Zealand (Uber Technologies, Inc, 2017), whereas Lyft is only available in the United States. As a worldwide phenomenon, it would make sense that Uber is more widely recognized by passengers and drivers. It is for this reason why many drivers that may prefer Lyft over Uber continue to drive for Uber.

While ride share drivers agree that they would continue to drive for Uber to stay busy, they still prefer Lyft because of tipping. For as long as Lyft has been around, Uber drivers have been demanding that Uber add a tip feature to their app. However, Uber continues to deny drivers the ability to make more money by adding a tip feature. According to a post from the Uber public policy team, Uber decided against including a tip option on the app "because we felt it would be better for riders and drivers to know for sure what they would pay or earn on each trip - without the uncertainty of tipping" (A Medium Corporation, 2016). Uber has continued this claim adding that passengers enjoy this "hassle-free" ride (A Medium Corporation, 2016). Unfortunately these statements, according to the drivers in this study, just prove that Uber is not concerned about the drivers. 


\section{CHAPTER VII INCIDENTS AND THE ACTIONS THAT FOLLOW}

The previous chapters explained why people choose to become a ride share driver, why they continue driving, and which company they prefer. As independent contractors, these drivers enjoy their autonomy but many question whether either company, Uber or Lyft, are concerned about their safety. Since they are not employees, the companies have provided no safeguards to protect them in the event of an attack. Additionally, what are they supposed to do if they are placed in a situation that becomes threatening or even deadly? There are no training guides or driver assistance for them to refer to when they find themselves in a bad situation. Therefore, many drivers utilize their own self-protective behaviors to ward off any potential incidents. Unfortunately, incidents do occur and it is impossible to know just how many have resulted in drivers ending their ride share careers. This chapter focuses on the incidents that have occurred to the drivers in this study. In addition, the drivers discuss what responses they have received when they contacted Uber or Lyft, as well as any self-protective behaviors they employ to ward off incidents.

Similar to taxicab drivers, ride share drivers are involved in incidents affecting their jobs and lives. According to previous studies presented in Chapter I, an average of $48-58 \%$ of all taxicab drivers have been threatened, attacked, robbed, confronted with a weapon, and/or physically assaulted. There are no statistics available on the number of 
ride share drivers that have been involved in incidents, but a review of newspaper articles reported 9 driver homicides between March 2016 and February 2017. Over half of the drivers in this study said that they have had some type of incident that made them worry about their safety. This is similar to the taxicab statistics mentioned above. Be mindful that not all incidents involve a physical attack, safety for drivers means that they are free from hostile or threatening words and/or movements.

Any ride share driver that agrees to pick up passengers at any time of day or night should understand that it is possible that he or she will have an incident. Some drivers prefer to only work during daytime hours to avoid the drunks or rowdy kids normally found on weekend nights. Avoiding certain areas of town can also take away a higher possibility of something bad happening to a driver. However, day or night, rich or poor neighborhood, incidents can occur anywhere and to the shock of some drivers, they happened to them.

\section{Incidents in the first week}

The first week of a new job can be exciting, especially for a ride share driver. Learning all the nuances of the job, like the best time to drive, where the gas stations are located around town, and shortcuts around traffic allow drivers the opportunity to learn more about being a ride share driver. However, some drivers have run into situations their first week that made them second guess their decision to continue as a ride share driver. One female driver in Louisville explained,

Okay, so I had one the very first time I was driving and I picked up this guy and I made a rule for myself after I picked up this guy that I would never pick up single men again and especially late at night during bar closing hours. I was taking him to his destination but he wouldn't tell me where we were going to put it into the GPS, he was just trying to tell me and he was very, very drunk kind of staggering out in the middle of the road and waving his phone at me whenever I pulled up, 
which I didn't know at the time that I could cancel. I think because I was brand new and still trying to figure it out and it was one of the busier nights of the week, I probably should have used a little bit more common sense in that situation but I learned from the school of hard knocks so. So it's been a very big learning experience.

So with him whenever I was taking him home he would tell me what exit to get off of and then he would switch and then I would be like this exit and then the last one that I was really supposed to stop at he said okay this one. I said are you sure it's this one and he just started yelling at me. He was like yes isn't that what I just said, like getting very angry yelling and I felt very threatened and (I'm) really kind of petite and I probably couldn't do harm well so. To me in my situation I know that I have to be protected after that because I didn't think that would actually happen. You know it was kind of one of those Lifetime Movie moments but I finally got him to his house and whenever I dropped him off he was like yeah I got some beer up in my room if you want to come up and I said no that's okay. He said I'm really sorry for yelling I'm just an alcoholic and it's just it's very you know I'm drunk. I'm like no it's okay you have a good night and then I drove away and after that night I got a Taser. It looks like a flashlight that I carry in my lap at all times and so, especially if I'm driving at night because nobody really suspects and so I do let it be known, since I drive and XL there's a lot of bridal parties that come through, bachelor parties and bachelorette parties but if I pick up a bachelor party, it is known that I have a Taser and they do not bother me.

Even with a Taser at her disposal, this driver had a couple more instances that have given her the education and experience to become better prepared as a ride share driver. Not only will she no longer pick up single men but she now refuses to pick up people after 2am in hopes on cutting down on more incidents. The taser and her decision to alter her driving habits are self-protective behaviors she has put in place to ward off another incident. The other two incidents that led her to make those changes to her driving are:

I was driving for Uber and I picked up downtown at a hotel and they all just started running to my van and they looked like college kids and they turned out to be and then everybody got into the van and they were like hurry up close the door, close the door and this guy just came barreling out of the hotel and flings open my back door and it like hits hard and I was like hey, you know because I've got a big mouth. He was like seriously trying to get into the van to fight one of the passengers that was in my vehicle and so finally they pushed him out of the van and the guy shut the door real fast. The guy that was trying to get into my van to fight the guy ended up punching my window and that was the second thing that happened. So I just drove away really fast. 
Then the last thing that happened was I was picking up passengers and I have like automatic locks or whatever and whenever actually it was two weeks ago at Tin Roof and I had to get somebody's attention to get this guy out of my van because. So I picked up this guy and instead of hitting the lock button I hit the window button and he jumped in my van as my passenger and he was like I need to go here and I was like well what is your name and he said I'm your passenger. I said I don't think you're my passenger and you need to get out of my van and he was like I don't understand why you're being so rude and he got aggressive. I was like sir I'm not being rude but I need you to get out of my van please. You have not ordered a ride and you need to get out of my van please. I was being as nice as possible because I know that's right so I made it a rule after that experience that I was no longer going to be picking up the last two hours of the bars closing at 4 , they close.

This driver was not alone in having an eventful first week of driving. Another new driver, also in Louisville but this time a man, had an incident his very first week of driving as well,

I picked someone up in the south end, off Taylor Boulevard. It was just like a real sketchy area like the person had me pull down an alley and back into a driveway and turn my headlights off and it was just because it was only my second day doing it. So I didn't really know okay can I drive away what happens because I felt nervous. The person that got in the car there were two of them had just got done doing either Meth or Crack or something because they stunk I know what it smells like because I used to work in a hotel. It stunk pretty badly and they were sweating profusely both of them and when they got out of the car eventually there was sweat all over it was awful. But I was nervous just given the situation and where I was knowing what they had just done, I didn't know what to do and it scared me. That's probably and it was my first week and I've learned since then now I would just drive off.

Again, this driver has employed a self-protective behavior, driving away and cancelling a ride, should he ever be in another uncomfortable situation.

Both of these drivers did not know that it was permissible to drive away or cancel a ride if they felt uncomfortable or if they were in an area of town that they did not want to drive. Neither driver was given a training guide or even a set of helpful hints when they signed up, they were just sent information on how to maneuver the app on their 
phone. Many of the drivers said that they do not think Uber or Lyft would ever provide training or helpful hints because they would lose drivers before they even started.

Fortunately, these drivers were not harmed and they have now learned what to do in the future. It is unclear though, how many other drivers had incidents in their first week and then decided to quit.

\section{Impaired Passengers}

Dealing with impaired passengers is probably the most challenging aspect of being a ride share driver. These passengers could be drunk, on drugs, or just mentally unstable and without prior experience, the situation can be scary as the two drivers above discovered. However, they gained experience and knowledge from those incidents and are more comfortable knowing how to deal with them in the future. Other drivers have relied on past experiences to defuse situations that they felt may escalate and become violent. A 57-year-old driver, that has 23 years of operational security experience, said that it is because of that experience that he can neutralize situations and people before things get worse. According to him, "I very rarely allow myself to get into a situation I can't get out of quickly". Dealing with a lot of drunks, he understands that people can get belligerent, so for him he prefers "to just try and treat people with respect and you know if they are angry or upset that helps to defuse the situation as opposed to coming back at them which is always going to be bad". Without that security experience, would this driver know what to do, especially if it was his first week on the job? A few of the respondents were former taxicab drivers and they lean on those years of experience and training to provide them with the knowledge necessary to keep themselves safe. 
One previous taxicab driver who is now a ride share driver in Cincinnati said that

he if he feels unsafe then he has no problem to "stop the car and tell whoever it is to get the "F" out, you know and mean it so". He goes on to mention an incident to where he had to throw people out of his car:

I had a person in the front seat, who was the account holder and I had three people in the backseat, they were all girls in this case, it doesn't really matter and the person in the front seat wanted to listen to the radio, the person in the back seat wanted to have a conversation. Well you can't hear to have a conversation if the radio is turned up. So they started to have sort of a battle between what radio station we were going to listen to and what volume we were going to have the radio at and I like to drive and pay attention. So I don't mind a loud radio but there is a point when loud is too loud for me personally and there's just one thing that irks, two things that irk me a lot with customers and one will really push me over the edge. You do not mess with the radio. You can ask me to change the station, I'll turn it up, turn it down but a customer just doesn't start messing around with the radio. Because there's too many buttons that are there and there's too many buttons that are close that are there that potentially become a safety issue for me. That's basically a big red flag and that's basically what happened here the girl just reached up and started changing the station. I reached over and literally slapped her hand, I said that's not for you to touch, keep your hands to yourself. And then she's like okay. She got it and then her friend just started basically yelling louder and louder with their conversation and finally I said look ladies there is only one radio volume that we are going to have, the one that I want or off. Take your choice and choose wisely. And they were like you can't f-ing do this to us f-ing, f-ing. I said yes I can and I kicked them all out well we weren't on the highway but I basically kicked them off at another we were close to a gas station, I didn't leave them on the side of the road or anything but I threatened to and if they hadn't had been ladies if they had been some young guys I probably would have left them on the side of the road but I'm a little nicer to ladies because I have been trained to be. I guess I'm a little sexist but I just wouldn't leave people in an unsafe situation even guys.

Admittedly this driver did not fear for his life, but if he had not dropped these girls off at the gas station, the argument could have escalated and they could have started assaulting him or caused an accident. Just because the outcome turned out uneventful, does not diminish the safety concern for many drivers. He wanted to lighten the mood a little so he also told me of a time when a male passenger was touching him while driving and not 
touching in the bad way. He reported it and supposedly that man is banned. He continued by saying that it is probably worse for women, to which this researcher agreed. Neither situation should have occurred but, because of his years of experience as a taxi driver, he knew what he needed to do to remain safe.

There is one recurring theme that the above stories have in common, intoxicated passengers. Just like taking a cab, ordering a ride share is a great alternative to driving while impaired. It is widely known that alcohol and drugs impair a person's cognitive ability, which is why it is illegal to drive under the influence. This impairment can also affect a person's ability to react to normal situations like giving directions or having a conversation without getting irritated. Additionally, some passengers may become aggressive or overly flirtatious which may cause the driver to feel afraid. The following stories are some examples where drivers felt unsafe because of their impaired passengers. Many are able to use self-protective behaviors to defuse the situation so that it does not escalate to something more violent.

Similar to some taxicab drivers, ride share drivers do not know who they are picking up when they receive the request. Most drivers are aware that if they work on a Friday or Saturday night they are likely to pick up intoxicated passengers. These passengers may be respectable, upstanding citizens but when they imbibe too much, their behavior can turn a fun evening into a scary situation. Respondent \#16 only works on weekend nights so he is used to having intoxicated passengers in his car, especially couples. He relayed the story of one night when he picked up an Australian couple from a Louisville bar,

They were fighting and it got to the point I was fearful it was going to get physical. So I just stopped the truck, unlocked the doors, put the windows down, 
turned the ignition off and I turned to them and said if both of you are going to fight you can get out of my vehicle. If you want to talk about I'll sit here in this parking lot, if you want to shut up and be a normal passenger I'll take you to your destination. That's your three choices you've got to pick. She got out of the car and started walking and I took off with him in the car and about ten minutes after driving around he said can we go find my wife? You going to fight anymore, he said no, let's go, we went back and picked her up and I took them back to the hotel they were staying.... I offered for one of them to sit in the front but they were just back there screaming and arguing, I'm forty-five years old I don't need to hear that. I do the same thing to my kids, you want to get mad and nasty go and come back when you're an adult again and maybe alcohol isn't involved. Yeah I mean I've had the same circle with Uber I'll just back down the guy.

Fortunately, this driver was able to handle the situation just as others have. Another driver, a bit older at 67 and a psychologist, said he has had some "dicey" situations but he tries to add humor. He may also ask the passengers about themselves and/or where they are going to try and ease things up a bit. Having a $\mathrm{PhD}$ in psychology obviously cannot hurt when you are dealing with intoxicated passengers. His education and experience, counseling people, allowed him to know what to do with an unruly passenger. In this instance, he is able to use his words for self-protection.

Respondent \#35 may not be a psychologist but he said he knows how to read people and he knew exactly how his first UberPool ride was going to turn out. As a reminder, UberPool is when passengers going in the same direction can request to be picked up on the same ride. So this driver began by telling me that he picked up a young lady around 20-years-old that was getting off work. This 50-year-old male driver added that she was very cute and "a good girl" and he wanted to keep her that way. After he picks her up, there is a request from someone else to pick up nearby, he asks if this is okay with her and she says yes. Unfortunately, this new passenger is a drunk man that sits 
in the backseat with her and does not want to keep his hands to himself. The driver asked

the lady if she wanted to move to the front seat but she declined. He continues,

so we're driving along and I'm kind of noticing the behavior or this ass half sitting behind me. I'm constantly looking in my rear view mirror behind me because I'm looking at her face, I wanted to see her reactions...However, when I hear her say listen you need to keep your hands to yourself well basically she just turned on my on switch now I feel that I have more than even the right but the obligation to speak up and I warned the guy, dude I'm going to tell you one last time you need to behave yourself, keep your hands to yourself or I'm going to have you exit my vehicle. Oh, okay. So now we're off rolling again I go to drop this lady off... I notice that the back door behind me opens up and the dude gets out of the car ... and I said dude get back in the car. He's not listening to me so I think to myself oh shit I don't get paid for this. So, I threw the car in park I exited the door and I automatically I threw open the door behind me and I start to approach this guy who is following the girl, okay he gets about 10 feet from the girl I'm about 10 feet from him and I tell him one more time dude you need to get back in the car. Well at that point she turns around and the look of fear on this girl's face. Quickly things are going through my brain what do I do, do I put hands on him, do I risk getting sued you know what excuse my language but fuck him. I'm not going to be the one to let this go so I grab him by the back of his collar, shirt collar and the back of his jeans where the belt loop is and I lean him backwards towards me... So I keep him leaning backwards and I drag him to my car you know I've got the door already opened, I push him in the backseat and I said look junior you've got two options, you can close your little pie hole and I will take you where you want to go or I'm going to make you get out of my vehicle and I'm going to call the police. I'll just get out then damn it you don't have to call the police. Oh yes I do because I don't want to see that girls face on the news tomorrow telling them she got raped or murdered oh no that ain't happening on my watch Jack. So, he said he would behave I drop him off as soon as I'm done ...I pull over and I start sending emails to Uber telling them about the situation. They respond to me Dear Michael thank you for letting us know about that situation blah, blah, blah, please rest assured that we here at Uber strive to ensure your safety. So basically, I replied back thank you. If you don't mind telling me how exactly you do that because I don't see you in the car with me. You know and you're talking about doing background checks on the drivers I think you need to be doing background checks on the passengers. Okay so not only is it financially a rip-off for the driver but it's not fair, it's not safe. I mean listen we're already asking a stranger as a passenger to get in a vehicle with another stranger which is me now we're going to put another stranger in the car who is a stranger to both of us. It's not a good idea it really isn't and Uber 
doesn't really care because their biggest concern is what they can put in their pockets.

This was the only respondent that mentioned UberPool at all in any of the interviews. But he was not the only one that dealt with drunk passengers.

A San Diego driver said he has been fortunate to have only one incident in his two and a half years of driving. It was $6 \mathrm{pm}$, when his intoxicated passengers became verbally abusive and he was forced to tell them to get out of his car. The soberer of the two passengers apologized for their behavior. According to him, "That was the only time that I ever had any feeling that I need to a) might need to call the police and b) I did feel a little unsafe". As a daytime driver, he never thought he would be in that kind of situation because he thought all the bad stuff happened at night. But he is not the only daytime driver that has had to deal with daytime drinkers.

Our Muslim driver from Philadelphia said that not only was the passenger a daytime drinker but he was also racist and a bigot, according to her based on the conversations. During the ride, they stopped at a liquor store when the passenger bought a bottle. When he returned to the vehicle he opened the bottle and started drinking. The driver, who admitted that she was a bouncer for five years, said that she wanted to keep him in the car and defuse the situation instead of kicking him to the street. However, she did do something else as well, "at the same time by continuing talking I was able to send a text message to a friend of mine like hey this is where I am if I hit this button call 911". A smart woman who knew a friend would help her, not Uber or Lyft, but she relies on her friends for help when in a potentially bad situation. This driver was fortunate that her words could defuse the situation but she employs the backup of friends for self- 
protection. She knows that not every situation can be neutralized with words so having

another means of self-protection is vital to keep her safe.

A retired veteran who became a driver was able to use his military experience to

subdue a drunk marine who had a few too many.

I had a Marine guy he was drunk. He was not very receptive to tell me where he wanted to go. He only gave me like a town and I drove twenty minutes. I had to hear him barf and everything. The guy he wouldn't come out of my van. So, I said look this is where you told me to drop you off and he said no I'm not leaving the van and I was like you're going to leave the van even if I have to drag you out by your ear. So I did what I said I was going to do right then I dragged him by the ear, he didn't realize that I was a veteran so he thought he could intimidate me by saying he was a Marine Corp guy. I said I don't give a crap who you are you're going out of my van, you're going to the barracks and I yanked him by the ear and we did have a scuffle and I won and I brought him to his superiors that night. It's what is called the Sgt. in Charge at night. So I dragged him by the Sgt. And the Sgt. Said what happened to him? I said he didn't pay his Uber bill. He said oh we'll pay for the Uber bill I said that's okay I charged him and the Sgt. was like wow I've never seen a Marine beat up that way. I said I didn't beat him up he just kept hitting the van.

It was nice that the incident ended with a joke, but what would have happened if that driver had not been a veteran and knew how to handle that situation. The ride may not have ended so well.

This was not the only instance in which this veteran was able to defuse a bad situation involving a drunken passenger. In this instance, it was discovered that this man was not only a drunk but abusive as well. Even though, it is not part of his job, this driver chose to step in to help this woman passenger.

There was one time when the very first couple of months I was working at Jersey Shore there was a couple that I picked up at the OD. Okay I just picked them up from a club the husband was drunk the wife was not. The wife was very submissive; the husband was accusing his wife of flirting with guys in there. She didn't seem like she was that type of person but the husband was just drunk and I just fell silent and checked in every now and then in the rear-view mirror to make sure everything is okay. But when I did see the guy lift up his hand it looked like 
he was going to hit her. I pulled off the side of the road and jerked him out of the car and I gave him a flashlight and I said you're going to stay right here until I drive your wife to a safe area and then I'm going to pick you up and I'm going to drive you home. So, he said oh I'm not going to do this I'm going to sue Uber. I said I don't care you're not going to have anything dramatic happen in my backseat. So he sat there with the flashlight that I gave him I said if you lose that flashlight I'm not going to pick you up that's what I told him. I drove the wife to their place and for like a ten-dollar fare she was going to give me sixty dollars. I said you need that sixty dollars to get you out of wherever you need to go to get out of this situation. I said I'm hoping and praying you go to your next door neighbor, when I come back you better not be here or I am going to call the cops, that's what I told her. So, I went back to get the husband, the husband was talking all kinds of shit ad he yelled you're so glad Uber driver that I'm drunk because I'm going to kick your ass. I was like yeah sure whatever. So, I drove him to their apartment and the wife was gone and he was saying I'm going to sue Uber, I'm giving you one star and stuff.

The passenger did indeed give the driver a one-star rating, but because this was not his

first incident, the passenger was deactivated by Uber.

Unfortunately, most drivers must deal with drunk passengers during the ride.

However, just because the ride is over does not mean the involvement ends for the driver.

A male driver in Dallas, Texas tells about in incident that lasted well into the next day,

I had two buddies get in the truck and they had been out bar hopping to strip clubs and they were arguing one sat in the front seat and one sat in the back seat. They started cussing at each other real bad and swinging at each other and then when I tried to calm them down they got mad at me. But I kept them calm enough to get them wherever they were going but they did start swinging and got blood on my seat and so right after I dropped them off I stopped in a parking lot and noted it with pictures and then let them know at Uber what happened. And the guy actually called me the next morning while I was at church and I didn't know who it was but they kept calling so I went outside to answer it and he started calling me all kinds of names and said he was going to end my life because I charged the guy $\$ 200$ cleaning bill and let him now that his passenger got blood on my seat. He said he's your responsibility not mine and I said no if you read your contract it tells you that you are responsible for the people that you bring in the vehicle with you. Anyway I told him where I was and he never showed up. And then his buddy ended up calling me and asking me how come you charged him, I'll pay you cash just give him the money back. I said it ain't up to me it's up to Uber. There the ones they see what the damages are they say what to charge not me. So 
anyway, they gave me a new phone number, I don't know what they did with him. I don't know if he is still a rider or not.

These two passengers, like most, feel comfortable making threats when drunk but fortunately many do not follow through with their threats. But threats are not the only thing that intoxicated passengers make while in the car. Sometimes they just like to make the driver feel uncomfortable. This same driver had another incident in which three drunk guys were trying to see if they could upset the driver. According to him the guys got in the car and,

the guy in the backseat that was with him told me that guy out there is a serial killer. I told him that was nice. He said he killed a couple of guys in the oil field and the guy looked at me and said yeah that's the best place to kill them because you can hide them real easy out there. I said man I understand I come from a long line of killers it don't bother me. So they kind of left that awhile it kind of makes you feel uncomfortable when they first say it, there were three guys but I have no problem defending myself.

This is just another example of the behaviors of drunk passengers. Had they been sober; the conversation would probably not have taken place. Fortunately, the driver knew how to take care of himself, but what if it was a woman driver or another man that did not know what to say or do in that situation? The night could have ended differently. The following is just another example of a passenger acting strangely after having a little too much to drink.

This event occurred at $2 \mathrm{am}$ in Boston and the intoxicated male passenger was sitting in the backseat and,

He was making like Friday the $13^{\text {th }} \mathrm{ch}$ ch ch noises behind me and he would ask me periodically are you afraid. He would ask me things like does anybody know you're with me and of course I lied, absolutely I tell everybody what I am doing. I have a video camera in my trunk at the time I did not and I also told him I'm a 
licensed carrier and he kind of poo poo'd me about everything but I couldn't let him know that he was creeping me all of the way out and then he attempted to get me to go down this really backwoods unlit road that I was losing service and I made the executive decision to not take that route and afterwards you know what he said to me. Good choice not taking that road. I don't know what that meant yeah but this is the type of stuff that he was doing and I don't think they kicked him off of the platform and I reported everything and they sent me these very cookie cutter answers. That was a really, really creepy time.

She admitted she was scared and because he was drunk, she was not sure what he had planned. She was very lucky that she made the right decision, her words protected her. But some drivers are unsure of what they should do at any given time when the situation turns scary. For example, Respondent \#3 had just picked up a couple of drunk guys after a ballgame in Louisville, one got in the front seat and the other in the back. She then goes on to say

And the guy in the back was like dude I can drive my car I'm not that drunk and the guy up front was drunk and he was like well gone this far we might as well just use it. They were kind of going back and forth and I was like are you coming or are you going and they were like okay. Then we start up the road and it gets sort of funny but it's scary. So the guy in the backseat well I've got boys he farted big deal, the guy in the front seat starts going off on him, oh my god you're so gross I can't believe you did that. The guy in the back seat just flips out, man I'm so sick of your blanket blank stuff, I am over this I ain't doing this no more. I mean it was like full blown you're crazy, you're crazy and I was like okay should I stop and just let them out or they're going to duke it out, what the heck are they doing here. And so you're sitting here going through all of this in your mind as fast as you possibly can should I just stop, spray them both down with some mace and go on. What do I do here? So I just kind of kept my eyes up front and just drove. I know I'm going to have to do something I just don't know what. So then it went quiet, just quiet, and silent and I'm getting real nervous and I kind of look over my right shoulder at that guy and he is passed out cold as heck. He just goes on and passes out after all of that he just passes out... Okay, so I take the guy back to the house, the guy in the back raises up, are we at the bar and the guy says no we're at the house... And I just got out of there I said I' $\mathrm{m}$ going to get out of here before they request another Uber and want to go somewhere else as drunk as they both are. But I swear for a few minutes I didn't know which way that was going to go. It made me real nervous. 
After she told the story, you could tell she was shaken by the experience again. She did not know what would have happened if the one guy in the backseat had not passed out. The argument between the two passengers could have escalated into violence. In this instance, she had two drunk passengers and no experience on how to deal with them. However, she did mention that she carries a gun and pepper spray and would use them. So, even though she had no training on how to deal with passengers, she was knowledgeable enough to have weapons at her disposal.

Naturally, impaired passengers are not always drunk, sometimes they are high on some type of narcotics. Fortunately, the following male driver was able to use his experience to deal with the following situations.

I picked up this one lady over in the downtown area and I waited for her the house kind of looked abandoned but I called and I said well maybe the ping is wrong you know this is not the right house because you know that happens occasionally but no she came out of it and she was on drugs I could tell right away but at this point she had seen me. I knew if I canceled I was going to take a hit, you know. So when I hit the start she had a decently long ride going somewhere I didn't mind going so I did it but while we were on the highway she started biting herself, yeah you know not to the bloody sense but almost like a dog would itch themselves. So she was really sketchy you know. So nevertheless she didn't attack me or anything like that but that wasn't obviously a normal situation because I didn't know if she had drugs on her or what or something crazy was going to happen while we were driving.

And sometimes, those high passengers want to share their drugs with the driver, even when she declines repeatedly. This black female driver in Boston explains what happened to her

He kept offering me drugs and wouldn't get out of my car he wasn't even the passenger. The passenger sat behind, the person whose account it was sat behind me and this guy sat in the front and I should have known when the guy behind me said don't touch her I thought he was just joking. People make all kinds of jokes and comments. He was serious. So the guy wouldn't get out and offered me every drug in the book and then offered me, I've never done a drug in my life, 
what my drink of choice, he wouldn't get out. It got to the point where I had to use expletive's you're going to get out of my car and you're going to get out now and I said it as loud as I could and he would not get out. He was probably hopped on something himself. It took like a lot he would not get out. He was like intent on giving me drugs that I don't use and I was insulted that he would even offer me that. Do I look like I use drugs to you? No.

According to her, it took a lot of coaxing to get him out of her car. She had pepper spray available to her as well as a spiked keychain in the event that the passenger refused to get out of the car. Fortunately, she did not have to use either item, her words were enough to handle the situation.

Of course, the passengers do not have to be drunk or on drugs, they may just be crazy as this female driver discovered,

You know you've got to work real hard to scare me I'm from New York, you've got to work pretty hard. One time I ever and I hate to say nervous, there was this one guy that was having three conversations one was with me, one was with him and one was with somebody who wasn't there so I just jumped into what I was doing and left him alone with the other two conversations and I don't think alcohol was involved at all.

When asked if she thought he was on drugs she responded,

No, I think there was three people going on inside of his head. I don't know if I felt scared or unsafe I just had things a little higher with him because it wasn't alcohol or drugs he just wasn't as stable as he should be.

Fortunately, the ride ended safely. The following exchange took place a short time after the Kalamazoo incident where a ride share driver killed multiple people in between his pickups. This driver was not sure if the passenger was crazy or just trying to get a reaction out of her, regardless she was quick witted enough to handle the situation.

I had one guy get in the car and say to me do you ever worry about getting murdered? Just like that he looked me in the eye and said that and I looked him 
right back in the eye and I said I'll make you a deal I won't murder you if you don't murder me and he said okay, and that was the end of our conversation.

She could smile after she said that but at the time she said she was scared.

All the above incidents took place because of passengers being impaired. Whether the passengers were drunk, on drugs, or just crazy they created a dangerous environment inside the vehicle.

\section{Police Assistance}

There are of course situations where drivers are unaware of how to react to impaired passengers. Without experience or any weapons to protect her, this female driver was thankful that the police were nearby.

It was during Chicago's Pride fest and I went to pick up somebody at Montrose's harbor. Montrose harbor incident was actually a little before I went up there to pick someone up and a group of people were standing on a curb. There were seven of them the car can only hold six, four people plus myself and I politely told them that I can't take all of these people but just the drunkenness and aftermath of the incident that just happened. They got a little rowdy one of them got inappropriate. One of them tried to assault me but he didn't the others were pretty much just banging on my car. So I basically had the police escort me out of Montrose harbor. But in the instance it actually felt unsafe just needed someone to facilitate between me and the passenger.

Even after this incident, this female driver refuses to carry any sort of weapon even though she continues to drive in the evenings around Chicago. She was lucky the police were nearby for protection but what happens next time the police are not around, is she going to know what to do? Although the following driver carries pepper spray and a stun gun, he was thankful that the police noticed the antics happening in his call and decided to pull him over. This male driver in California had picked up a group at 3am and, while we were on the freeway everybody just started arguing. Started yelling at each other I said okay that's fine they can yell at each other I'm not going to say 
anything. The next thing you know they start throwing punches I'm not lying, the girls are pulling hair in dresses the guys are punching and you know what it was kind of funny because they were all drunk and high all of them was like dissing each other. I didn't want to pull over I was on the freeway because I know for a fact once you pull over guess what they're going to do they're going to exit out in the freeway I guess what is really lucky ten minutes while this is happening I get pulled over by CHP and CHP as soon as I pull over says man what is going on in your car? Man you know what for their safety I didn't want to pull over I am trying to find an exit so I can exit I know for a fact these people are so rowdy they don't care; they don't care for each other. They're just going to bail out there's cars they're speeding left and right so I mean I'm not about to let them out. So we're there for an hour and I have my (?) I didn't stop it but one of them got arrested for having drugs with him. So that was actually one of my worst experiences but not really because that was kind of funny.

This driver can look back at the situation and laugh about it, but at the time he was unsure of what would have happened had the police not pulled him over. The only thing better than having the police aid in a bad situation, is having a police officer as the driver.

One of the respondents in this study is an undercover officer who works part time as a ride share driver. Needless to say, she is well equipped to handle intoxicated passengers that happen to get unruly in her vehicle.

The biggest incident I had is when I had to call the police and being police it just kind of threw me off. I was on 64 two gentlemen; very prominent gentlemen I have to say I found out after that. They were coming off what they call the Whiskey Trail or whatever and they got out of control, they started fighting each other in my backseat, physically there was blood drawn. So they hopped out in the middle of I-64 in the middle of the road because there was a big traffic jam due to a big fatal wreck ahead and they stood out boxing it out, completely covered in blood in the middle of the street. I'm sitting there driving, okay. Then they proceeding in coming back to the vehicle and I'm like oh lord here we go again. I let them back in, hand them both a towel and I'm like here don't get blood on my car. You already got it on the seat cover and I'll have to take that out in a minute. They were like we're sorry, we're sorry and then one of them raised a hand to me. Okay you just lost your ride, so I actually took a few hits to the right side of my face. I said okay you all just sit tight, I locked them in the car, they couldn't figure out how to unlock the car and I stepped to the side for safety and waited for the cops to show up. It didn't take them long they were just 
about a half a mile ahead of me at an accident scene. So I was like, I just let them sit there until the cops got here to arrest them.

Although she had various weapons available to her, it was her experience as a police officer that allowed her to realize that she needed extra help in that situation. The police are always ready to lend a hand for drivers. Now that ride sharing has become more popular, the police like the idea of more options to keep impaired individuals off the road. Specifically, the head of New York's Association of Chief of Police has asked the Governor "to expand ride-sharing services like Uber and Lyft to upstate (New York) to curb drunk driving" (Lovett, 2016).

Some of the drivers could rely on their experiences as taxicab drivers, police, members of the military, or other jobs to know what they needed to do or say to get out of a bad situation. Others choose to carry weapons in the event they need them, while others found themselves lucky to have the police around. These situations could have ended worse than they did and all because the passenger was not in their right mind. However, some incidents have occurred to drivers where there is no evidence that the passenger(s) is impaired. It could be that the driver was unlucky and picked up a passenger(s) up to no good.

\section{Passengers up to no good}

This driver mentioned one incident that appeared to start out normal but resulted in him calling the police.

Back on Valentine's Day this year I picked up two riders at Morgantown and you know it was kind of it was night time, it was the coldest night of that month you know and they told me to pick them up at Morgantown. They made me wait for a couple of minutes like more than the usual five minutes and stuff. I was about to leave when they finally came out and as soon as they got in I felt that little I feel uncomfortable with these two. So when I turned on the app they didn't have an 
address in there so that kind of put a warning sign on them. To make a long story short they tried to carjack me... They reached out for my keys and tried to choke hold me from behind my seat but I knew how to actually get out of the jam and everything and I ended up throwing them out of the vehicle. I called the cops.

Ride share drivers would rather not have these dangerous rides, uneventful travels earn the same amount of money and can be less stressful. Many drivers tell stories of fun passengers, especially bachelor and bachelorette groups, that are just out to have a good time. Those are the tales drivers would rather talk about, not the ones that could have become violent or did.

One driver, who thought she was having an uneventful ride, soon discovered it was not going to be that simple. It involved drugs, terroristic threats, the police, and a new phone number for her. Here is what happened,

I had a lady get in my car and she was talking about how she was going to get her hook-up and she kept talking about different drugs and stuff like that and I was getting very uncomfortable it was like 4:30 in the morning. It was in Lexington, I hadn't been driving but about three months at that time and I got to the destination and she said okay I've just got to go do something from someone and then have you take me home. I said oh I'm sorry it's a one-way trip I have some place I have to be and I signed off because I didn't want her and the stuff in my vehicle.... So her pimp, boyfriend what he was started calling my phone and threatening me "I'm going to kill every white woman that drives that type of car, you better watch yourself bitch" and all kinds of stuff? He was crazy, he said I have your license plate and I know your car yada, yada, yada. When I played it for a detective on the Lexington Police Force he was not happy and he took all of the information and I never got called for anything so. Then they ended up changing my information.

This driver also changed her personal phone number at the advisement of the police. According to this driver, Uber used to give out the driver's personal phone number to the passengers. They no longer employ that method and use dummy phone numbers to relay the calls. This frightening experience did not stop this driver from driving for good, but she did stop driving in that city for a while. Again, this driver was very fortunate that this 
incident did not turn out worse. Just like this next driver who feared about what would have happened had someone not stepped in.

This female driver from Salem, Massachusetts was giving a short ride to three passengers and,

one of them was actually making a lot of racial comments under his breath, you know he was very, very loud. And they wanted me to turn it up (the radio) and why not it's a short ride but afterwards he put his hand out for a handshake, we had a lot of fun. So I thought why not I'll shake his hand but when I shook his hand he pulled me towards him in a bear hug and started kissing my neck. The two other passengers yanked open the door sat down on the sidewalk. My arms were you know as a female driver I carry pepper spray but I couldn't reach it my arms were pinned. I reached for it but he was about a half a second from it you know first I yelled but I was about to bite him because you know what else could I do. Luckily he had his friend who said hey, hey, hey and pulled him off.

After that incident she reported it to Uber but it took several emails over several days before she was contacted and she still does not know if anything was ever done to the passenger.

While some of the incidents mentioned may not appear life-threatening, but remember that this researcher only interviewed current ride share drivers. Most drivers that have more serious incidents have stopped being a ride share driver. This is according to current drivers that have known of others that had bad experiences. However, there is one ride share driver that this researcher interviewed that has had several incidents that each alone would make anyone stop driving. But even after these incidents, she continues to drive and she tells me why after she reveals the horrific details of her incidents. She, by the way, is also the undercover cop that already spoke of one incident..

So the second incident was on the west end around $42^{\text {nd }}$ and Market I had 5 black males in my vehicle because I carry 5 passengers, mine is the only 5 seater car in Louisville and it was only room. I'm not sure what the incident was all about they were all bickering back and forth, I asked them just to tone it down a notch. 
I kicked up the music just trying to ease the mood in the vehicle. By the time they had gotten to the corner of $42^{\text {nd }}$ and Market it had just gone ape and I noticed they were all strapped with weapons at that point and I was like oh great I'm about to get shot and I have no vest on and I'm like great and they did proceed to start shooting at each other and so I was sitting there going oh great I'm caught in the cross fire my car is right in between the two groups that got out on each side and I'm like okay it's not going to be a good night. So I just sat there and just prayed that's all I could do. As shots were flying over, behind and in front of my vehicle. I'm sitting there going okay. Well at least two of them were shot they hit the ground but I wasn't sure if the other shooters were gone so I just stayed in the vehicle, called 911 and just sat there and said okay I'm caught in the middle of crossfire you all might want to show up.

That was the second incident that was about a year in. The third incident was recently just before Oaks and Derby; I almost didn't drive after that. I had a gentleman I picked up on Bardstown Road .... I could tell he was strapped I didn't think much of it until he pulled it and pointed it to my head about a mile down the road and I'm trained in close quarters combat so. In a vehicle that's not much of an issue with me because I can strip that gun out of his hand too easy but if it had been another driver lord help us. I don't think they would have known what to do in that situation.... I was dependent on my dash cam to see where he was and exactly where he was positioned and with no notice at all I just slammed the brakes and he lost his grip... and the gun just kind of grazed forward unto the back of my hand and at that time I just took the gun out of his hand and I left him sitting and I locked him in the car and called the police.

After unveiling those incidents, she said that the reason she continues to drive is because she is concerned for the other drivers that do not have the experience or training that she has. She wants to set up a defense class to train the drivers. According to her the other drivers, "they don't have a half a chance if they don't have some kind of training". She goes on to say that she would be willing to set up a two-hour training class for 20 drivers at a time so that they can learn how to "fend off a backseat attack". She would just like to be compensated for her time and travel and she thinks that $\$ 200$ a class is a reasonable amount. Unfortunately, neither Uber or Lyft have taken her up on her offer. 
These are just some of the incidents mentioned by the drivers in this study. As mentioned earlier, many drivers said that they knew of others that quit driving because of incidents that happened to them. It is impossible to know just how many people stopped driving because they either had an incident or felt unsafe while driving.

\section{Responses from Uber and Lyft}

So, what is Uber and Lyft's response to these incidents? Only one of these incidents resulted in a policy change for Uber - the one about not using the drivers' personal phone number as a contact number. Even that driver had a difficult time getting information about the passenger, Uber required a warrant before they would share the information with the police.

Normally the only response that ride share drivers receive is some type of canned response generated from a computer-generated email system. There is no company phone number for drivers to call when they need assistance. The only number listed is 911. Should a driver or passenger have been in an accident they are instructed to call 911 and then report the incident to the company. This can only be accomplished through email. Once an email is sent to the company, it may take days to receive that canned response.

Some of the most popular canned responses as told by drivers are, 'thank you for letting us know' or 'we will make sure you are not matched up with that passenger again'. It is unclear if anything will happen because of the email sent. Respondent \#22, who did not know if anything was ever done about the incident he reported, lamented, "I mean you do your due diligence to get what you need done but you don't know whether anything had been done to take care of the problem". Luckily for him the incident he 
spoke of did not escalate, but he did mention that it was the only time he felt unsafe and that he may need to call 911 for help.

This driver is not alone in receiving those canned responses. Other drivers mentioned the lack of personal attention received when sending an email to the companies. If they report a problem with a passenger, there is no way of knowing if the passenger has been banned from using the service. However, all the drivers knew that those passengers would probably not be banned because the companies do not want to lose the revenue. Therefore, the only recourse that drivers have is to rate those passengers with a 1 and hope that other drivers do as well.

Just as drivers are rated on a scale of 1 to 5 stars with 5 being the best, passengers are rated as well. The average for drivers is based on 500 rides for Uber and 100 rides for Lyft. Obviously, most passengers do not take this many rides, so their average is based on actual trips taken. Should multiple drivers give the same passenger a low rating, then drivers will avoid picking up that passenger because they know there is a problem. As always, any driver giving a passenger below 3 stars will never be partnered with them again. This works for passengers as well. This system of ratings is just one way drivers have learned to take matters into their own hands, as a result of not receiving proper customer service from either company.

However, there are drivers that feel that Uber and Lyft are obligated to providing assistance to the drivers and they refuse to give up until they know the problem has been addressed. Continual emails, according to one driver, caused so much irritation for one driver assistance representative at Uber that "he said okay, okay, I'm dealing with it". Drivers should not have to bombard the companies with emails, but that is exactly what 
has to happen when dealing with Uber and Lyft. The constant canned responses have even resulted in many drivers not even contacting driver assistance because they do not think anything will be done, so why bother.

But they should at least make the initial report to the company, according to respondent \# 10 is "you always want to cover your own behind" because "there are quite a few riders out there who are notorious on trying to get over on the driver and the company, their frauds, their scams or whatever". So even though she may not have gotten anything more than a canned response, she at least had a record of contacting them.

There are of course the rare occasions that a driver will receive a call from driver assistance. This usually only occurs when the police become involved in the incident, however when a female driver reported the advances of a male passenger, Uber scheduled a phone call. A representative called her to get her side of the story as to what occurred in the vehicle. This driver said that afterward, "I felt like that was going the extra step and we had a nice conversation and they said they would follow up with the passenger". Unfortunately, the passenger turned the tables on the driver and said that she "had made a sexual advance towards a passenger". She believed that the passenger retaliated against her because she turned him down. She noticed her ratings went down, due to the passenger's complaint, and it really upset her. Although she was grateful for the phone call, it did not end quite like she had hoped.

As mentioned it is a rarity for a driver to receive a call from Uber, however it was quickly explained that this driver is an Uber Expert and is involved in many pilot and test programs for the company and that could be the reason why she received a phone call. 
She was one of the original drivers in Nashville and had conversations with corporate members of the Nashville Leadership team, which she said has provided her with a high level of integrity with the company. Or perhaps, Uber was attempting to get her side of the story to ward off a sexual assault case.

Driver assistance should not be available only for the privileged few drivers that already have a relationship with the company. All drivers should be afforded the opportunity to speak to a live person when an incident occurs. At the very least, stop sending canned email responses if the driver is still sending emails on the same subject. Driver assistance is admittedly an enormous problem for Uber and Lyft. Canned responses and lack of human interaction sends a picture to the drivers that they are not important.

\section{Weapons}

This lack of response from the companies has resulted in many drivers taking their safety in their own hands, even when it is outlawed. In June of 2015, Uber enacted a ban on firearms from being carried by passengers and drivers. Prior to this time, Uber allowed firearms if the owner had a valid permit (MacMillan, 2015). Uber still allows drivers to carry non-lethal weapons such as pepper spray and Tasers. However, Lyft bans all weapons, lethal or non-lethal from being used by a driver on their platform. Therefore, no matter what kind of license or permit the driver has, lethal weapons are banned by both companies. If any driver is reported to have any banned weapons they will be deactivated and no longer allowed to drive.

Although this is the policy, many drivers have decided that they need to have some sort of protection while out on the roads. These drivers have decided to not comply with the weapons ban and have a gun at their disposal. A few even admitted that they are 
going to get their concealed carry so they can carry a gun with them. A driver in Kentucky, that has his concealed carry license, keeps his gun in his door pocket because he admits there are "sketchy" neighborhoods and it makes him feel safe. He thinks that if the companies want the drivers to pick up passengers in all areas of town at all times, and then they should "give them a chance to protect themselves". The key word here is protection, the companies provide no safeguards for the drivers, so they should not take away their ability to protect themselves. However, that is exactly what they are doing.

For those drivers not wanting to carry a gun, they have other options to keep them safe. Perhaps the cheapest and easiest weapon for drivers to obtain is mace or pepper spray. It is sold at many national stores including Walmart and Target as well as popular gun or sporting goods stores for around ten dollars. Pepper sprays are so popular that a driver in Lexington gave them to all the female drivers that he knew as a way to keep them safe.

Even though it is the most popular and easiest to obtain, pepper spray/mace is not the only weapon that ride share drivers have at their disposal. Some drivers have gotten a little creative in the type of weapon they carry and/or where they carry their weapons.

Every policy ban ignites creativity in some to find ways around the ban. Carrying or having a weapon available for drivers is no different. Drivers have found everyday items that can be kept in their vehicle that can be used to protect them in the event of an attack. The most popular item would be a flashlight and not the normal household variety. Police-style or Mag Light flashlights are quite large and heavy and could actually prove to be deadly depending on where a person is hit. These items are not banned because it can be reasoned that drivers need flashlights in case their need to change a tire 
or someone drops a small item in their car. Should a driver be questioned after using one he can always say, "that's a flashlight, it's not for bonking anyone on the head". But in reality the driver may be thinking, "but it's for bonking people on the head if I need to". Sometimes these flashlights serve a "dual purpose", driver \#21 said that his flashlight is also a stun gun but you would not know by looking at it.

Other everyday items that serve a "dual purpose" are knives, keychains, tire irons, and even a fire extinguisher. Many men, especially former military men, carry a pocket knife, and as long as it is less than 3 inches (rules vary by jurisdiction), it is not considered a lethal weapon. However, some drivers have been known to carry hunting knives which are legal in some states and not considered a lethal weapon. Many women carry keychains that have "weapons" attached to them or are part of the design. Driver \#34 mentioned that she had a cat keychain that has "these spiked ears" which she can use to defend herself by simply putting her fingers through the "eyes". A simple online search of keychains as weapons provides thousands of keychains that can be used as a weapon.

Tire irons are an obvious tool that can be used to defend a driver, but since it is often stored in the trunk, it is not the most realistic or handy source of protection. A perhaps not so obvious item for protection is a fire extinguisher. Obviously, it can be a wonderful item to have in the event the car overheats and starts to emit flames. This rarely happens so most people do not consider carrying a fire extinguisher in their car, much less inside the vehicle. However, this is exactly what driver \#16 explained as his way of getting around carrying an illegal weapon. The reason he carries a fire extinguisher is because its purpose, "is to take oxygen away from fire when you put a fire 
out...you shoot them (passengers) with an extinguisher they can't breathe and they back off'. As an officer with the fire department it is natural for him to have a fire extinguisher in his car, but he added that anyone can carry one, "it's legal to carry".

Fortunately, none of the drivers reported that they have ever used, or needed to use, their "weapon" while they were working. But they all enjoy the safety of having it available should they need it. According to one of the female drivers,

I've talked to a lot of the other drivers and they don't carry weapons whatever of any sort because they follow the rules, and you know what if they're (Uber/Lyft) not looking out for my safety then I have to look out for my own self.

Both companies have made it clear that they are not going to lift their ban on weapons. Although many have become creative in having alternative sources for protection, there is still one item that is allowed by both Uber and Lyft. This item has the ability to be a deterrent to crime as well as providing valuable evidence should a crime occur. This item is a dashcam.

\section{Dashcams}

Car dashcams arrived on scene in the 1980s in Texas where they were large enough to hold a VHS tape (Goddard, 2013). They were mounted on the front or back window of police cars and were used primarily to assist officers in rural areas. These enormous cameras did not have sufficient video quality to make out license plates or features of a person (Goddard, 2013). As years passed, and the quality has increased and the size of the cameras have decreased, many police departments are now using them in their vehicles. They are used to keep the police accountable as well as to prove when the behavior of others has been questioned. 
Dashcams have become so affordable that other companies have started using them to include taxicab companies, trucking companies, and bus companies. The public has even started purchasing these lightweight cameras for personal use. Whether to provide the details of a car accident or evidence of road rage, this technology has become very beneficial in proving guilt or innocence. For ride share drivers, the value of dashcams have gone a step further in their valuableness and have proven to be more even more beneficial than a weapon. For example, the driver that was attacked by the Taco Bell executive had a dashcam and was able to use the video and audio from that dashcam to provide evidence of the altercation that took place.

As previously discussed, many passengers are intoxicated when they request a ride and are not always on their best behavior. Sometimes this behavior results in blood, vomit, or other damages to the vehicle. Having a dashcam allows the driver to prove to Uber or Lyft that the passenger created the mess. For example, respondent \#1 was glad he had his dashcam to record his passenger from the night before. Even though he only has a forward facing dashcam, it records audio from inside the car. He was able to record the guy puking and offered it to Lyft to verify the incident. Lyft did not request the recording but this driver was grateful he had it in case he needed it.

Depending on the type of vehicle or level of comfort, some drivers choose to have multiple dashcams in their vehicle. The most popular dashcams are dual facing and can be affixed to the rear view mirror on to the middle of the dash. Dashcams are made for the basic sedan and while they claim to have a 180-degree field of view, having other cameras throughout the vehicle provides more coverage. For example, a driver in Chicago said that he has multiple cameras in his vehicle. In addition to the typical dual 
dashcam on his dash, he has one pointing out the back window, and a camera mounted on the ceiling. In the event that one of cameras stops working or a passenger breaks one, he has backups available. Additionally, the feed from the cameras goes to a server in his car then to a DVR at this house through WIFI. He has this remote system because, "That way if somebody bad shoots me or beats me up even if they destroy the camera they will never get to the video". Just like a weapon, the dashcam is there in case it is needed. Although this self-protective device cannot be used to stop an attack, it provides the driver with the knowledge that if something should occur they have evidence. This evidence can be used to identify the passengers as well as provide the sequence of events leading up to an attack.

Just as the dashcam has the ability to be a witness to an altercation, it can also provide proof that nothing took place. More specifically, sexual assaults or sexual harassment of drivers and/or passengers. As mentioned earlier, many ride share passengers are intoxicated. This is fine, especially when it means they are not on the road driving drunk. However, some intoxicated passengers tend to get a little flirtatious or "handsy" which can make the driver feel uncomfortable and sometimes fearful. Most of the time the passenger is harmless but there have been instances where drivers feared that they may endure physical harm. In these instances, the driver would report the passenger to the company so that perhaps the passenger could get deactivated. At the very least, the passenger would not be able to have the driver again. Unfortunately, what happens is that the passenger denies what happened and usually turns the story around so that it appears that the driver made the advances. For that reason, many drivers have bought a dashcam and are prepared to provide the evidence if needed. Respondent \# 26 says that he has 
been fortunate that he has never had to use his dashcam as evidence but he has it available and running, "in case someone is attacked or in case a woman says that I touched her inappropriately or anything like that. That way it's on the camera and I can say no it didn't happen, here it is". While a dashcam is not a typical weapon, it does provide protection for drivers.

The installation of a dashcam, especially one that is mounted on the dash so that passengers can see it, also provides a deterrence. Similar to security cameras in businesses, having a camera in the car lets the passengers know they are being watched. The driver is unable to keep an eye on the passenger at all times, so the camera is like a partner in the vehicle watching to see what is happening, especially in the back seat. Passengers take note of the camera and tend to be on their best behavior while in the vehicle.

Sadly, some states do not allow any recording devices in the vehicles, while others just require a sticker letting the passenger know they are being recorded. Many drivers, that do not currently have a dashcam, said they would like to have a dashcam, they just do not have the money. Decent dual facing dashcams with audio can cost at least $\$ 160$, which for many drivers is not at the top of their priority list. Many of them said that they just use their phones if they need to take pictures or record the audio going on in the car. While, phones are not ideal, drivers know that they need some type of protection since weapons are banned.

Ride share drivers have needed to use self-protective behaviors like weapons, dashcams, and experience to ward off possible attacks and some already in progress. These drivers understand that they must find ways to keep themselves safe because Uber 
and Lyft have nothing in place for safety. This self-protection is vital because there is no guardian (Uber or Lyft) to provide a protective barrier around the drivers. Although capable, neither company is willing to act as a guardian and provide, or allow, weapons, training, or support to increase the safety of the drivers. Without guardianship, drivers become attractive targets to offenders.

These drivers have learned, whether through personal experience or stories from others, that they must become their own guardian and instill self-protective behaviors or measures. These behaviors and measures can provide a means of target hardening which makes them less attractive to would-be offenders. Because they are dealing with the public at all hours of the day and night, these drivers understand that their passengers may not always be on their best behavior. Some passengers may be intoxicated which causes them to act aggressive. That aggressiveness can result in violence against the driver, thereby making them an offender. In this instance crime occurs because the target (driver) lacks guardianship and is attractive because he does not have protective measures in place. As previously mentioned, there needs to be an absence of one of the elements, motivated offenders, suitable target, and absence of a guardian, to prevent a crime. Therefore, it is up to the driver, who is alone in the vehicle with a possible offender, to use self-protective behaviors/measures to appear less attractive to the offender in hopes that no criminal activity will take place.

While ride share drivers understand that crime is possible, they think that there are ways that Uber and Lyft can decrease the chances of it happening. Allowing drivers to carry weapons, encouraging or providing dashcams, providing training, and/or having driver assistance available are some possibilities that either company can employ to 
become a guardian. This guardianship as well as allowing drivers the ability to have selfprotection would assist in providing a safer work environment for the drivers. 


\section{CHAPTER VIII SUGGESTIONS FOR DRIVER SAFETY}

The previous chapters have covered some of the incidents that have happened to the drivers as well as why they continue to drive and what happened when they contacted Uber or Lyft. As they discussed their experiences, the drivers also wanted to pass on some suggestions for Uber and Lyft that they think would make their jobs safer. They realized that it is easy to complain about the problems but these drivers are also willing to provide ideas that would enhance their safety and security. These suggestions include having some training or instruction for drivers when they sign up, requiring passenger pictures as well as their destination address, having a phone number and 24-hour driver assistance, allowing drivers to carry weapons, and providing or assisting with the purchase of dashcams.

Generally, these suggestions incorporate ideas of making the drivers feel safe and secure, as well as allowing the companies to show that they value their drivers and are concerned about their wellbeing. As will be shown below the issues that are most frustrating and for which drivers make the strongest arguments are training, whether through safety orientation, videos, or instruction manuals; passenger identification; required destination addresses; driver assistance; lifting the ban on weapons; and providing dashcams. It is important to view these things in context because this is a new type of industry. These drivers are not employees and there are no regulations stating that 
safeguards must be put into place. These companies are not bound to protect these independent contractors. However, these suggestions are not outrageous and many of them are common among transportation companies worldwide. These ideas are not created on a case by case basis and should be established to the industry at large. Mainstream economy is changing, and more and more businesses are turning toward utilizing independent contractors in lieu of employees. The question of what responsibilities should the companies have for this new breed of workers is something that needs to be considered. With the number of drivers reaching into the hundreds of thousands, these companies can no longer ignore their needs. Some of these ideas need to be explored further.

\section{Training}

Mentor. Most of the drivers mentioned that they thought that training was the most important thing missing from the companies. The only training that Uber provides is how to access the app on the phone and how to use the features of the app. The drivers mentioned that they think that Lyft does a better job than Uber in that they require a meeting with a mentor before a driver can start driving. This meeting allows the mentor to take pictures of the driver, his/her license, registration and insurance, as well as pictures of the car. The mentor also has the new driver take them for a short drive to make sure the driver is a safe driver. The mentor shows the driver how to use the app and may or may not give any other type of instruction. This researcher's Lyft mentor spent much of the time talking about her personal life. She said she would answer any questions but being new, this researcher did not know what to ask. Most companies provide a job description and policies and procedures for a new employee. However, 
neither company has any of those things to give new drivers to help them get acclimated to their new position. During the interviews with the drivers, the mentor meeting was sometimes shorter or longer and varied in the information given to the driver. No real training was involved.

As previously mentioned, most drivers work for both Uber and Lyft so they are aware of the differences in the hiring process. Many of them are grateful for the mentor session they had as a Lyft driver and wished that Uber would follow suit. Many were astounded at the hiring process of Uber, "I was personally shocked and surprised at how quickly I was able to get hired on as a driver for Uber. It took four days. I didn't talk to a single soul and ready to go. That was it", said one driver. No training, no mentor, nothing for new Uber drivers.

Both companies, per drivers, should provide city-specific videos or some type of training, so that drivers are aware of the laws pertaining to ride share drivers especially at airports. When ride sharing began many airports banned the service due to outrage from the taxicab companies. Taxicab companies must pay fees to pick up passengers at the airport. Therefore, they thought it was unfair for these ride share companies to allow drivers to pick up passengers without paying any fees. Eventually both companies worked out some kind of arrangement with most airports and now drivers are allowed to pick up passengers but only in specified areas. Driver \#6 illustrates this new driver ignorance at an airport when he discussed what happened when he drove during Derby week in Louisville. He said he was picking up passengers at the arriving flights area, not knowing it was illegal, until a friend and fellow Uber driver told him there were designated areas for Uber and Lyft drivers to pick up passengers. There is a yellow line 
for Uber pickups and a pink line for Lyft pickups and drivers must wait in the cellphone lot until they receive a request. For him, it was all confusing and he thinks that the companies should have a city-specific video for the drivers to explain the nuances of the city's laws and regulations, especially dealing with airports.

Both companies assume drivers know what to do but they do not. Initial instruction from a mentor could go a long way on making the drivers feel like their safety is important to the company. Unfortunately, Lyft has stopped having the mentor session in some cities like Chicago. Driver \#24 said that she wishes they would not have stopped that program. She said that she had a great experience with her mentor and continues to keep in touch with him. She added that it was different than when she signed up for Uber, with Lyft "it was just something I didn't feel alone in the whole process". As a friendly, outgoing person this driver said that if she saw an Uber driver she would go up and talk to them. She was trying different avenues to get her questions answered since Uber did not provide any source of training. She continued saying that the new drivers are not understanding Lyft's stance about ride sharing and what separates them from Uber. Without this mentoring session, Lyft has become just like Uber.

Videos. Beyond having a mentoring session, many of the drivers suggested that instructional videos would be a more cost effective way of training new drivers. These videos, said one female driver, could instruct drivers "on different ways that you could protect yourself so that you are not some naïve girl going out into the city driving around". She then added that men need the videos too. In Chicago, all drivers are required to go through training according to an ordinance. Therefore, drivers think it should be easy for Uber and Lyft to extend that type of training to drivers in other cities. 
Drivers understand that with any new company there are adjustments to be made or problems to be fixed, which is why they have been providing these ideas to both companies. However, those that have worked for a few years have not seen any changes when it comes to the safety and security of the drivers. Providing safety videos or some type of orientation is something that the following drivers wished they had been provided so they could understand what to expect before they started driving. Driver \#26, who had an incident his first week of driving, mentioned that he wished Uber would give the driver some information when they first start. This information, he suggests, could include telling the driver that if they feel uncomfortable they could cancel the ride and drive away. Something he did not know when he first started. As he continued his thought he said, they "should make that a bit more clear, your safety is number one if you feel at all that there is an issue drive off, don't sit around. But of course, they don't tell you that because they want the money". They are afraid if they tell the new drivers what can happen, then they would never retain drivers.

It is for this reason that the only training that Uber drivers receive "go out on the road and turn your app on and start to drive", said one driver. She continued on by saying that she thinks that Uber should "take the first step and train their drivers" because they were the first company and have more drivers. Not that Lyft does not need to train their drivers as well. She added, "One of the companies needs to step up".

The male driver in Camden, New Jersey who was carjacked relied on his military training to know what to do in his situation but he said that many drivers have no idea how to handle themselves. He went on to say, "I do believe that we need driver safety because with new drivers they're thrown to the wolves". Having gone through military 
training, he knew how to handle the carjacking situation, however he fears that others may not "have a good mindset of what they could do". He thinks Uber should provide an orientation for drivers before they even start to drive. Other drivers spoke about the companies giving each driver a fact sheet with helpful topics or a how to guide on what to do in certain situations.

So why do these companies not provide training? Many drivers think that neither company cares about the drivers and that is why they do not provide safety training. As one driver suggested, "These platforms are not concerned with drivers, their concern is their revenue, they're not concerned with us and I think they make that really clear". Additionally, if the companies were to provide training, whether videos, how guides, or an orientation, they would lose a lot of drivers before they even started driving because "maybe they're afraid that if people see that stuff some of the driver's leave and don't come back" explained driver \#41. However, by providing instruction, the companies would be sending out the idea that they care about the drivers. Something that none of the drivers believe to be true.

Social Media. Offering training or orientation can be costly for the companies and many of the drivers have mentioned that the companies are greedy and do not want to spend anything to make the drivers feel safe. For this reason, drivers have made some suggestions that would not cost the companies any money. The simplest idea would be to promote the Facebook groups to new drivers to get the information they needed. As a new driver in Charlotte, one driver said he had questions about a certain area of Charlotte, knowing that he would not get an answer from Lyft or Uber, he would log on to Facebook and go to the group page for Charlotte drivers and ask them. He then went 
on to say, "You get a response on a whole lot of stuff in just a few minutes believe or not". However, he went on to mention why he thinks that this is not currently being done, "maybe they're afraid that if people see that stuff some of the driver's leave and don't come back if they look into that stuff'. But if the companies are not going to answer questions, then drivers need some way to find them.

Social media is the best way to gather information about anything ride share related, said one driver. He went on to say, "Now you can go on Facebook and you can go onto an Uber or Lyft (driver) site and find out any information you're looking for or to do anything and if you have any questions you can ask people". Either company could simply send an email to the driver, once he was approved, and mentioned that there are Facebook groups as well as YouTube videos that might be of some use. This researcher was not aware of either of these tools until embarking on this study. However, after some research, she could find out more information about the companies and ride sharing in general. Many drivers do their own research as well.

Driver \# 28 said that she researched ride sharing before signing up, which she admits most drivers do not. By doing so she was able to get some valuable information from other drivers which included being told that there was a group page on Facebook for ride share drivers in Richmond. When she was accepted and added to the group, the administrator told her if she had any questions to just ask. Thinking that the group would just be like Uber or Lyft, in which she would ask a question and get a canned response in a few days, she was surprised to discover the opposite. She posted that she was new and was going to start driving the next day and she had some questions. She said she received a response from the group administrator giving her lots of information including the 
airport restrictions. Drivers unaware of the airport restrictions can face fines and car impoundment. So not only did this administrator provide some valuable information but also instructed this driver on ways to avoid getting into trouble. Uber did not provide that information to her.

Facebook groups and forums are the main source of information for drivers and they do not understand why either company does not promote their existence. The sentiment shared by many about this is that "Uber is only interested in making money, they don't really care about their driver". But this would be an inexpensive idea, with only an email being sent to the new driver that would encourage the driver to learn more before driving and would at least give the illusion that the companies care about the drivers' safety.

To assist drivers with training and provide answers to questions, a few drivers have promoted themselves as the person to go to for this type of information. The most well-known is "The Rideshare Guy". His name is Harry Campbell and he is also a ride share driver. He has a Facebook page that consists of podcasts, a blog, surveys, and articles relevant to ride share drivers. His popularity grew so much that he now has a website that is updated daily. Featured pages on the website include information about insurance, sign-up bonuses, video courses, resources, about him, his contact information, and links to YouTube videos. You are free to join "the community" which provides you with emails with up to date information on ride sharing. All of this would seem great for drivers, however unless someone tells a new driver about him or his page, the new driver is still left out in the dark when signing up. In other words, it is up to the new driver to 
research and seek out information rather than having the information available from the company, Uber or Lyft.

That is exactly what one driver from Chicago talked about when he said that he automatically researches everything but he noticed that many drivers that he has met did not know about the Facebook groups or YouTube videos. He even mentioned The Rideshare Guy when he spoke of a post that a female driver made on his website. She shared her experiences and gave advice to women drivers by explaining what selfprotective behaviors she uses. It is these resources that he thinks that drivers need to know about since the companies are not going to do anything to help the drivers.

Training of new drivers was the most important thing lacking from both companies per these drivers. Not knowing what to expect from this new position is a safety and security concern which has caused drivers to second guess their decision to be a ride share driver. However, these drivers are willing to assist by making suggestions to decrease their levels of concern. The mentor session that Lyft introduced should be continued and perhaps started by Uber. The addition of training videos or instructional guides can be a less expensive means of training new drivers. Finally, the most costeffective way for both companies to provide training is to promote social media, especially Facebook groups. A simple email letting drivers know that there are resources out there to help, allows drivers to get assistance which reduces their level of anxiety.

\section{Passenger identification and destination address}

A requirement for all drivers is that they must have a profile picture that matches their driver's license photo so that passengers know what their drivers looks like. 
However, passengers are not required to submit a photo of themselves. Some Lyft customers connect their Facebook account to their Lyft account and that will put their profile picture from Facebook as their profile picture on the Lyft app. However, people do not always use pictures of themselves as their profile picture on Facebook. Therefore, when a driver looks at the profile picture of a Lyft passenger, he could see puppies or flowers or whatever the passenger decided to make as his profile picture that day.

Many drivers have an issue with not being able to see what the passenger looks like before picking them up. Unlike taxicabs, ride sharing does not allow for random pickups or cash payments. The passenger must request the ride via the app and their credit card is charged for the ride. There is a record of the passenger's name and credit card. If a random person gets in the ride share vehicle, there is no record of who it is. This could result in a dangerous situation, especially if the passenger becomes an offender. Should an incident occur, the driver would not know who the passenger was, nor would the company. This would cause a problem when trying to identify the suspect.

Passengers are protected from taking a ride from the wrong driver because they have the drivers picture as well as a picture of the car. The only information given to drivers is the first name of the passenger and the pick-up location. Many of the drivers in the study have mentioned times when they have picked up the wrong passenger because 1) the person they picked up had the same name as the passenger that requested the ride, 2) the driver asked the passenger if his name was "Bob" and the person said yes, trying to get a free ride, or 3) the passenger recognized the driver and just hopped in the car, knowing the driver would not remember his name. In all cases, the correct passenger would be waiting and eventually contact the driver and ask why he has not arrived to pick 
him up. Both apps allow the passenger to see where the driver is at all times, so when the driver leaves the pick-up location without the correct passenger, the passenger knows there is a problem and cancels the ride. Subsequently, the driver has lost the fare and even worse, given a free ride to the person he did pick up. Not to mention, the driver has no idea who is in his backseat and there is no record because the passenger does not have an account. In the event that something should happen, there is no way to track who was in the car with the driver. If the driver was able to see the passenger's face, he would know it was the wrong person. This is a simple protective measure that could alleviate a lot of problems. In addition to providing an extra level of safety to the drivers it would prevent customers from being abandoned at their pickup location, resulting in them having to wait for another ride. Furthermore, this would protect passengers from getting charged for rides they did not take.

The following is an example of such a situation that could have turned out worse, but this female driver was fortunate. She went to pick up a passenger and asked him if his name was "John" and he said yes. There was no destination address so she asked him where he wanted to go and he said the name of the hotel he was staying at. Then,

we got three quarters of the way to the Brown Hotel and this guy calls and he says according to my Uber you picked me up early my name is John and I said I have a guy in the car named John and the guy in the backseat said I thought you said Don that wedding was so loud I couldn't hear anything. So that's one of those cases, then I had to cancel it so the guy didn't get charged then the guy I was driving winded up giving me cash and he had to call the Uber that was waiting for him to cancel. Obviously in that particular case a face would have been nice.

According to drivers, there are two things that Uber and Lyft could do to prevent the situations mentioned above: Require passenger profile pictures and that the destination address be entered by the account holder before leaving the pick-up location. The first 
part seems simple enough, ask passengers to provide a profile picture when they sign up for the service. By doing so, the driver will not allow anyone else to enter the vehicle saying they are the account holder. It is in the best interest of the passenger, as well as the driver, to make sure the right people are in the vehicle. This ensures that passengers will not be left stranded waiting for their ride and protecting them from getting into the wrong vehicle that could be driven by a non-ride-share driver.

However, respondent \#17 from Chicago thinks he knows why the companies do not require pictures of the passengers, "because they want you to take all rides all of the time. They don't want you to discriminate and if a picture were to come into that people would say you're racist". He went on to say that seeing the picture is not going to prevent racism, many drivers cancel if they do not like what the passenger looks like and vice versa. The Muslim driver in this study made the comment that many people will see her picture and cancel because they do not want a Muslim driver. Why force people to accept all rides, perhaps by cancelling the ride a bad situation could be avoided.

The second part, requiring destination addresses before the start of the ride, is a way to alleviate a lot of potentially bad situations. For example, many drivers that work Friday and Saturday nights pick up drunks that do not put in their address. Instead, they want to give the driver directions, but that does not work when the passenger is too drunk, gets sick, or even passes out in the vehicle. Referring again to the Taco Bell executive, he would not give the address to the driver and was unable to tell him the directions. He proceeded to get mad at the driver when he stopped his car and told him to get out because he did not know where to take him. If the app required an address before 
a passenger could request a ride, that situation and many others would not escalate into a volatile situation.

Perhaps drivers need to be proactive about who they are picking up, as suggested by driver \#20. For him, he calls the passenger before he picks them up to confirm all the information. Once he arrives at the pick-up location he adds, "if there's anything that you feel it's a feeling and you know that feeling so don't open your door, don't unlock your doors until you get a name. If there is any weirdness with the name, cancel". This driver also mentioned that by calling or texting the passenger he can "kind of feel them out". If they are too inebriated to text back or carry on a simple conversation, he cancels the ride. Another piece of advice, this time from a female driver in Louisville. She said that she always asks the passenger what her name is. As she put it, "if they don't know my name then they're not expecting me as an Uber driver". These are both good suggestions made by drivers because they know that they must provide their own self-protection.

The addition of a passenger profile picture and requiring a destination address are two ideas that would go a long way to make drivers feel that the companies are concerned about their safety and security. Both ideas can be implemented through simple changes to the phone app, which would not be costly. Furthermore, they would allow the passenger to have a stress free ride if they were not concerned with having to give turn by turn directions to their driver.

\section{Better driver assistance to include phone number}

Most companies that deal with the people understand that there needs to be a way for people to contact them when there is a problem. The transportation industry is no 
different. Taxicab drivers are able to reach out to the dispatchers 24 hours a day, either through a panic button or by phone, to notify them of a problem. Once notified, the company can tell the driver what he needs to do or can simply contact the authorities. Even self-employed taxicab drivers have this same access to the company. However, neither drivers nor passengers in the ride share industry have this type of immediate access to the company. As previously mentioned, drivers and passengers must email the company and wait for a response. This response could take several days and, for drivers, is often a canned response. The phone number given by Uber to drivers is a recording telling the person calling to send an email to the company.

Better driver assistance which includes a phone number connected to a live person comes just behind training as the biggest suggestion made by these ride share drivers in this study. Many drivers feel like they are out there on their own with no one supporting them. For example, a male driver in Charlotte mentioned that he would like,

a point person just to communicate with Uber other than just email. I know that's what they use for everything but just to have somebody to talk to about those issues that could be helpful too, one on one guidance or assistance. Instead of just 'hey sorry about that' in an email copy paste that's all they do.

Whether this change would require one person in an office or many, drivers feel that they are all alone. At least a "direct line" for drivers to report assaults said another male driver. After an incident, it is important for there to be good driver assistance, but according to the driver in Lexington that had the terroristic threatening incident she thinks that the companies "should cooperate more with the police and stuff. If there is an incident, we shouldn't have to jump through a billion hoops to get information". In this instance, Uber wanted a warrant before releasing, just the name of the passenger, to the police. 
Dealing with the police is something that these companies do not want to contend with according to another driver in Salem, Massachusetts. She had to threaten to go to the police before she received an email that addressed her situation. As she puts it,

There definitely needs to be a faster response instead of copy and paste emails, really it's like nobody even reads the first one they just have an automatic response set up. I had to send several emails even threatening to go to local police and things like that.

Drivers should not have to threaten to contact the police when all they want is a response to their email. A proper response, not just a standard copy and paste reply. Suggestions to alleviate this include some sort of policy put in place so that the drivers know what the next steps are in case of an assault. For example, "there should be a policy stating if you're attacked these are the steps you need to take, here's what Uber is going to do for you". Rather than call 911 and then send us an email. Emails involving the words assault or police could perhaps get routed to an actual person.

"I think customer service with Uber is horrible" exclaimed one driver who went on to describe of a time when he was owed $\$ 80$ and it took him 23 emails and a week later before he received a personal response. According to him, "They literally would not take responsibility and every answer they had was like pre-recorded". This is the unfortunate reality that many drivers spoke about and it did not matter what kind of situation there were in, driver assistance does not seem to be of concern to either company.

When it comes to communicating with drivers, both Uber and Lyft are not providing the driver assistance that is expected from a people-based company. According to respondent \#41 in Chicago the following statement could be made about Lyft as well, 
"Uber is another perfect company that is blatant for not communicating with their employees (drivers), to build mistrust. There's not transparency”.

Although the suggestion of better driver assistance with a phone number is the costliest of all ideas, it would provide drivers with the assurance that their safety and security is important. Currently, drivers must wait for days and write countless emails to achieve a personal response. This delay could cost valuable time in the event of an incident and result in a criminal getting away.

\section{Weapons}

Many of the drivers in this study do not agree with the ban on guns and other weapons. For them, it is a means of comfort and provides self-protection for them in the event something bad happens. Some drivers admitted that they do not care what the policy is, they will have a gun because they are allowed by law. Driver \#47 mentioned that the companies could make the job safer if the drivers can legally have guns, "if you have states that are gun friendly as Kentucky...I think people should be allowed to you know". He went on to mention that he can carry it everywhere else (per state law), so he should be able to carry it while driving. For him, people should "be able to defend themselves and carry a weapon if they choose to and if they're abiding by their states law I think Uber should respect that". Additionally, drivers that do not carry guns think that drivers, especially women, should be able to carry so they can defend themselves. As a big man, driver \#48 said he does not feel the need for weapons but "They should have that right especially a woman" because "some of these drunks will flat do what they want 
to do and if it's uninviting then yeah they need to defend themselves". Having a gun is about protection and safety for the driver, no matter the gender.

Uber angered many drivers that were used to carrying their gun while driving. "I would tell them their anti-weapons; their gun free zone policy is ridiculous" said a guntoting driver. For over five years, drivers, with the proper license, had their guns with them while driving. However, in June 2015, Uber placed a ban on all firearms for drivers and passengers. For many drivers, this infringed upon their rights. For one driver, an officer of the fire department with arrest powers, he said "I don't think it's fair that I have a license and been able to carry one for twenty years, twenty plus years and for Uber to be in a state that says it's okay to carry one and I can't'. He added that he was sure that people do it anyway.

Non-lethal weapons were also discussed when talking about ways to make the job safer. One driver mentioned that he thought the companies should either make it “mandatory or suggest that driver's carry a mace can or pepper spray or something like that" for self-protection. He went on to say that he agrees that not everyone should be allowed to carry a gun because there would be drivers that do not know what they are doing with a gun. Without proper training, a driver could have that gun taken away and used against him or her. For him, pepper spray or mace would be a good idea.

Based on the many conversations with drivers, the topic of weapons, lethal or not, was a clearly defined topic. Drivers were either accepting of the ban and did not carry any weapons or drivers did not care what the bans were and said that their safety was more important. Although many of the drivers wished that the companies would lift the ban on weapons, they realize that this suggestion may never come to fruition. Therefore, 
many felt that if they were deactivated because they used their weapon to save their life, at least they were still alive.

\section{Dashcams}

The next topic that has had a lot of talk around the Facebook forums and groups was that of dashcams. These respondents were also very vocal about dashcams as well. Some of them have them, while others would like to have them but cannot afford one. According to one driver, the most popular dashcam costs around $\$ 170$. He said it fits over your rear view mirror and can see all over your car even at night. It records everything to a memory card that can be transferred to a computer if the file is needed as evidence.

The footage from a dash cam was instrumental in the case mentioned earlier about the Taco Bell executive that beat up his Uber driver. Had that driver not had a dash cam, the incident could have turned into a he said, he said situation to which, for both companies, the passenger is always right. After that incident many ride share drivers told me they purchased a dashcam and others wanted to get one but could not afford it. Many drivers think they should be provided.

A male driver from Louisville said that he thinks it would be in the best interest of the company to provide one. According to him, "I mean it's good for them to have that to be able to combat any negative image.... You know like all of the bad PR, I think it would be in their best interest to be able to have". Other drivers in this study agreed that they should be provided so that they can have some protection.

Respondent \#36 mentioned an incident in Florida where a drunk woman was attacking the driver and luckily someone was recording it. He said in that case, "a dashcam would be helpful". The female was petite and no would believe that she was assaulting a male driver, had it not been for that video from a bystander capturing the 
event on a phone. Would the woman have stopped or been less likely to assault the driver if she knew she was being recorded, maybe. According to the Hawthorne Effect, people are more behaved if they think they are being supervised or recorded. And even though he does not have a dashcam, he thinks that they should be required, but he knows not everyone can afford them.

Dashcams could be affordable. Driver \#49 said that Uber could send them to new drivers and take $\$ 10$ out a week or a month until it is paid for. If it was controlled by Uber, then they could get them at a reduced cost but still charge the driver the full amount. This sentiment was shared by others who mentioned that they should provide dashcams like they do phones in which you pay a little each week for them. One driver's reasoning for dashcams being the top priority is, "We've seen lots of stories where people are being abused, physically assaulted and that would prevent a lot of this at Lyft as well”. Neither Uber or Lyft have agreed to providing dashcams.

The female driver from Nashville, who admitted to being an entrepreneur, has a way for all drivers to have them and possibly make some money on the side. Instead of a typical dashcam, drivers should have trip cams. These are tablets affixed to the headrests and have dash cams within them. The tablet is always running and, according to her, the passengers can watch the news, weather, or even play games on them. Local businesses can even advertise on the trip cams for a dollar a day. Even though the item costs $\$ 200$, it can pay for itself quickly, plus you can get referral bonuses. She also mentioned that she has added a reminder to passengers to tip the driver. She said she attached a credit card reader and many passengers have tipped her and she did not even know about it. So, even 
though, she would like for the companies to provide dashcams to the drivers, she decided to take matters into her own hands.

This is typical for many drivers; they do not have faith that the companies have the drivers' safety in mind. Whether it is carrying weapons or buying dashcams, the drivers in this study felt that they must take care of themselves any way that they can. Unlike weapons, dashcams are non-lethal items that allow for self-protection for drivers and passengers.

After reviewing the interviews about suggestions made, it became clear that almost all of the drivers believe that anything they suggest would go on deaf ears with regard to both Uber and Lyft. However, they all wanted to be able to help other drivers, whether through training or just words of advice. Ride share drivers have formed communities that look out for one another because they all know that Uber and Lyft have yet to make any changes concerning driver safety. 


\section{CHAPTER IX DISCUSSION}

The present study explored the advent of ride sharing driving as experienced by the drivers. Through in-depth qualitative interviews, the information gathered gave insight into why people choose to become ride share drivers, what they like about it, and which company they prefer to drive for, Uber or Lyft. In addition, the drivers discussed their concern for their safety through incidents that have occurred to them, and the responses from the company. Finally, they made suggestions for improvement that would allow them to feel safer. This chapter will review those findings and explain what contributions can be made as well as any policy recommendations. Additionally, the study's limitations will be presented followed by a conclusion.

\section{Summary of Findings}

This study was the first, and hopefully not the last, that focused on ride share driving. As an exploratory study, it was necessary to look at other occupations to gain insight into the issues of safety in the workplace. The occupation most like ride share drivers is that of taxicab drivers. As noted in the literature review, taxicab drivers die while at work as a rate of 9 to 36 times higher than the average worker (BLS, 2007; Toscano, 1997). In addition, these drivers are likely to be murdered at a rate of 20 times higher than the average worker (OSHA, 2010). This rate of homicide victimization is higher than that of police officers (BLS, USDL, 2012). Unfortunately, most drivers are 
unaware of these statistics but what they do know is that being a ride share driver is not as safe as they imagined.

When Uber began hiring drivers in 2010, many people saw this as a new way to earn money. The drivers in this study are no different. Whether they chose to work full time or part time, they were lured by the possibility of making as much money as they wanted. Various populations of people became drivers because they needed income and could not find other means of employment. Retirees and other older people that felt discriminated against in the workforce are drawn to ride share because there is no upper age restriction. Those with medical needs or on disability like the opportunity to make money while still taking care of their needs. And people that may have been recently unemployed enjoy that they can quickly start earning money. Some of them enjoy the job so much, they decided to forgo looking for another job and continue as a ride share driver. In addition, becoming a ride share driver is a great part-time job for those wanting to earn extra money.

The second biggest reason the drivers mentioned why they became, and the top reason they continue to be, a ride share driver is the convenience and flexibility. In addition to making as much money as you want, both companies advertise that drivers can work whenever they want. There are no schedules, no time requirements, and no boss. Each driver is their own boss and can work as little or as much as they want. This convenience and flexibility provides freedom for drivers that must work around another schedule, like a full-time job or parenting duties. In addition, it allows those with special needs to start and stop whenever they want. 
The final reason many drivers chose to become a ride share driver is because they thought it might be fun. The idea of meeting people and hearing their stories has attracted many people to drive. Also, many people that may have started out as a driver for the other reasons mentioned above, have discovered that they really enjoy being a driver. As a ride share driver, no two rides are the same nor are the passengers. It is this level of unknown that excites many people. While others just enjoy talking to people and driving around the city.

Regardless of why people became ride share drivers or what they like best about the position, the drivers in this study indicated that there is a difference in which company they prefer. Overall, Lyft was the preferred company to drive for because of tipping. In the service industry, tipping allows the customer to show gratitude for good service. Most people that take a taxicab give a tip to the driver if the service was good or the ride was uneventful. However, Uber does not have a feature on their app to allow passengers to tip the driver. What is worse, they originally had falsely advertised that the tip was included in the fare. They have since informed the passengers it is not. Lyft, on the hand, has always had a tip option on their app. Passengers are not required to, but they have the ability to tip the driver without having cash on hand. All but one of the drivers in this study work under the Lyft platform and all of them say they receive tips. The only reason that these drivers drive for Uber is because Uber is more widely recognized. Due to this recognition, Uber has a larger clientele which allows the drivers to stay busier than they would if they only worked under the Lyft platform. However, the drivers in this study acknowledged that if Lyft kept them busy, they would not drive for Uber. 
One thing about ride share driving that is common among all drivers is that they all have stories to share. For those that drive on the weekends, many of the stories are humorous accounts of intoxicated passengers. However, not all stories are funny. For many of the drivers in this study, those stories became incidents in which they feared for their safety. Without any safeguards provided by either company, it was up to the driver to employ their own self-protective behaviors to handle those incidents. Although banned, many drivers chose to carry weapons such as pepper spray, Tasers, and guns. For them, their self-protection was more important than a silly restriction. They would rather be kicked off the driving platform than be injured or dead.

Other self-protection measures used by the drivers include having a dashcam(s). These audio/video devices can record everything outside and inside the car. Just the mere presence of them can be a deterrent to would be offenders. Dashcams can also be used as evidence of a car accident or an incident occurring in or around the car. Finally, they can also provide proof that nothing occurred, specifically sexual harassment or assault claims. Although not considered a true weapon, many of the drivers consider it to be just as invaluable to keep them safe.

While these drivers understand that they are not immune from incidents occurring, what they do not understand is the type of response they received when contacting either company. Neither Uber or Lyft provide a number for drivers to call with questions, concerns, or to report a problem. Drivers are instructed to send an email to the company. In the event of an emergency, they are instructed to call 911 and then follow up with an email explaining what happened. Once a driver sends an email, it can often take days to receive a response. Often, the drivers receive "canned responses". These 
computer-generated responses are based on keywords in the email and may not answer the question posed. For many drivers, they have had to send numerous emails before finally ending up with a person responding. Incidents involving the police require warrants before either company will provide any information about the passenger.

The drivers mentioned that they would not be so upset about the responses or lack thereof if either company would provide some training. Training from Uber consists of instruction on how to use the app, nothing about local ordinances, driver etiquette, or how to deal with difficult situations. Lyft used to provide a mentor to all new drivers. This mentor met with the new driver to check out the car and make sure the driver was acceptable. Some would offer to answer questions, according to drivers, but being new many drivers did not know what to ask. Unfortunately, the mentor program has been eliminated in some cities. Therefore, drivers have little to no instruction or guidance when they start their new job. Because of this, drivers feel that they are left to learn on their own.

This leads to the last section of the results which is what suggestions the drivers made that would make them feel safer. At the top of the suggestion list was training. Some kind of orientation or training guides so that drivers do not feel alone and scared. Some drivers in this study have either had incidents their first week or have committed some type of violation they were not aware of as a new driver. Without training, they had to rely on their own experience or the use of self-protective measures to keep them safe. One alternative to the companies providing training is for them to promote the Facebook groups or forums dedicated to ride share drivers. Restricted to active drivers, these groups provide valuable information to drivers while building a community support 
system. A simple email from the company letting the driver know that the groups exists would be enough and not cost anything to the company.

The next suggestion made by the drivers was that the passengers be required to have a profile picture and they must enter the destination address before the ride begins. Both features would provide extra security for the driver and the passenger. When the driver and the passenger have pictures of each other, it limits the confusion on the wrong passenger getting in the wrong vehicle. When this occurs, either by accident or on purpose, there is no record of who the passenger is in the vehicle in the event of an incident. Additionally, if the passenger is required to put the destination address in the app, should the wrong passenger get in the car, it can be fixed. There is another reason that having the destination address entered would be an added safety measure. It helps if the passengers are too drunk or high on drugs and are unable to give directions to where they want to go. Without knowing where to go, drivers feel very uncomfortable proceeding with the ride. Passengers may become irate and dangerous if they think the driver is not going in the right direction. This has caused many violent incidents. Then there are passengers that have passed out in the backseat and the driver is forced to call the police because they have no address to drop the person off. The drivers in this study have no idea why either company does not require the passenger photo or the destination address.

Better driver assistance to include a phone number has already been mentioned as something that is needed. The lack of response or even a delay in responding to incidents has upset many of the drivers. According to the drivers, neither company wants to spend any money that would assist drivers. Many of them said that "they don't care about us". 
One driver suggested if they do not want to provide a direct line for drivers then perhaps they should have a fact sheet or something letting the driver know what the next steps are after an incident has occurred. Unfortunately, drivers are faced with emails as the only form of communication.

This lack of communication builds "mistrust" said one driver and how can drivers feel that either company is going to provide for their safety if they cannot effectively communicate with them. As such, drivers must use their own self-protective measures to stay safe. This includes carrying weapons, which is banned by both companies. Drivers suggest that as long as they have a license to carry concealed, then they should be able to have weapons for protection. Some of the drivers in this study continue to carry weapons regardless of the ban, but they would rather the ban not be in place.

The last suggestion made by the drivers in this study is for both companies to provide or help offset the cost of dashcams. They already allow drivers to pay monthly for the use of phones, why not do the same thing for dashcams. Many drivers would like to have them but they cannot afford them. If either company were to partner with a dashcam provider, the cost would be significantly lower, one driver mentioned. Dashcams would not only increase driver safety, it would allow Uber or Lyft to be use them for evidence in the event of a wrongful sexual assault/harassment suit. Currently neither company has offered to provide or assist in the procurement of dashcams.

All the suggestions made by the drivers in this study have been shared with both companies by many of these drivers. However, there have been no changes to the operations of either company regarding driver safety. As such, drivers will continue to 
utilize their own protective measures as well as the community of ride share drivers to keep themselves safe.

\section{Contributions and Policy Implications}

When dealing with crime, it is often necessary to have a theory as the theoretical foundation. However, for this study this researcher is not testing a theory but merely using Routine Activity Theory to assist in explaining why crimes occur against ride share drivers. This opportunity theory, as developed by Cohen and Felson (1979), posits that the factors of a motivated offender, a suitable target, and the absence of a guardian must all be present and interact for a crime to occur. Should one of these factors be missing, the likelihood of crime occurring is reduced. These factors regarding ride sharing would suggest that the driver is the suitable target, the guardian is the ride share company (Uber or Lyft), and the motivated offender(s) is the passenger(s).

As has been illustrated from the interviews with these ride share drivers, guardianship is absent. There will always be passengers, whether they are motivated to commit crime is unknown. But the nature of the job requires that passengers/would-be offenders will always be present. The same can be said for drivers, drivers must be present. Given the above factors, crime is highly possible if not inevitable. While it would be nice if passengers would always be upstanding citizens and on their best behavior, that is never going to happen. Therefore, drivers are left with making sure they are not suitable targets.

To become less attractive to would-be offenders, drivers have employed various self-protective measures to assist in keeping them safe. These target hardening measures have included changing their behavior, relying on their experience, and finally, having 
weapons/dashcams for protection. Changes to behavior have included not working at night, so as to not have intoxicated passengers; not accepting rides from single men, which may make a female driver feel unsafe; and not picking up passengers in certain areas of town, these are mostly high crime areas. Additionally, some drivers may require single passengers to not sit directly behind him or her. This leaves the driver in a vulnerable position since it is difficult to see what the passenger is doing.

Some of the drivers mentioned relying on their experience to thwart a possible crime. Whether they were in the military, worked at a bar, or worked as a taxicab driver, each of them have used the skills they learned to defuse a situation. Regardless of changing behavior or having experience to rely on, many drivers thought that the best way to keep them safe is to carry a weapon. This weapon could be a gun, Taser, pepper spray or a variety of non-banned items to use for protection. Furthermore, drivers would have dashcams in addition to all the above measures for not only protection but to provide evidence in the event of an incident.

Unfortunately, even with all of these self-protective measures, drivers are still becoming the victims of crime. Part of the lure of ride share is that it allows people unable to drive themselves to request a ride. While not all of these passengers are impaired, those that are may stray from their normal behavior and become aggressive or dangerous. Therefore, it is necessary to find ways to change the guardian status so that it becomes a presence and not an absence.

Based upon the interviews, drivers think that Uber and Lyft do not want to take on the role as guardians. Having drivers as independent contractors, they distant themselves from being required to provide a safe and secure working environment. By having a 
cashless system, both companies believe they have eliminated the opportunity for crime. However, robbery is not a main concern for the drivers. They are concerned about getting threatened, assaulted, or killed. Limiting the amount of cash in the vehicle will not stop a passenger from attacking a driver.

There are many ways that Uber and Lyft can provide guardianship without becoming an employer. Allowing drivers to carry weapons, provided it is legal in the state and the driver is licensed, would not cost the companies a dime. While some drivers already carry their weapons, others have not for fear of getting banned. Although Uber allows non-lethal weapons such as Tasers and pepper spray, Lyft drivers would like to be able to carry them as well.

The suggestion of requiring a passenger picture and destination address would be a minimal cost, if any, to update the app. These items would go a long way to make the drivers feel safe but the companies refuse to do it. Their refusal is based on the idea that they do not want the passengers to be discriminated against because of their looks or where they need to be taken. They fear that drivers will not accept rides which will result in less revenue for the company. Additionally, they are only concerned about the passengers (customers) safety which is why drivers must have a profile picture and a picture of their car. They are acting as guardians for the passengers but not the drivers.

This lack of concern about the drivers is also apparent in the absence of 24-hour driver assistance. Drivers only communication with either company is through emails. Not having a real-time response allows the companies to refrain from being a guardian. While drivers would like this to change, the addition of driver assistance is costly and would probably never happen. 
Perhaps the most requested change that the drivers would like to see from both companies is to provide training or instructions. However, should either company provide any type of training or instruction to the drivers they would be considered employees. This fact was upsetting to the drivers but they offered an alternative to the companies. By suggesting to new riders that they may want to check out Facebook groups, they can distance themselves from providing training the drivers. They could promote these groups as ways to keep in touch with other drivers, not to learn how be a ride share driver. This would allow Uber and Lyft to provide guardianship without becoming employers.

As it stands now, neither company is willing to take on the role of guardian. The drivers in this study would prefer for both companies to step up and become a guardian and not leave safety in the hands of the drivers. However, the drivers in this study acknowledge that those suggestions have fallen on deaf ears.

\section{Limitations}

This study is not without limitations. As the first study about ride share driving, there were no previous studies to draw upon. As such, it was necessary to find a similar occupation to research. Although taxicab drivers are like ride share drivers, the biggest difference is that most taxicab drivers are employees of a company. Regulations and safety measures are put in place to help prevent incidents. In addition, these companies provide compensation should an incident happen. Understanding what is provided to taxicab drivers allowed this researcher to know what may be lacking for ride share drivers. 
The generalizability of the study is another limitation. Given that this was the first study about ride sharing, having fifty participants seemed an appropriate number with which to start. Previous studies based on qualitative semi-structured interviews found that 35 was the median sample size (Copes, Brown, \& Tewksbury, 2011). This researcher was assured that saturation was achieved upon completion of the interviews and analysis of the data. Nonetheless, the thoughts and actions of these drivers may or may not extend to other ride share drivers. The study was not random as the only drivers that participated in Facebook groups were solicited. Additionally, due to limited funds only twenty-one of the interviews took place in person. The remaining interviews took place via Skype or Facetime which still allowed the researcher to see and hear the driver during the interview. It was important to extend the interview criteria to be able to get a large enough sample size.

\section{Conclusion}

The advent of ride share has been around for less than ten years and it continues to expand, not only in the United States but internationally. As with any new endeavor, there are challenges to overcome, and ride share is no different. As a technology-based company that has few employees, it is able to provide service through the use of drivers that are independent contractors. Without regulations, these companies are not bound to provide training, insurance, or safeguards to the drivers because they are not employees. In fact, the only governance of these companies are city ordinances and airport rules. As a result, it is up to the drivers to provide their own safety and security.

This study is the first to explore ride sharing safety as depicted by the drivers. Through the use of interviews, these drivers were able to speak about their likes, dislikes, 
concerns, and suggestions for change. Future research should be conducted to continue this exploration of ride share and the safety concerns of the drivers. 


\section{REFERENCES}

A Medium Corporation. (2016, April 28). Our Approach to Tipping. Uber under the Hood. Retrieved from https://medium.com/uber-under-the-hood/our-approach-totipping-aa0074c0fddc\#.s8ek73ha6

ABC News. (2016). Florida Uber Driver Attack Caught on Camera. Miami, Florida. Retrieved from http://abcnews.go.com/GMA/video/florida-uber-driver-attackcaught-camera-36443405

Appleby, T. (2000, January 4). How to make the job safer for cabbies. The Globe and Mail. Retrieved from www.taxi-1.org/toronto

As an Uber/Lyft driver, how safe am I to pick up passengers? (n.d.). Retrieved from https://www.quora.com/As-an-Uber-Lyft-driver-how-safe-am-I-to-pick-uppassengers

Badger, E. (2014). Are Uber and Lyft responsible for reducing DUIs? Retrieved from https://www.washingtonpost.com/news/wonk/wp/2014/07/10/are-uber-and-lyftresponsible-for-reducing-duis/

Baker, P. (2016). Uber and Safety. Retrieved from http://www.recode.net/2016/3/2/11586648/uber-and-safety

Barton, G. (1996). Taxicab Driver Safety: 28 Driver Safety Tips. Retrieved from www.taxi-library.org/gord28.htm

Berg, B. L., \& Lune, H. (2012). Qualitative Research Methods for Social Sciences. Boston: Pearson.

Birkbeck, C., \& LaFree, G. (1993). The situational analysis of crime and deviance. Annual Review of Sociology, 19, 113-137.

Blankenship, K. L., Nesbit, S. M., \& Murray, R. A. (2013). Driving Anger and Metacognition: The Role of Thought Confidence on Anger and Aggressive Driving Intentions. Aggressive Behavior, 39(4), 323-334.

Boetig, B. P. (2006). The routine activity theory: A model for addressing specific crime issues. FBI Law Enforcement Bulletin, 12-19. 
Braga, A. A., Hureau, D. M., \& Papachristos, A. V. (2011). The Relevance of Micro Places to Citywide Robbery Trends: A Longitudinal Analysis of Robbery Incidents at Street Corners and Block Faces in Boston. Journal of Research in Crime and Delinquency, 48(1), 7-32.

Brainy Quote. (2017). Marc Anthony Quotes. Retrieved from https://www.brainyquote.com/quotes/quotes/m/marcanthon418819.html

Brazil, N., \& Kirk, D. S. (2016). Uber and Metropolitan Traffic Fatalities in the United States. American Journal of Epidemiology, 184(3), 192-198.

Brown, S. E., Esbensen, F.-A., \& Geis, G. (2015). Criminology: Explaining Crime and Its Context. New York: Routledge.

Bryant, K. M., \& Miller, J. M. (1997). Routine Activity and labor market segmentation: An empirical test of a revised approach. American Journal of Criminal Justice, 22(1), 71-100.

Buck, A. J., Hakim, S., \& Rengert, G. F. (1993). Burglar alarms and the choice behavior of burglars: A suburban phenomenon. Journal of Criminal Justice, 21, 497-507.

Bureau of Labor Statistics (BLS). (2007). Fatal occupational injuries by occupation and event or exposure, All United States, 2007. Retrieved from www.bls.gov/iif/oshwc/cfoi/cftb0227.pdf

Bureau of Labor Statistics (BLS). (2012). Fatal occupational injuries, total hours worked, and rates of fatal occupational injuries by selected. Retrieved from http://www.bls.gov/iif/oshwc/cfoi/cfoi_rates_2011hb.pdf

Bureau of Labor Statistics, U.S. Department of Labor. (2012). National Census of Fatal Occupational Injuries in 2011. Retrieved from www.bls.gov/news.release/archives/cfoi_09202012.pdf

Bureau of Labor Statistics, United States Department of Labor. (2015). Occupational Outlook Handbook, 2016-17 Edition, Taxi Drivers and Chauffeurs. Retrieved from http://www.bls.gov/ooh/transportation-and-material-moving/taxi-driversand-chauffeurs.htm

Burgel, B. J., Gillen, M., \& White, M. C. (2012). Health and Safety Strategies of Urban Taxi Drivers. Journal of Urban Health: Bulletin of the New York Academy of Medicine, 89(4), 717-722.

Burgel, B. J., Gillen, M., \& White, M. C. (2014). Work-Related Violence Experienced by Urban Taxi Drivers. American Journal of Industrial Medicine, 57, 1377-1385.

Campbell, H. (2016). Uber and Lyft Drivers Work Dangerous Jobs - But They're On Their Own. Retrieved from https://www.wired.com/2016/03/uber-lyft-can-muchkeep-drivers-safe/ 
Carney, M. (2014). With another Uber driver robbed in LA, questions mount about safety of ride-sharing apps. Retrieved from https://pando.com/2014/08/25/with-anotheruber-driver-robbed-in-la-questions-mount-about-safety-of-ride-sharing-apps/

Casteel, C., \& Peek-Asa, C. (2000). Effectiveness of Crime Prevention through Environmental Design (CPTED) in Reducting Robberies. American Journal of Preventive Medicine, 36(2), 99-115.

Catalan, J. (2016). A Female Uber Driver Tells All. Retrieved from http://www.refinery29.com/2016/03/105521/female-uber-driver-essay

Cava, M. d. (2017, March 22). Lyft's driver pitch: join us, make tips - \$200M so far. USA Today. San Francisco. Retrieved from http://www.usatoday.com/story/tech/talkingtech/2017/03/22/lyfts-driver-pitchjoin-us-make-tips-200m-so-far/99508400/

CBS Los Angeles. (2015, March 4). CBS Local. Retrieved from CBS LosAngeles: http://losangeles.cbslocal.com/2015/03/04/uber-driver-says-she-was-threatenedassaulted-by-customer-but-company-refuses-to-give-her-rider-info/

Cecil, A. (2015). The insurance secret that Uber doesn't want you to know. Retrieved from https://www.policygenius.com/blog/insurance-secret-uber-doesnt-wantknow/

Chafkin, M. (2015). What Makes Uber Run. Retrieved from https://www.fastcompany.com/3050250/what-makes-uber-run

Clarke, R. V. (1997). Situational Crime Prevention: Successful Case Studies. Albany, NY: Harrow \& Heston.

Clarke, R. V., \& Bichler-Robertson, G. (1998). Place managers, slumlords and crime in low rent apartment buildings. Security Journal, 11(1), 11-19.

Cohen, L. E., \& Cantor, D. (1981). Residential burglary in the United States: Life-style and demographic factors associated with the probability of victimization. Crime Delinquency, 18, 113-127.

Cohen, L. E., \& Felson, M. (1979). Social Rate and Crime Rate Trends: A Routine Activity Approach. American Sociological Review, 44(4), 588-608.

Cohen, L. E., Kluegel, J. R., \& Land, K. C. (1981). Social Inequality and Predatory Criminal Victimization: An Exposition and Test of a Formal Theory. American Sociological Review, 46, 505-524.

Copes, H., \& Cherbonneau, M. (2006). The Key to Auto Theft Emerging Methods of Auto Theft from the Offenders Perspective. The British Journal of Criminology, 46(5), 917-934. 
Copes, H., Brown, A., \& Tewksbury, R. (2011). A content anaylsis of ethnographic research published in top criminology and criminal justice journals from 2000 2009. Journal of Criminal Justice Education, 22(3), 341-359.

Cromwell, P. F., Olson, J. N., \& Avary, D. W. (1990). Breaking and Entering: An Ethnographic Analysis of Burglary. Newbury Park: Sage Publications.

Crook, J. (2016). Uber adds driver safety features like break reminders, daily driving reports. Retrieved from https://techcrunch.com/2016/06/29/uber-adds-driversafety-features-like-break-reminders-daily-driving-reports/

Cullen, F. T., \& Agnew, R. (2011). Criminological Theory: Past to Present (Fourth ed.). New York: Oxford University Press.

Curran, D. (2016). Two Uber drivers shot and killed in separate incidents. Retrieved from http://www.sfgate.com/news/article/Two-Uber-drivers-shot-and-killed-inseparate-6963326.php

Daewood, S. (2008). Workplace bullying in the voluntary sector: An application of routine activity theory. $\mathrm{PhD}$ Thesis, University of Leicester, UK.

Dalziel, J. R., \& Job, R. S. (1997). Taxi Drivers and Road Safety. Report to the Federal Office of Road Safety. University of Sydney, Department of Psychology.

Danielson, T. (2015). Uber just formed a board to address growing safety concerns. Retrieved from http://www.businessinsider.com/uber-forms-safety-advisoryboard-in-wake-of-growing-driver-safety-concerns-2015-11

De Coster, S., Estes, S. B., \& Mueller, C. W. (1999). Routine Activities and Sexual Harassment in the Workplace. Work and Occupations, 26(1), 21-49.

Dixon, D., Wolfe, J., \& Reed, K. (2016). Lyft driver found shot to death in his car. Retrieved from http://www.11alive.com/news/crime/lyft-driver-found-shot-todeath-in-his-car/227976993

Durham, J. (2012). How to Ensure Your Personal Safety as a Taxi Driver. Retrieved from www.workplacesafetyadvice.co.uk/how-ensure-your-personal-safety-taxidriver.html

Eck, J. (1994). Drug Markets and Drug Places: A Case-Control Study of the Spatial Structure of Illicit Drug Dealing. Doctoral Dissertation, Department of Criminology and Criminal Justice, University of Maryland, College Park, MD.

Eck, J. E., \& Madensen, T. D. (2015). Meaningfully and Artfully Reinterpreting Crime for Useful Science: An Essay on the Value of Building with Simple Theory. In M. A. Andresen, \& G. Farrell, The Criminal Act: The Role and Influence of Routine Activity Theory (pp. 5-18). New York: Palgrave MacMillan. 
Ellement, J. R. (2016). Two Uber drivers robber by passengers in Jamaica Plain. Retrieved from https://www.bostonglobe.com/metro/2016/03/30/two-uberdrivers-robbed-passengers-jamaicaplain/spt2o3KGWi0pSvCzhCmBxK/story.html

Empie, K. M. (2001). Routine activities of mental health workers and risk of violent victimization. PhD Dissertation, Indiana University of Pennsylvania.

Erickson, E. (2016). Detroit man charged for killer Uber driver. Retrieved from http://www.fox2detroit.com/news/local-news/121138561-story

Facey, M. E. (2010). "Maintaining talk" among taxi drivers: Accomplishing healthprotective behavior in precarious workplaces. Health and Place, 16, 1259-1267.

Felson, M. (1986). Linking criminal choices, routine activities, informal control, and criminal outcomes. In D. Cornish, \& R. Clarke, The Reasoning Criminal (pp. 119128). New York: Springer-Verlag.

Felson, M., \& Boba, R. (2010). Crime and everyday life: Insight and implications for society. Thousand Oaks: Pine Forge.

Felson, M., \& Clarke, R. V. (1998). Opportunity Makes the Thief. Police and Reducing Crime Unit. London, England: Crown.

Freeman Jr, V., \& Hipolit, M. (2015). Police seek armed suspect who robbed, abducted Uber driver in Chesterfield. Retrieved from http://wtvr.com/2015/10/26/policeseek-suspect-that-robbed-abducted-uber-driver-in-chesterfield/

Garofalo, J., \& Clark, D. (1992). Guardianship and residential burglary. Justice Quarterly, 9(3), 443-463.

Gilbert, B. (2011). The Nature of Occupational Violence Against Taxicab Drivers. Public Health Nursing, 28(4), 335-348.

Goddard, J. (2013, September 3). History of Car Dash Cameras. Retrieved from Car Dash Cameras: https://cardashcameras.com.au/history-of-car-dash-cameras/

Groff, E. R. (2007). Simulation for theory testing and experimentation: An example of using routine activity theory and street robbery. Journal of Quantitative Criminology, 23, 75-103.

Gussen, J. (2016). Uber Unveils Secret Emergency Hotline Amid Driver Assaults And Safety Concerns. Retrieved from http://www.designntrend.com/articles/71899/20160313/uber-secret-emergencyhotline-assaults.htm

Haines, F. (1998). Technology and taxis - the challenge of uncoupling risk from reward. Security Journal, 10, 65-78. 
Hawkins, A. (2015). Uber Driver Robbed at Gunpoint Two Weeks After Company Disarmed Drivers. Retrieved from http://www.breitbart.com/biggovernment/2015/06/25/uber-driver-robbed-at-gunpoint-two-weeks-aftercompany-disarmed-drivers/

Hempel, J. (2016). The Inside Story of Uber's Radical Rebranding. Retrieved from https://www.wired.com/2016/02/the-inside-story-behind-ubers-colorful-redesign/

Hennessey, R. (n.d.). Researchers Find Uber Use Leads to a Decrease in DUI Deaths. Retrieved from https://www.entrepreneur.com/article/249958

Hindelang, M. J., Gottfredson, M. R., \& Garofalo, J. (1978). Victims of personal crime: An empirical foundation for a theory of personal victimization. Cambridge, MA: Ballinger.

Hirschi, T. (1969). Causes of Delinquency. Berkeley: University of California Press.

Hollis-Peel, M. E., Reynald, D. M., van Bavel, M., Elffers, H., \& Welsh, B. C. (2011). Guardianship for crime prevention: a critical review of the literature. Crime, Law and Social Change, 56, 53-7.

Huet, E. (2015). Why Aren't There More Female Uber And Lyft Drivers? Retrieved from http://www.forbes.com/sites/ellenhuet/2015/04/09/female-uber-lyftdrivers/\#59398dab5298

Jacobs, B. (2012). Carjacking and Copresence. Journal of Research in Crime and Delinquency, 49(4), 471-488.

Jacobs, B. (2013). The Manipulation of Fear in Carjacking. Journal of Contemporary Ethnography, 42(5), 523-544.

Jacobs, B. A., Topalli, V., \& Wright, R. (2003). Carjacking, Streetlife and Offender Motivations. British Journal of Criminology, 673-688.

Jennings-Edquist, G. (2014). Explain to me: "What is Uber and is it actually safe to use?". Retrieved from http://www.mamamia.com.au/is-uber-safe/

Jones, R. G. (2015). Uber Can't Really Prove That It's Caused A Reduction In Drunk Driving Accidents. Retrieved from http://www.huffingtonpost.com/2015/02/04/uber-drunk-drivingstudy_n_6612106.html

Kelly, H. (2016). Uber doesn't decrease drunk driving, study says. Retrieved from http://money.cnn.com/2016/07/29/technology/uber-drunk-driving/index.html

Kloberdanz, K. (2016, January). Taxi Drivers: Years of Living Dangerously. Retrieved from https://consumer.healthday.com/encyclopedia/work-and-health41/occupational-health-news-507/taxi-drivers-years-of-living-dangerously646377.html 
Kochanek, K. D., Murphy, S. L., Xu, J., \& Tejada-Vera, B. (2016). Deaths: FInal Data for 2014. National Vital Statistics Reports, 65(4), 1-122. Retrieved from https://www.cdc.gov/nchs/data/nvsr/nvsr65/nvsr65_04.pdf

Kodellas, S., Fisher, B. S., \& Wilcox, P. (2015). Situational and dispositional determinants of workplace victimization: The effects of routine activities, negative affectivity, and low self-control. International Review of Victimology, 21(3), 321-342.

Laing, C. (2010). Aggressive driving. Washington, D.C.: U.S. Dept. of Justice, Office of Community Oriented Policing Services. Retrieved from http://purl.fdlp.gov.echo.louisville.edu/GPO/bpo10406

Landau, S. F., \& Bendalak, Y. (2008). Personnel Exposure to Violence in Hospital Emergency Wards: A Routine Activity Approach. Aggressive Behavior, 34, 88103.

Larimer, S. (2016). Robbery suspect threatened Uber driver with HIV injection, police say. Retrieved from https://www.washingtonpost.com/news/postnation/wp/2016/05/18/robbery-suspect-threatened-uber-driver-with-hiv-injectionpolice-say/?utm_term $=.5 \mathrm{~d} 25654 \mathrm{af09c}$

Larkin, M. (2014). Uber Driver Ribbed, Stabbed After Stopping for Directions. Retrieved from http://www.nbclosangeles.com/news/local/Uber-Driver-Robbed-andStabbed-Multiple-times-by-Passenger-in-South-LA-283814901.html

Lazo, L. (2016). Uber says most of its safety incidents involve 'abusive riders on drivers'. Retrieved from http://www.chicagotribune.com/bluesky/technology/ct-ubersafety-incidents-20160812-story.html

Lecher, C. (2016). Uber asks riders to 'reflect on gun violence' as it pauses app for one minute. Retrieved from http://www.theverge.com/2016/7/9/12135346/uber-appgun-violence-pause

Linehan, L. (2016). Uber driver robbed, stabbed early Friday in downtown Las Vegas. Retrieved from http://www.reviewjournal.com/crime/uber-driver-robbed-stabbedearly-friday-downtown-las-vegas

Lovett, K. (2016, December 5). Police chiefs want Uber in upstate to help curb drunk driving. New York Daily News. Retrieved from http://www.nydailynews.com/news/politics/police-chiefs-uber-upstate-curbdrunk-driving-article-1.2898729

Lyft. (2016). Safety Policies - Lyft Help. Retrieved from https://help.lyft.com/hc/enus/articles/213584258-Safety-Policies

Lyft, Inc. . (2017). Drive. Retrieved from Lyft: https:/www.lyft.com/drive-with-lyft 
Lynch, J. P. (1987). Routine Activity and Victimization at Work. Journal of Quantitative Criminology, Special Issue: Lifestyle and Routine Activity Theories of Crime, 3(4), 283-300.

Lytton, C. (2015). Uber Actually Reduces Drunk-Driving Deaths. Retrieved from http://www.thedailybeast.com/articles/2015/08/06/uber-actually-reduces-drunkdriving-deaths.html

MacMillan, D. (2015, June 19). Uber Bans Weapons in Cars Amid Gun-Control Debate. Wall Street Journal. Retrieved from http://blogs.wsj.com/digits/2015/06/19/uberbans-weapons-in-cars-amid-gun-control-debate/

MacMillan, D. (2015, January 25). Uber Touts Its Employment Opportunities. Retrieved from Wall Street Journal: http://www.wsj.com/articles/uber-touts-itsemployment-opportunities-1422229862

Madriz, E. (1996). The Perception of Risk in the Workplace: A Test of Routine Activity Theory. Journal of Criminal Justice, 24(5), 407-418.

Mayhew, C. (2000). Preventing Assaults on Taxi Drivers in Australia. Australian Institutte of Criminology Trends and Issues in Crime and Criminal Justice, 179, $1-6$.

Mazerolle, L. G., Kadleck, C., \& Roehl, J. (1998). Controlling Drug and Disorder Problems: The Role of Place Managers. Criminology, 36(2), 371-404.

McGhee, T. (2015). Denver taxi murder puts spotlight on safety for cab drivers. Retrieved from http://www.denverpost.com/2015/09/13/denver-taxi-murder-putsspotlight-on-safety-for-cab-drivers/

Meier, R. F., \& Miethe, T. D. (1993). Understanding theories of criminal victimization. Crime and Justice: A Review of Research, 17, 459-499.

Menendez, C. C., Amandus, H., Damadi, P., Wu, N., Konda, S., \& Hendricks, S. (2014). Cities with camera-equipped taxicabs experience reduced taxicab driver homicide rates: United States, 1996-2010. Crime Science, 3(4), 1-5.

Menendez, C. K., Amandus, H. E., Damadi, P., Wu, N., Konda, S., \& Hendricks, S. A. (2013). Effectiveness of Taxicab Security Equipment in Reducing Driver Homicide Rates. American Journal of Preventive Medicine, 45(1), 1-8.

Mest, C. E. (2012). Light it up: Illuminated areas are a deterrent to crime. Hotel Management, 227(9), 36.

Miethe, T. D., \& Meier, R. F. (1990). Opportunity, Choice, and Criminal Victimization: A Test of a Theoretical Model. Journal of Research in Crime and Delinquency, 27, 243-66. 
Miethe, T. D., \& Meier, R. F. (1994). Crime and its social context: Toward an integrated theory of offenders, victims, and situations. Albany: State University of New York Press.

Miethe, T. D., Stafford, M. C., \& Long, J. S. (1987). Social differentiation in criminal victimization: A test of routine activities/lifestyle theories. American Sociological Review, 52, 184-194.

Ministry of Transport, New South Wales. (2007). Taxi Industry Safety and Security Taskforce Final Report. Retrieved from http://www.transport.nsw.gov.au/sites/default/files/b2b/publications/taxi-safetytaskforce-final-report.pdf

Moreno, J. A., Cheng, K., \& Mester, M. (2015). Uber Driver Says He Was Brutally Assaulted by 2 Passengers in Signal Hill. Long Beach. Retrieved from http://ktla.com/2015/01/05/uber-driver-says-he-was-brutally-assaulted-by-2passengers/

Morris, S. (n.d.). Has Uber Really Reduced DUI/DWI Rates in American Cities? Retrieved from https://addictionunscripted.com/has-uber-really-reduced-duidwirates-in-american-cities/

Murphy, S. L., Xu, J., \& Kochanek, K. D. (2012). Deaths: Preliminary Data for 2010. National Vital Statistics Report, 60(4), 1-52. Retrieved from http://www.cdc.gov/nchs/data/nvsr/nvsr60/nvsr60_04.pdf

Mustaine, E. E., \& Tewksbury, R. (1997). The Risk of Victimization in the Workplace for Men and Women: An analysis using routine activities/lifestyle theory. Humanity and Society, 21(1), 17-38.

Mustaine, E. E., \& Tewksbury, R. (1998). Predicitng Risks of Larceny Theft Victimization: A Routine Activity Analysis Using Refined Lifestyle Measures. Criminology, 36(4), 829-858.

Mustaine, E. E., \& Tewksbury, R. (1998). Predicting Risks of Larceny Theft Victimization: A Routine Activity Analysis Using Refined Lifestyle Measures. Criminology, 36(4), 829-858.

Mustaine, E. E., \& Tewksbury, R. (1999). A routine activity theory explanation for women's stalking victimizations. Violence Against Women, 5(1), 43-62.

Mustaine, E. E., \& Tewksbury, R. (2000). Comparing the Lifestyles of Victims, Offenders, and Victim-Offenders: A Routine Activity Theory Assessment of Similarities and Differences for Criminal Incident Participants. Sociological Focus, 33(3), 339-362.

Napoliello, A. (2016). Passengers rob Uber driver after 70-mile trip from NYC to Jackson. Retrieved from 
http://www.nj.com/ocean/index.ssf/2016/03/uber_driver_picks_up_3_men_in_ny c_gets_robbed_in_j.html

National Center for Injury Prevention and Control (U.S.). (2011). Alcohol Impaired Driving. Atlanta, GA: National Center for Injury Prevention and Control, Division of Unintentional Injury Prevention. Retrieved from http://purl.fdlp.gov.echo.louisville.edu/GPO/gpo23666

National Center for Injury Prevention and Control (U.S.), \& Centers for Disease Control and Prevention (U.S.). (2011). Drinking and driving: A threat to everyone. Atlanta, GA: Centers for Disease Control and Prevention. Retrieved from http://purl.fdlp.gov.echo.louisville.edu/GPO/gpo45020

National Center for Victims of Crime (U.S.), \& United States. (2009). Impaired Driving. Washington, D.C.: Office for Victims of Crime. Retrieved from http://purl.access.gpo.gov.echo.louisville.edu/GPO/gpo65226

National Institute of Occupational Safety and Health (NIOSH). (2006). Workplace violence prevention strategies and research needs report from the Conference Partnering in Workplace Violence Prevention: Translating research to practice November 17-19, 2004. Baltimore, Maryland. Retrieved from http://www.cdc.gov/niosh/docs/2006-144/pdfs/2006-144.pdf

Navarro, H., \& Yamamoto, J. (2016). Lyft Driver Killed in New Year's Day Crash. Retrieved from http://www.nbclosangeles.com/news/local/lyft-driver-killedcrash-hawthorne-possible-dui-torrance-anderson-new-years-day-364005641.html

NBC Universal Media. (2016, February 22). Uber Driver Attacked in Arlington After He Asks Passengers to Stop Drinking in Car. Arlington, Virginia. Retrieved from http://www.nbcwashington.com/news/local/Uber-Driver-Attacked-in-ArlingtonAfter-He-Asks-Passengers-to-Stop-Drinking-in-Car-369739571.html

Netzer, J. (2014). Does Ridesharing Reduce DUIs? Retrieved from https://www.thezebra.com/insurance-news/490/does-ridesharing-reduce-duis/

Newton, C. (2014). This is Uber's playbook for sabotaging Lyft. Retrieved from http://www.theverge.com/2014/8/26/6067663/this-is-ubers-playbook-forsabotaging-lyft

Occupational Safety and Health Administration (OSHA) fact sheet. (2000). Workplace violence: preventing violence against taxi and for-hire drivers. Retrieved from https://www.osha.gov/Publications/taxi-driver-violence-factsheet.pdf

Occupational Safety and Health Administration. (2010, April). OSHA Fact Sheet: Preventing Violence against Taxi and For-Hire Drivers. Retrieved from OSHA: https://www.osha.gov/Publications/taxi-driver-violence-factsheet.pdf 
Occupational Safety and Health Administration. (2010, April). Publications: OSHA Fact Sheet. Retrieved from OSHA: https://www.osha.gov/Publications/taxi-driverviolence-factsheet.pdf

Ortega, J. (2016). Uber driver robbed by man who threatened to inject him with HIV, police say. Retrieved from http://www.sun-sentinel.com/local/palm-beach/bocaraton/fl-boca-uber-driver-hiv-kidnapping-20160517-story.html

Pamer, M. (2015). Uber Driver Robbed at Gunpoint While Waiting for Her Passengers in Fontana: Police. Retrieved from http://ktla.com/2015/08/24/uber-driver-robbedat-gunpoint-while-waiting-for-her-passengers-in-fontana-police/

Pamer, M., \& Knight, N. (2016). Uber Driver, 27, Fatally Shot While on Duty in Inglewood; Shooter at Large. Retrieved from http://ktla.com/2016/03/21/uberdriver-fatally-shot-while-on-duty-in-inglewood-shooter-at-large/

Park, A. (2016). Husband of Georgia Prosecutor Shot Dead in Car While Working as Lyft Driver. Retrieved from http://www.people.com/article/lyft-driver-shot-deadin-car-atlanta-intersection

Poyner, B. (1991). Situational crime prevention in two parking facilities. Security Journal, 2(2), 96-101.

Radbone, I. (1998). Cameras in Perth's taxis. University of South Australia. Transport Systems Centre.

Report: Uber, Lyft As Safe As Taxis. (2015). Retrieved from http://www.usnews.com/news/articles/2015/02/11/report-uber-lyft-as-safe-astaxis

Reynald, D. M. (2009). Guardianship in action: developing a new tool for measurement. Crime Prevention and Community Safety, 11(1), 1-120.

Reynald, D. M. (2010). Guardians on guardianship: factors affecting the willingness to superview, the ability to detect potential offenders and the willingness to intervene. Journal of Research in Crime \& Delinquency, 47(3), 358-390.

Richardson, S., \& Windau, J. (2003). Fatal and nonfatal assaults in the workplace, 1996 to 2000. Violence in the Workplace Special Issue. Clinics in Occupational and Environmental Medicine, 3(4), 673-690.

Rocha, V., \& Hamilton, M. (2015). Taco Bell executive charged in attack on Uber Driver. Los Angeles Times. Los Angeles, CA. Retrieved from http://www.latimes.com/local/lanow/la-me-ln-taco-bell-executive-charged-uber20151103-story.html

Romero, D. (2014). Is Uber Reducing DUIs in L.A. . Retrieved from http://www.laweekly.com/news/is-uber-reducing-duis-in-la-5055648 
Roscigno, V. J., Mong, S., Byron, R., \& Tester, G. (2007). Age Discrimination, Social Closure and Employment. Social Forces, 86(1), 313-334.

Rylah, J. B. (2015). What It's Like To Drive Uber Or Lyft When You're A Woman. Retrieved from http://laist.com/2015/08/25/what_its_like_to_be_a_female_uber_d.php

Sargeant, M. (2001). Lifelong learning and age discrimination in employment. Education and the Law, 13(2), 141-154.

Scott, M., Emerson, N. J., Antonacci, L. B., \& Plant, J. B. (2006). Drunk Driving, No. 36. Office of Community Oriented Policing Services, U.S. Department of Justice. Retrieved from www.cops.usdoj.gov

Siddiqui, F. (2016). Uber unveils software update aimed at improving driver safety - and takes credit for a decline in drunk driving. Retrieved from https://www.washingtonpost.com/news/dr-gridlock/wp/2016/06/30/uber-unveilssoftware-update-aimed-at-improving-driver-safety-and-takes-credit-for-a-declinein-drunk-driving/

Smith, M. J. (2005). The Problem of Robbery of Taxi Drivers. Retrieved from http://www.popcenter.org/problems/robbery_taxis/

Sowell, D. (2001, Dec). Deterrent to Crime. American School \& University, 74(4), 46-47.

Stone, J. R., \& Stevens, D. C. (1999). The Effectiveness of Taxi Partitions: The Baltimore Case. Retrieved from www.taxi-library.org/stone_abs.htm

Stone, J., \& Bienvenu, M. (1995). Assaults Against Taxi Drivers and Protection Strategies. Institute for Transportation Research and Education, The University of North Carolina, and Southeastern Transportation Center, USA.

Sutter, C. (2016). Cab company addresses driver safety after violent week. Retrieved from http://www.wdrb.com/story/32294885/2016/06/Thursday/cab-companyaddresses-driver-safety-after-violent-week

Taxi Library. (2015). Crime Prevention Recommendations For Cab Company Owners, Drivers and Dispatchers. Retrieved from http://www.taxi-library.org/st-petepd.pdf

Tewksbury, R., \& Mustaine, E. E. (2003). College students' lifestyles and self-protective behaviors: Further considerations of the guardianship concept in routine activity theory. Criminal Justice and Behavior, 30, 302-327.

ThheeGrendel. (2016). Is being an uber/lyft driver dangerous? Retrieved from https://www.reddit.com/r/uberdrivers/comments/3xg1zv/is_being_an_uberlyft_dri ver_dangerous/ 
Toronto Police Services. (n.d.). Taxi Driver Safety. Retrieved from www.torontopolice.on.ca/crimeprevention/taxisafety.php

Toscano, G. (1997). Dangerous Jobs. Compensation and Working Conditions, 2, 57-60.

Tracking System Direct. (2016). Vehicle Tracking System Panic Buttons. Retrieved from www.tracking-system.com/for-businesses/vehicle-tracking-system/82-vehicletracking-system-panic-buttons.html?showall=1

Tseloni, A., Wittebrood, K., \& Farrell, G. (2004). Burglary victimization in England and Wales, the United States, and the Netherlands: a cross-national comparative test of routine activities and lifestyle theories. British Journal of Criminology, 44(1), 61-91.

U.S. Department of Justice. (2012). Violent Victimization Committed by Strangers, 1993-2010. Retrieved from http://bjs.ojp.usdoj.gov/content/pub/pdf/vvcs9310.pdf

Uber. (2014). DUI Rates Decline in Uber Cities. Retrieved from https://newsroom.uber.com/us-illinois/dui-rates-decline-in-uber-cities/

Uber. (2015). About Us: The Company. Retrieved from Uber: https://www.uber.com/about

Uber. (n.d.). Safety. Retrieved from www.uber.com/driver/safety

Uber Technologies. (2017). Drive. Retrieved from Uber: https://www.uber.com/drive/

Uber Technologies, Inc. (2015). Uber and MADD Report. Retrieved from https://newsroom.uber.com/wp-content/uploads/2015/01/UberMADD-Report.pdf

Uber Technologies, Inc. (2017). Cities. Retrieved from Uber: http://www.uber.com/cities/

United States. (2006). Teen unsafe driving behaviors: Focus Group. Washington, D.C.: U.S. Department of Transportation, National Highway Safety Administration. Retrieved from http://purl.access.gpo.gov.echo.louisville.edu/GPO/gpo102414

United States. (2009). The 2006 National Labor Day impaired driving crackdown: Over the limit, under arrest. Washington, D.C.: U.S. Dept. of Transportation, National Highway Traffic Safety Administration. Retrieved from http://purl.access.gpo.gov.echo.louisville.edu/GPO/gpo110908

United States. (2011). National phone survey on distracted driving attitudes and behaviors. Washington, D.C.: National Highway Traffic Administration. Retrieved from http://purl.fdlp.gov.echo.louisville.edu/GPO/gpo21974

Ursel, N. D., \& Armstrong-Stassen, M. (2006). How age discrimination in employment affects stockholders. Journal of Labor Research, 27(1), 89-99.

Victorian Taxi Directorate, Department of Infrastructure. (2007). Your guide to a safer workplace: Victorian Taxi Driver Safety. Retrieved from www.doi.vic.gov.au 
Vivanco, L. (2014, September 29). The walking ATM: Being a cab driver is dangerous. Retrieved from RedEye Chicago: http://www.redeyechicago.com/news/local/redeye-crime-on-taxi-cab-drivers20140929-story.html

WCVB News. (2016). Teen accused of robbing Uber, taxi drivers in Boston. Retrieved from http://www.wcvb.com/news/teen-accused-of-robbing-uber-taxi-drivers-inboston/38945208

Welsh, B. C., Mudge, M. E., \& Farrington, D. P. (2009). Reconceptualizing public area surveillance and crime prevention: Security guards, place managers and defensible space. Security Journal, 23(4), 299-319.

Why Lyft and Uber Endanger Both Passengers and Drivers: A Former Lyft Driver Speaks Out. (2014). Retrieved from http://www.autostraddle.com/why-lyft-anduber-endanger-both-passengers-and-drivers-a-former-lyft-driver-speaks-out261279/

Wilcox, P., Madensen, T. D., \& Tillyer, M. S. (2007). Guardianship in Context: Implications for Burglary Victimization Risk and Prevention. Criminology, 45(4), $771-803$.

Wilcox, P., Madensen, T. D., \& Tillyer, M. S. (2007). Guardianship in Context: Implications for Burglary Victimization Risk and Prevention. Criminology, 45, 771-804.

Wittebrood, K., \& Nieuwbeerta, P. (2000). Criminal Victimization during one's life course: The effects of previous victimization and patterns of routine activities. Journal of Research in Crime and Delinquency, 37(1), 91-122.

Wooldredge, J. D., Cullen, F. T., \& Latessa, E. J. (1992). Victimization in the Workplace: A test of routine activities theory. Justice Quarterly, 9(2), 325-335.

Wortley, R., \& Mazerolle, L. (2011). Environmental Criminology and Crime Analysis. New York: Routledge.

WPTV. (2016). Uber driver robbed, carjacked in Jupitor. Retrieved from http://www.wptv.com/news/region-n-palm-beach-county/jupiter/uber-driverrobbed-carjacked-in-jupiter

Wright, R. T., \& Decker, S. (1994). Burglars on the Job: Streetlife and Residential Break-ins. Lebanon, NH: Northeastern University Press. 
TABLE 1

$\underline{\text { Demographic Characteristics of Ride Share Drivers }}$

Variable

Gender

Male

$70.0 \%(\mathrm{n}=35)$

Female

$30.0 \%(\mathrm{n}=15)$

Race

White

$76.0 \%(\mathrm{n}=38)$

Black

$6.0 \%(\mathrm{n}=3)$

Hispanic/Latino

$6.0 \%(\mathrm{n}=3)$

Mixed

$6.0 \%(n=3)$

Asian

$4.0 \%(\mathrm{n}=2)$

Philipino

$2.0 \%(\mathrm{n}=1)$

Age (mean)

43.1

Twenties

$6.0 \%(n=3)$

Thirties

$32.0 \%(\mathrm{n}=16)$

Forties

$34.0 \%(\mathrm{n}=17)$

Fifties

$20.0 \%(\mathrm{n}=10)$

Sixties

$8.0 \%(n=4)$

Company

Both

$58.0 \%(\mathrm{n}=29)$

Uber only

$40.0 \%(n=21)$

Lyft only

$2.0 \%(n=1)$ 
Length of time driving

Less than a year

One year

Between one \& two years

Two years

Three years

Between three \& four years

Driving Status

Part Time

Full Time

Time of Day

Varies

Daytime

Evenings (before 9pm)

Nights (after 9pm)

Weekends

Nights and Weekends

Year of Vehicle

$2002-2005$

$2006-2010$

$2011-2016$

N/A
$48.0 \%(n=24)$

$16.0 \%(\mathrm{n}=8)$

$8.0 \%(n=4)$

$24.0 \%(\mathrm{n}=12)$

$2.0 \%(n=1)$

$2.0 \%(\mathrm{n}=1)$

$64.0 \%(n=32)$

$36.0 \%(\mathrm{n}=18)$

$36.0 \%(\mathrm{n}=18)$

$16.0 \%(\mathrm{n}=8)$

$10.0 \%(\mathrm{n}=5)$

$12.0 \%(\mathrm{n}=6)$

$22.0 \%(\mathrm{n}=11)$

$4.0 \%(n=2)$

$8.0 \%(n=4)$

$40.0 \%(n=20)$

$42.0 \%(\mathrm{n}=21)$

$10.0 \%(\mathrm{n}=5)$ 


\title{
CURRICULUM VITAE
}

\author{
Angie Schwendau \\ Department of Criminal Justice \\ Lindsey Wilson College \\ (502) 440-9012 \\ schwendaum@lindsey.edu
}

\section{Education:}

2017

2005

1996

Research Interest:

Restorative Justice, Ethics, Policing, Deviance, Criminal Behavior, Emergency Management, Criminal Investigation

\section{Publications:}

Encyclopedia Entries

Schwendau, A. (in press) Deterrence. The Encyclopedia of Corrections. ScholarOne Manuscripts.

Enhanced Research

Keeling, D and Schwendau, A. (2016) 2015 Domestic Violence Survey:

Summary Findings. Presented and submitted to Louisville Metro Domestic Violence Prevention Coordinating Council. The information from this 
research will provide empirical knowledge of citizens perceptions of domestic violence, available resources for victims, the use and satisfaction of those resources, and who they would call if they were a victim.

Keeling, D. and Schwendau, A. (2016) 2015 Citizens Attitude Survey. Submitted to Louisville Metro Police Department and Louisville Metro Government as an assessment of the current citizens' attitudes toward the police which will guide the Mayor and Chief of Police on current policy and procedures. https://louisvilleky.gov/sites/default/files/police/sop_searchable_and_repo rts/lmpd_2015_attitude_survey_report___final.pdf

Keeling, D. and Schwendau, A. (2015) 2014 Vehicle Stops Report. Submitted to Louisville Metro Police Department as an assessment of the current conditions for a vehicle stop as well as the outcomes of said stops. This report will guide the Chief of Police so that he can have statistical information to review the policy and procedure. https://louisvilleky.gov/sites/default/files/police/sop_searchable_and_repo rts/lmpd_annual_vehicle_stops_report_2014.pdf

Keeling, D. and Schwendau, A. (2015) 2014 Citizens Attitude Survey. Submitted to Louisville Metro Police Department and Louisville Metro Government as an assessment of the current citizens' attitudes toward the police which will guide the Mayor and Chief of Police on current policy and procedures.

https://louisvilleky.gov/sites/default/files/police/sop_searchable_and_repo rts/lmpd_citizens_attitude_survey_report_2014.pdf

\section{Teaching Experience:}

Lindsey Wilson College

2016 - Present

Department of Criminal Justice

Introduction to Criminal Justice - CRJS 1003

Criminology - CRJS 2103

Criminal Courts - CRJS 2303

Police Investigation - CRJS 3023

Police \& Society - CRJS 3123

Corrections - CRJS 3203

Criminal Procedure - CRJS 3903

\section{University of Louisville}

2015 - 2016

Department of Criminal Justice 
Criminal Behavior - CJ 305

Sex Crimes - TA - CJ 352

Juvenile Justice - CJ 360

\section{Sullivan University}

2013 Department of Justice and Public Safety Administration

Emergency Management - PSA 230

\section{Professional Experience:}

$\begin{array}{ll}2016-\text { Present } & \begin{array}{l}\text { Lindsey Wilson College } \\ \text { Columbia, Kentucky } \\ \text { Criminal Justice } \\ \text { Instructor }\end{array} \\ & \begin{array}{l}\text { University of Louisville } \\ \text { Louisville, Kentucky } \\ \text { Criminal Justice } \\ \text { Graduate Assistant }\end{array} \\ & \begin{array}{l}\text { Ryne Enterprises/CPR Louisville } \\ \text { Louisville, Kentucky } \\ \text { Owner/Instructor }\end{array} \\ & \begin{array}{l}\text { Falls City Towing Company } \\ \text { Prospect, Kentucky } \\ \text { Human Resources Director/ISO Quality Manager }\end{array} \\ & \begin{array}{l}\text { Guardsmark, LLC } \\ \text { Louisville, Kentucky and Chicago, Illinois } \\ \text { Security Branch Manager }\end{array}\end{array}$

Presentations:

$\underline{2016}$

Angie Schwendau. Dangers and Self-Protective Behaviors of Rideshare Drivers: The Results. American Society of Criminology, New Orleans, LA.

Angie Schwendau. Dangers and Self-Protective Behaviors of Rideshare Drivers: A Proposal. Southern Criminal Justice Association, Savannah, GA.

Angie Schwendau and Nadia Nelson. Citizens Attitudes about the Police: A Three-Year Study. Academy of Criminal Justice Sciences, Denver, CO. 
Deborah Keeling, Allen Copenhaver, Leslie Greenwell, Angie Schwendau, Molly Block and Leah Shon. Evaluation of the Effectiveness of a Day Reporting Center. Academy of Criminal Justice Sciences, Orlando, FL.

Angie Schwendau. Comparing Racial Profiling using Vehicle Stops Reports from 2006 and 2013. Southern Criminal Justice Association, Charleston, SC.

Angie Schwendau. The Faculty and their Qualifications to teach in Criminal Justice/Criminology PhD programs. American Society of Criminology, Washington, D.C.

Cherie Dawson-Edwards, Angie Schwendau. Restorative Practices for PBIS Schools. Western High School, Louisville, KY

Professional Service:

Facilitator with Restorative Justice Louisville

Reviewer:

Journal of Criminal Justice Education

\section{University Service:}

2016 - Present $\quad$ Advisor, Alpha Phi Sigma (Mu Sigma Chapter), Lindsey Wilson College

2015 Graduate Student Council Representative, Criminal Justice Graduate Program, University of Louisville

2000 - Present $\quad$ Alpha Phi Sigma (The National Criminal Justice Honor Society), University of Louisville, President 2015-2016

\section{Professional Development:}

2015

Grant Writing Academy, School of Interdisciplinary and Graduate Studies, University of Louisville 


\section{Affiliations:}

2013 - Present $\quad$ Academy of Criminal Justice Sciences

2013 - Present $\quad$ American Society of Criminology

2013 - Present $\quad$ Southern Criminal Justice Association

\section{References}

Dr. Richard Tewksbury - Dissertation Chair

Professor

Department of Criminal Justice

University of Louisville

502-852-0379

Ratewk01@louisville.edu

Dr. Deborah Keeling

Associate Dean of Faculty Affairs \& Professor

Department of Criminal Justice

University of Louisville

502-852-0370/2237

Dgwils01@1ouisville.edu

Dr. George Higgins

Professor

Department of Criminal Justice

University of Louisville

502-852-0331

Gehigg01@1ouisville.edu

Dr. B. Cherie Dawson-Edwards

Associate Professor

Department of Criminal Justice

University of Louisville

502-852-0800

Cherie.dawson@louisville.edu 